U5t

no.

$M-339$

y Corps

neers

tion Engineering

I Laboratory

US-U. - Broperty of the Unitod Statos Governut

Technical Report M-339

February 1984

\title{
FIXITY OF MEMBERS EMBEDDED IN CONCRETE
}

by

Fernando Castilla

Phillippe Martin

John Link

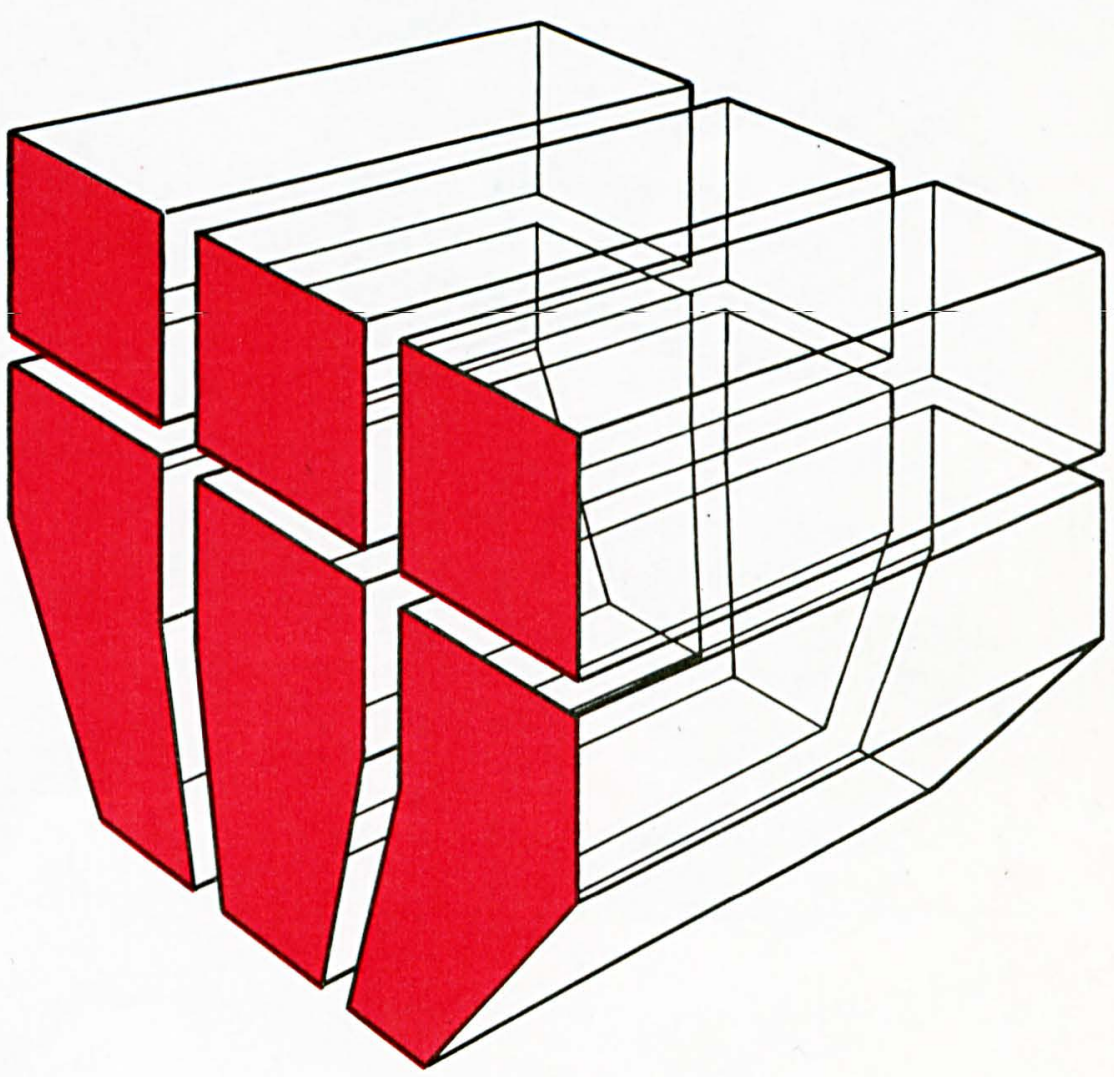

LIBRARY BRANCH

IECHNICAL INFORMATION CENTER

US ARMY ENGINEER WATERWAYS EXPERIMENT STATION VIT.KSBIIRG. MISSISSIPPI 
The contents of this report are not to be used for advertising, publication, or promotional purposes. Citation of trade names does not constitute an official indorsement or approval of the use of such commercial products. The findings of this report are not to be construed as an official Department of the Army position, unless so designated by other authorized documents. 


\begin{tabular}{|c|c|}
\hline REPORT DOCUMENTATION PAGE & $\begin{array}{l}\text { READ INSTRUCTIONS } \\
\text { BEFORE COMPLETING FORM }\end{array}$ \\
\hline $\begin{array}{l}\text { 1. REPORT NUMBER } \\
\text { CERI TR M-339 }\end{array}$ & 3. RECIPIENT'S CATALOG NUMBER \\
\hline \multirow[t]{2}{*}{$\begin{array}{l}\text { 4. TITLE (and Subttio) } \\
\text { FIXITY OF MENBBERS EMBEDDED IN CONCRETE }\end{array}$} & $\begin{array}{l}\text { 5. TYPE OF REPORT \& PERIOD COVERED } \\
\text { FINAL }\end{array}$ \\
\hline & 6. PERFORMING ORG. REPORT NUMBER \\
\hline $\begin{array}{l}\text { 7. AUTHOR(a) } \\
\text { Fernando Castilla } \\
\text { Phillippe Martin } \\
\text { John Link }\end{array}$ & 8. CONTRACT OR GRANT NUMBER(B) \\
\hline $\begin{array}{l}\text { 9. PERFORMING ORGANIZATION NAME AND ADDRESS } \\
\text { U.S. Army COnstruction Engr Research Laboratory } \\
\text { P.O. Box } 4005 \\
\text { Champatgn, IL } 61820\end{array}$ & $\begin{array}{l}\text { 10. PROGRAM ELEMENT. PROJECT, TASK } \\
\text { AREA \& WORK UNIT NUMBERS } \\
\text { 4A162720A896-A-019 }\end{array}$ \\
\hline \multirow[t]{2}{*}{ 11. CONTROLLING OFFICE NAME AND ADDRESS } & $\begin{array}{l}\text { 12. REPORT DATE } \\
\text { February } 1984\end{array}$ \\
\hline & $\begin{array}{l}\text { 13. NUMBER OF PAGES } \\
61\end{array}$ \\
\hline \multirow[t]{2}{*}{ T4. MONITORING AGENCY NAME ADDRESS(It dilforent from Controllind Offlco) } & $\begin{array}{l}\text { 15. SECURITY CLASS. (ot thio report) } \\
\text { UNCLASSIFIED }\end{array}$ \\
\hline & $\begin{array}{l}\text { 15a. DECLASSIFICATION/DOWNGRADING } \\
\text { SCHEDULE }\end{array}$ \\
\hline
\end{tabular}

Approved for public release; distribution unlimited.

17. DISTRIBUTION STATEMENT (of the abstract ontered in Block 20, if difforent from Roport)

18. SUPPLEMENTARY NOTES

Copies are available from National Technical. Information Service Springfield, VA 22161

19. KEY WOROS (Continus on reveree alde If neceseary and Identlfy by block number)

pile structures

concrete

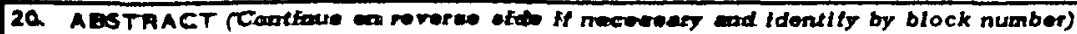

For concrete structures founded on piles, the length of pile embedment required to develop a condition of full fixity has a significant impact on the cost of the structure. The purpose of this research was to determine the pile embedment length required to provide reasonable assurance that a condition of full fixity exists for a pile embedded in the base of a concrete structure. A two-part study was performed on models of a cap-member-soil system and a cap-member system to evaluate the degree of rotational fixity associated with various pile embedment lengths and various pile types, including typical design conditions for HP $14 \times 73$ and HP $14 \times 117$ piles. The study results indicate that a pile 
UNCLASSIFIED

SECURITY CLASSIFICATION OF THIS PAOE(When Dato Entered)

embedment length equal to or greater than twice the pile depth or diameter is required to develop a condition approximating full fixity for a pile embedded in the base of a concrete structure.

INCLIASSIEIED

SECURITY CLASSIFICATION OF THIS PAGE(Whon Date Entered) 


\section{FOREWORD}

This investigation was performed for the St. Louis District, U.S. Army Corps of Engineers, under Inter-Army Order FAD ED81-69. The work was conducted by the U.S. Army Construction Engineering Research Laboratory (CERL), Engineering and Materials Division (EM), in conjunction with the University of Illinois at Urbana-Champaign (UIUC), Department of Civil Engineering. Mr. John Jaeger, St. Louis District, served as project monitor for this investigation.

COL Paul J. Theuer is Commander of CERL, and Dr. L. R. Shaffer is Technical Director. Dr. J. C. Liebman is Head of the Department of Civil Engineering at UIUC, and Dr. R. Quattrone is Chief, CERL-EM. 


\section{CONTENTS}

\section{Page}

DD FORM $1473 \quad 1$

FOREWORD

LIST OF TABLES AND FIGURES

1 INTRODUCTION ............................. 9

Background

Objective

Approach

2 METHODOLOGY .........................

Cap-Member-Soil Model

Cap-Member Model

3 CAP-MEMBER-SOIL MOdels $\ldots \ldots \ldots \ldots \ldots \ldots \ldots \ldots \ldots \ldots \ldots$

Introduction

Method of Analysis

Soil and Concrete Parameters

Parametric Analysis

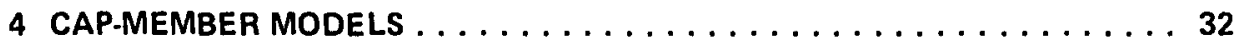

Introduction

Exploratory Finite Element Tioodeis

HP 14X117 Typical Design Loading Analyses

HP 14X117 Parametric Analysis

5 CONCLUSIONS ........................ 52

$\begin{array}{lc}\text { REFERENCES } & 52\end{array}$

DISTRIBUTION 


\section{TABLES}

Number Page

1 Model Parameters and Ranges $\quad 10$

2 Typical Design Loadings for HP 14X73 and HP 14X117 Piles 11

3 Values of $n_{h}$ for Sands $\quad 13$

4 Soil Coefficients for Clays 15

5 Limit Elastic Deformation ( $y_{1 \mathrm{e}}$ ) for Sands $\quad 15$

6 Limit Llastic Deformation $\left(y_{1 \mathrm{e}}\right)$ for Clays 16

7 Comparison Between $I_{H S}$ and $I_{R B} \quad 18$

8 Computed Response to Typical Design Situations 19

9 Angular Rotation of HP 12X74 Pile 40

10 Index Correlating Analysis Case and Model Parameters 43

11 Basic Parameters for HP 14X117 Parametric Analysis 50

\section{FIGURES}

1 Model Parameters and Ranges $\quad 10$

2 Design Loadings for HP 14X73 and HP 14X117 Piles 11

3 Graphical Definition of $p$ and $y \quad 14$

4 Typical Load-Deformation Curves (p-y curves) for Sands and Clays 16

5 Elastic Half-Space Under a Strip Load, Generalized Solution 17

6 Elastic Half-Space Under a Strip-Load, Centralized Solution 17

7 Plot of $I_{R B}$ in Terms of $m=4 a$ and $v=0.2$

8 Typical Moment and Deflection Curves for HP 14X117 Pile with 12 in. Embedment 20

9 Typical Moment and Deflection Curves for HP 14X117 Pile with 48 in. Embedment

10 Effect of Le/B Ratio on Pile Rotation at Soil-Cap Interface, Typical Design Situation for HP 14X73 Pile 


\section{FIGURES (Cont'd)}

\section{Number}

11 Effect of Le/B Ratio on Pile Rotation at Soil-Cap Interface, Typical Design Situation for HP 14X117 Pile

12 Effect of Le/B Ratio on Pile Rotation at Soil-Cap Interface, HP 14 X73 Pile with 15 kip Shear at Base of Cap

13 Effect of Le/B Ratio on Pile Rotation at Soil-Cap Interface, HP 14X117 Pile with 15 kip Shear at Base of Cap

14 Effect of Le/B Ratio on Pile Rotation at Soil-Cap Interface, HP $14 X 117$ Pile in Loose Sand, $n_{h}=4$ ton/cu ft

15 Effect of Le/B Ratio on Pile Rotation at Soil-Cap Interface, HP 14 X117 Pile in Dense Sand, $n_{h}=34$ ton $/ \mathrm{cu} \mathrm{ft}$

16 Effect of Le/B Ratio on Pile Rotation at Soil-Cap Interface, HP 14X73 Pile in Stiff Clay, $k=50$ tons $/ \mathrm{cu} \mathrm{ft}$

17 Effect of Le/B Ratio on Pile Rotation at Soil-Cap Interface, HP $14 X 73$ Pile in Hard Clay, $k=200$ tons $/ \mathrm{cu} \mathrm{ft}$

18 Effect of Le/B Ratio on Pile Rotation at Soil-Cap Interface, Various Pile Sections in Medium Dense Sand with 5 kip Shear at Base of Cap

19 Effect of Le/B Ratio on Pile Rotation at Soil-Cap Interface, Various Pile Sections in Medium Dense Sand with 10 kip Shear at Base of Cap

20 Stress Distribution in an HP Pile Section

21 Exploratory Finite Element Models

22 Lateral Displacement Curves for HP 12 X74 Pile with $0.5 \mathrm{D}, \mathrm{D}, 2 \mathrm{D}$, and $4 \mathrm{D}$ Embedments

23 Finite Element Representation of HP Pile

24 Two-Dimensional Interface Element

25 Force-deflection Relationship for the Interface Element

41

26 Typical Displacement Field for HP 14X117 Pile

27 Typical Stress Contour Plot for $\sigma_{\mathbf{x}}$

28 Typical Stress Contour Plot for $\sigma_{\mathrm{y}}$ 


\section{FIGURES (Cont'd)}

Number

29 Typical Stress Contour Plot for $\tau_{x y}$

30 Typical Stress Contour Plot for $\sigma_{\max }$

31 Typical Stress Contour Plot for $\sigma_{\min }$

46

32 Typical Stress Contour Plot for $\tau_{\max }$

46

33 Lateral Displacement Curves for Centerline of HP 14X117 Pile with $2 \mathrm{D}$ and $4 \mathrm{D}$ Embedments, $\mu=0.4$

34 Interface Element Forces for HP 14X117 Pile with 2D Embedment, $\mu=0.4$

35 Interface Element Forces for HP $14 \times 117$ Pile with 4D Embedment, $\mu=0.4$

36 Lateral Displacement Curves for Centerline of HP 14X117 Pile with 2D Embedment, $\mu=0.4,0.7$, and 1.4

37 Interface Element Forces for HP 14X117 Pile with 2D Embedment, $\mu=0.7$

38 Interface Element Forces for HP 14X117 Pile with 2D Embedment, $\mu=1.4$

39 Sections in Concrete Cap Used for Normal and Shear Force Distribution Comparisons

40 Normal Force Distribution at Section A-A for Cap Thickness of 4D

41 Shear Force Distribution at Section A-A for Cap Thickness of 4D

42 Normal Force Distribution at Section B-B for Cap Thickness of 4D

43 Shear Force Distribution at Section B-B for Cap Thickness of 4D 56

44 Lateral Displacement Curves for Centerline of HP 14X117 Pile for Effective Widths of Concrete Cap of 14.9 in. and 44.7 in.

45 Lateral Displacement Curves for Centerline of HP 14X117 Pile for Pile Spacings of 3D to 5D

46 Normal Force Distribution at Section A-A for Cap Thicknesses of $4 \mathrm{D}$ to $7 \mathrm{D}$ 


\section{FIGURES (Cont'd)}

Number $\quad$ Page

47 Shear Force Distribution at Section A-A for Cap Thicknesses of $4 \mathrm{D}$ to $7 \mathrm{D}$

48 Normal Force Distribution at Section B-B for Cap Thicknesses of $4 \mathrm{D}$ to $7 \mathrm{D}$

60

49 Shear Force Distribution at Section B-B for Cap Thicknesses of $4 \mathrm{D}$ to $7 \mathrm{D}$ 


\section{FIXITY OF MEMBERS EMBEDDED IN CONCRETE}

\section{INTRODUCTION}

\section{Background}

The Corps of Engineers designs and const ructs many concrete structures with pile foundations such as locks, dams, pumping stalions, bridges, and floodwalls. Structural piles (steel, concrete, or timber) are used to transfer the horizontal and vertical loadings on these structures to soil layers which can provide adequate support. The degree of fixity of the piles is an im. portant assumption in the analysis and design of the pile groups that support the structures. For instance, elastic solutions for a pile subjected to lateral load and moment forces indicate that a structure loaded horizontally will deflect approximately one-quarter to onehalf as much for piles that are fully fixed at the base of the structure as opposed to piles that are simply pinned to the base of the structure. ${ }^{1}$ For concrete structures founded on piles, the resistance to lateral forces depends on the degree of fixity of the embedded piles and the complex interaction of the piles with the surrounding soil. For example, piles embedded a limited depth will resist only shear and axial loads piles embedded an adequate depth will resist moments, shears, and axial loads and significantly reduce the lateral deflections for the structure.

Pile foundations represent a considerable portion of the total cost of a structure founded on piles. Consequently, the length of pile embedment required to develop a condition of full fixity has a significant impact on the cost of the pile foundation and ultimately the cost of the structure. Corps-wide, this cost could be in the millions of dollars.

A "rule of thumb" is commonly used in the design for steel HP shape piles for determining embedment length. An embedment of $1 \mathrm{ft}$ or less into the concrete structure is considered pinned, a 1 - to 2 - $\mathrm{ft}$ embedment is considered partially fixed, and a 4 -ft embedment is considered fully fixed. However, there are no known theoretical or experimental data that support these assumptions. For some structures, it is desirable to fully

\footnotetext{
${ }^{1}$ H. G, Poulos and E. H. Davis, Elastic Solutions for Soil and Rock Mechanics (John Wiley and Sons, Inc., 1974).
}

fix the piles to limit deflection. A considerable amount of theoretical and experimental research is available to define the load transfer mechanism for a pile embedded in the soil below the pile cap; however, there appears to be little data available to define the load transfer mechanism for the portion embedded in the concrete pile cap.

At the request of the St. Louis District, U.S. Army Corps of Engineers, a two-part study was performed to develop relationships between the degree of fixity and the pile embedment length. The studies were performed through a joint effort of the U.S. Army Construction Engineering Research Laboratory (CERL) and the University of Illinois at Urbana-Champaign (UIUC), Department of Civil Engineering.

\section{Objective}

The objective of the present research is to determine the pile embedment length required to provide reasonable assurance that a condition of full fixity exists for the pile embedded in the base of the structure and that acceptable stresses created by the moment developed in the restrained condition are transferred from the pile to the concrete cap and vice versa.

\section{Approach}

CERL and UIUC examined the fixity of embedded piles through the use of computer models. UIUC used cap-member-soil models in its analysis; CERL examined the structural integrity of piles using capmember models. Parameters and ranges used in these studies were developed by CERL and coordinated with the St. Louis District. A more detailed explanation of the approach used in these studies is provided in the following chapter on methodology.

\section{METHODOLOGY}

The problem of what pile length will ensure full fixity is analogous to a beam-column connection which is usually assumed to be perfectly rigid. But if a more precise determination of the deflections is made, considering deformation of the joint, the angles existing between connecting members at the joints will not be preserved. Likewise for steel piles embedded in a concrete cap: the angle between the pile and concrete cap will not be maintained after loading has been applied to the structure due to the deformability and degrada. tion of the materials involved, especially the concrete. 
Analytical studies were performed by CERL and UIUC using models of the cap-member system and the cap-member-soil system. These studies were initially conducted using the parameters and ranges presented in Table 1 and diagrammed in Figure 1. These parameters and ranges were developed by CERL in conjunction with the St. Louis District before this investigation began. Preliminary results from both the CERL and the UIUC studies using these parameters indicated, however, that an embedment length of approximately twice the diameter or depth of the pile was adequate to develop a condition approximating full fixity. The St. Louis District, therefore, requested CERL and UIUC to investigate the behavior of HP $14 \times 117$ and HP $14 \times 73$ steel piles with $2-\mathrm{ft}$ and 4 -ft embedments in a concrete cap and subjected to the typical design loadings conditions presented in Table 2 and Figure 2.

\section{Cap-Member-Soil Model}

UIUC represented the concrete cap-pile-soil system as a Winkler model, i.e., the pile was supported by a series of independent springs. ${ }^{2}$ Springs with linear loaddeformation characteristics represented the concrete cap, and springs with nonlinear characteristics represented the soil. The pile was assumed to be linearly elastic. Variations of the significant parameters were investigated to-study the relationships among the degree

\footnotetext{
${ }^{2}$ L. C. Reese, "Laterally Loaded Piles: Program Documentation," ASCE' Proceedings. Vol. 103. No. GT4 (April 1977), pp. 287-305.
}

Table 1 Model Parameters and Ranges

\begin{tabular}{lc}
\multicolumn{1}{c}{ Parameter } & Range \\
Member Spacing & 3 to $5 \mathrm{D}^{*}$ \\
Member Embedment & 1 to $4 \mathrm{D}$ \\
Cap Thickness & 6 to $10 \mathrm{D}$ \\
Member Configuration (D) & \\
Circular & \\
"H" & 10 to 24 in. in dia. \\
Modulus of Elasticity & $10 \times 10$ to $14 \times 14 \frac{1}{2}$ \\
Concrete & \\
Steel & 3 to $5 \times 10^{6} \mathrm{psi}$ \\
Poisson's Ratio & $29.6 \times 10^{6} \mathrm{psi}$ \\
Concrete & \\
Steel & \\
Soil & 0.15 to 0.20 \\
Soil Subgrade Reaction & 0.3 \\
Sands & 0.1 to 0.5 \\
Clays & \\
Soil Embedment Length & 4 to 56 tons $/ \mathrm{cu} \mathrm{ft}$ \\
& 50 to 200 tons $/ \mathrm{cu} \mathrm{ft}$ \\
& 20 to $60 \mathrm{ft}$
\end{tabular}

*D designates member diameter or depth depending on member configuration.

of fixity of the pile, the pile embedment length in the concrete cap, and the interaction of the pile with the surrounding soil. UIUC used the computer program COM 622 to perform the calculations for the cap-

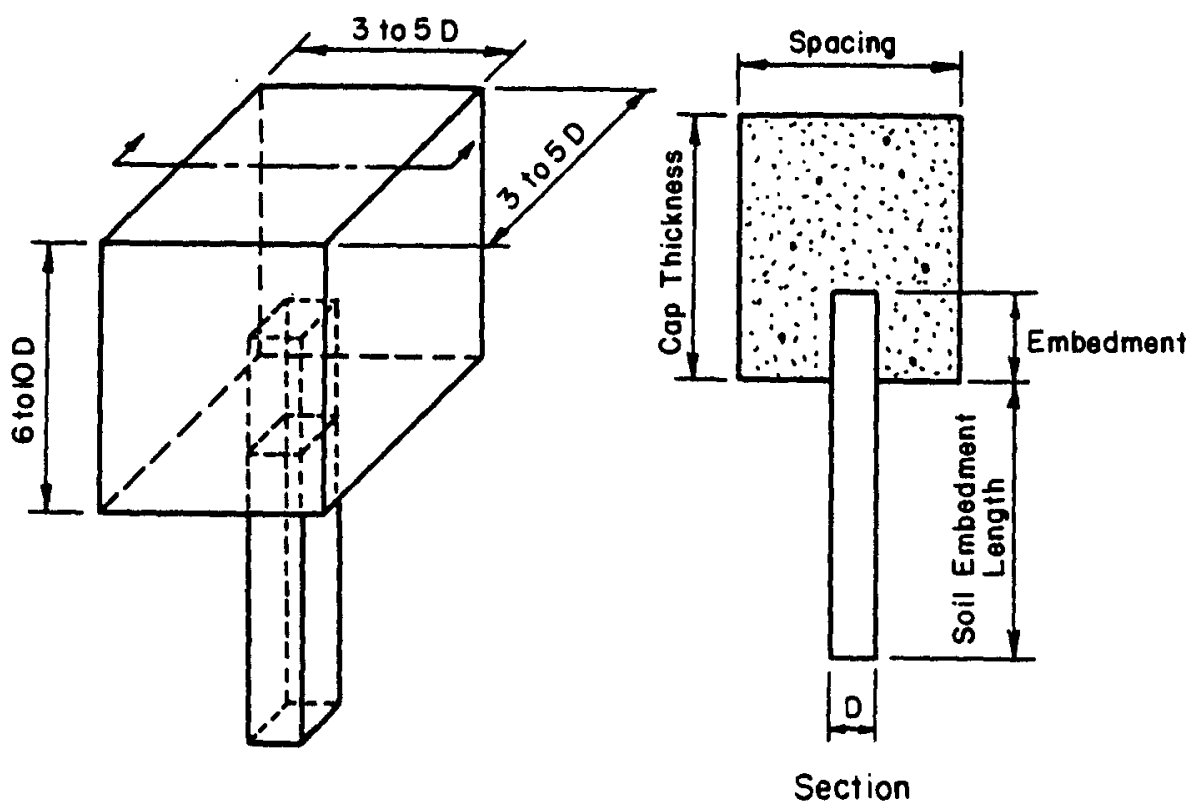

Figure 1. Model parameters and ranges. 
Table 2

Typical Design Loadings for HP 14 X73 and HP 14X117 Piles

$\begin{array}{cccccc}F_{1} & F_{2} & F_{3} & F_{4} & F_{5} & F_{6} \\ \text { (kips) } & \text { (kips) } & \text { (kips) } & \text { (in.-kips) } & \text { (in.-kips) } & \text { (in.-kips) }\end{array}$

\section{NORMAL OPERATING}

Pinned HP $14 \times 73 \mathrm{n}_{\mathrm{h}}=.017 \mathrm{kips} / \mathrm{cu}$ in

End HP $14 \times 117 \mathrm{n}_{\mathrm{h}}=.003$

Fixed HP $14 \times 73 n_{h}=.001$

End $\quad \mathrm{HP} 14 \times 117 \mathrm{n}_{\mathrm{h}}=.001$

\section{NORMAL OPERATING}

(0.1 g E.Q.)

Pinned HP $14 \times 73 \mathrm{n}_{\mathrm{h}}=.027$

End HP $14 \times 117 \mathrm{n}_{\mathrm{h}}=.03$

Fixed HP $14 \times 73 n_{h}=.03$

End HP $14 \times 117 n_{h}=.03$

-1.3
0
2.8
2.2

6.4

0

125

188

191

138

$\begin{array}{rcc}-26 & -1.7 & 123 \\ 22 & 1 & 201 \\ & & \\ 18 & 0 & 228 \\ 15 & 0 & 142\end{array}$

0
0
0
0

0

0

295

260

0

0

0

0

To minimize computer costs and to produce results

member-soil model. ${ }^{3}$ The program was modified to model the embedment of the pile in the concrete cap. To accurately represent the different soil conditions it was necessary to determine soil spring constants for sands and clays of various st rengths and limit pressures. Spring constants were also determined for the concrete cap section of the model.

The relationships among the parameters were analyzed for various values of soil stiffness, pile embedment length, pile type, and shear force at the interface between the soil and the cap.

\section{Cap-Member Model}

CERL analyzed the problem from a purely structural standpoint. Finite element models of the pile embedded in the concrete cap were assembled without consideration of the underlying soil material. Variations of the significant parameters were investigated in an effort to determine guidance on the length of pile embedment required to produce a condition approximating full fixity.

A general purpose computer program, ANSYS, was used to analyze the embedment-fixity problem. ANSYS is a large-scale finite elements program that can analyze two-dimensional and three-dimensional linear or nonlinear models under static and dynamic conditions, and small or large displacements. ${ }^{4}$

\footnotetext{
${ }^{3}$ Reese, pp 287-305.

${ }^{4}$ ANSYS User's Manual Revision 3 (Swanson Analysis Systems, Inc., Houston, Pennsylvania, 1977).
} that were readily comparable with the UIUC results, only two-dimensional linear and nonlinear models of

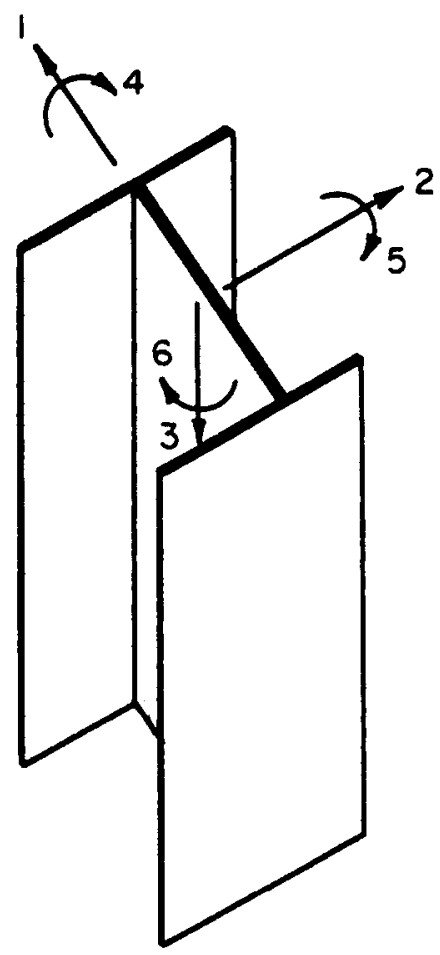

Figure 2. Design loadings for HP $14 \times 73$ and HP 14 X117 piles. 
the cap-member system were analyzed. Dimensions for the two-dimensional models were based on the ranges in Table 1 and equal orthogonal spacing of the members was assumed. The finite element used in the twodimensional linear models was STIF 42, a general purpose element for modeling solid structures. The element was used in a biaxial plane strain state. The element is defined by four nodal points, each having two degrees of freedom translations in the nodal $x$ and $y$ directions. For the two-dimensional nonlinear models, the STIF 42 element was also used; however, the flanges of the pile were modeled with a plane bar element, STIF 1. The interface between the pile section and the concrete cap was modeled with a twodimensional interface element, STIF 12. The interface element represents two plane surfaces which may maintain or break physical contact and which may slide relative to each other. The element is capable of supporting only compressive forces in the direction normal to its surfaces, and shear (Coulomb friction) in its tangential direction. The element has two degrees of freedom at each node-translations in the nodal $x$ and $y$ directions. The input properties required to represent the model's materials characteristics were the modulus of clasticity. Poisson's ratio, coefficient of friction, and shear modulus.

The measure of pile fixity is based on rotational response of the embedded pile section at the concrete cap face. Since the ANSYS STIF 42 element provides only displacements at its nodal points, a procedure was developed to interrogate the ANSYS displacement results and obtain displacement values for selected nodes. These displacements were then used to compute the required rotational values at the cap face for the various cases analyzed.

\section{CAP-MEMBER-SOIL MODELS}

\section{Introduction}

In the UIUC analytical study, the degree of fixity of the pile embedded in a concrete cap and the underlying soil was analyzed as two independent pile sections, i.e., one in the cap and the other in the soil. The concrete cap was modeled as springs with linear load-deformation characteristics, and the soil was represented by springs with elastic-plastic load-deformation characteristics. The pile was assumed to be linearly elastic. UIUC modified the COM 622 computer program to perform the analysis.

\section{Method of Analysis}

\section{Original Method}

The COM 622 program was modified to solve the problem of a beam resting on a nonlinear Winkler's foundation with a finite difference numerical scheme. The boundary conditions (four conditions are required to solve the problem) are preprogrammed at the tip of the pile and are input-dependent at the head of the pile (soil-cap interface).

The conditions of zero moment and zero shear at the tip of the pile are preprogrammed in COM 622. At the head of the pile, the input boundary conditions can be shear and moment, shear and slope, or shear and ratio of moment to slope (rotational spring constant).

\section{Modified Method}

The approach taken by UIUC consists of a two-step iterative scheme which was used because only one of the two boundary conditions at the head of the pile was known. The full pile is modeled in the cap and in the soil as two independent pile sections. The analysis is carried out for each section separately. The head of each pile section begins at the soil-cap interface. Iterations are performed until the continuity of boundary conditions at the soil-cap interface is achieved.

A complete iterative cycle consists of the following steps:

Step one: Analysis of pile section in concrete cap.

(a) Assign moment: the moment is assumed to be zero at the head of the pile for the first iteration. For the second iteration, the moment assigned to the head is the value computed in (d) below for the first iteration. Note that the shear in the pile at the concrete soil interface is a known value for the problem.

(b) Perform analysis: compute the slope of the cappile section at the soil-cap interface for the value of the assigned moment and shear from (a).

Step two: Analysis of pile section in soil.

(c) Assign the slope computed in (b).

(d) Perform analysis: obtain the computed value of moment in the soil-pile section at the soil-cap interface.

(e) Compare the moment computed in (d) with the moment assigned in (a). If the two values are not within an acceptable tolerance, perform a new iterative 
cycle. Otherwise, the solution has been reached. (Acceptable tolerance is reached when

$$
\left|\frac{M_{1}-M_{2}}{M_{1}} \times 100\right| \leqslant 1
$$

where $M_{1}$ and $M_{2}$ are moments computed from cappile and soil-pile analysis.)

The iterative procedure is automatic in the modified version of the COM 622 computer program. A degree of convergence acceptable for engineering purposes was usually achieved within four cycles of iterations.

\section{Soil and Concrete Parameters}

For the solution to the problem of a laterally loaded pile by the method used in the COM 622 computer program, it is necessary to predict a set of load-deformation curves (known as p-y curves) for each medium (soil and concrete). Figure 3 shows the graphic definition of $p$ and $y$ and a typical set of $p-y$ curves. The following two sections deal with construction of $\mathrm{p}-\mathrm{y}$ curves for soil and concrete.

\section{Soil Parameters}

Sands and clays are the two soil types considered in this study. For pressure levels below the limit pressure, the stiffness values used are from Terzaghi. 5 The method described below was used to establish limit pressures for both sand and clay. Elastic-plastic p-y curves were constructed for both sands and clays by combining Terzaghi's recommendation for the elastic portion and using the limit pressure calculations to establish the upper limit of $\mathrm{p}$.

The derivations and values retained for analysis are shown in the following subsections. The soil coefficient (spring constant) characterizes the elastic part while the limit pressure describes the plastic region.

Evaluation of Soil Coefficients. Soil coefficients were evaluated for sands, clays, and a typical design situation using Terzaghi's recommendations.

1. Sands-The soil coefficient $k$ for sands at a given depth $\mathrm{z}$ below the surface depends on the width $\mathrm{B}$ of the pile (measured at a right angle to the direction of the displacement), the effective unit weight $\gamma$ of the sand, and the relative density of the sand. The modulus

\footnotetext{
${ }^{5}$ K. Terzaghi, "Evaluation of Coefficients of Subgrade Reaction," Geotechnique, Vol. 5, No. 4 (1955), pp 297-326.
}

of elasticity of the sand for a given depth $z$ can be defined as

$$
\mathrm{E}_{\mathrm{s}}=\lambda \sigma_{\mathrm{v}}=\lambda \gamma z
$$

where $\lambda$ is a coefficient which depends only on the density of the sand, and $\sigma_{\mathrm{v}}$ is the effective overburden pressure at the depth $z$.

The soil coefficient for a vertical beam with width $B$ is determined by the relation between the contact pressure $\mathrm{p}$ and the corresponding lateral displacement $y$ of the contact face. The theory of elasticity defines the relation between $p$ and $y$ as

$$
\mathrm{p}=\mathrm{y} \frac{\mathrm{E}_{\mathrm{s}}}{1.35 \mathrm{~B}}=\mathrm{y} \frac{\lambda \gamma}{1.35} \frac{\mathrm{z}}{\mathrm{B}}
$$

Hence the soil coefficient:

$$
\mathrm{k}=\frac{\mathrm{p}}{\mathrm{y}}=\frac{\lambda \gamma}{1.35} \frac{z}{\mathrm{~B}}=\mathrm{n}_{\mathrm{h}} \frac{\mathrm{z}}{\mathrm{B}}
$$

and the load per unit length of the pile:

$$
P=p B=n_{h} z y
$$

where the factor:

$$
\mathrm{n}_{\mathrm{h}}=\frac{\lambda \gamma}{1.35}
$$

The valuc of $\lambda$ ranges from about 100 for very loose sand and 2000 for dense sand. The average unit weight of dry or moist sand is considered as $\gamma=100 \mathrm{lb} / \mathrm{cu} \mathrm{ft}$, and the average effective unit weight of submerged sand as $\gamma^{\prime}=60 \mathrm{lb} / \mathrm{cu} \mathrm{ft}$. The values of $n_{h}$ given in Table 3 are consistent with these values of $\lambda, \gamma$, and $\gamma^{\prime}$.

2. Clays-For piles embedded in clays, the value of the soil coefficient $\mathrm{k}$ increases approximately in simple proportion to the unconfined compressive strength of the clay $\left(q_{u}\right)$. Table 4 shows the proposed value of soil coefficients for piles embedded in clay.

Table 3

Values of $n_{h}$ for Sands (tons/cu $\mathrm{ft}$ )
Loose Medium Dense

$\mathrm{n}_{\mathrm{h}}$ (dry or moist)

$\mathrm{n}_{\mathrm{h}}$ (submerged)

7

21

56

$4 \quad 14$




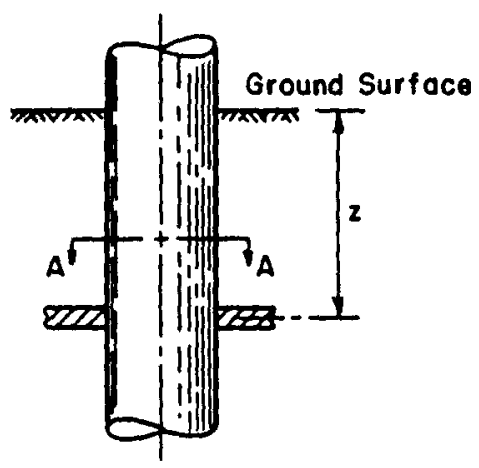

(a)
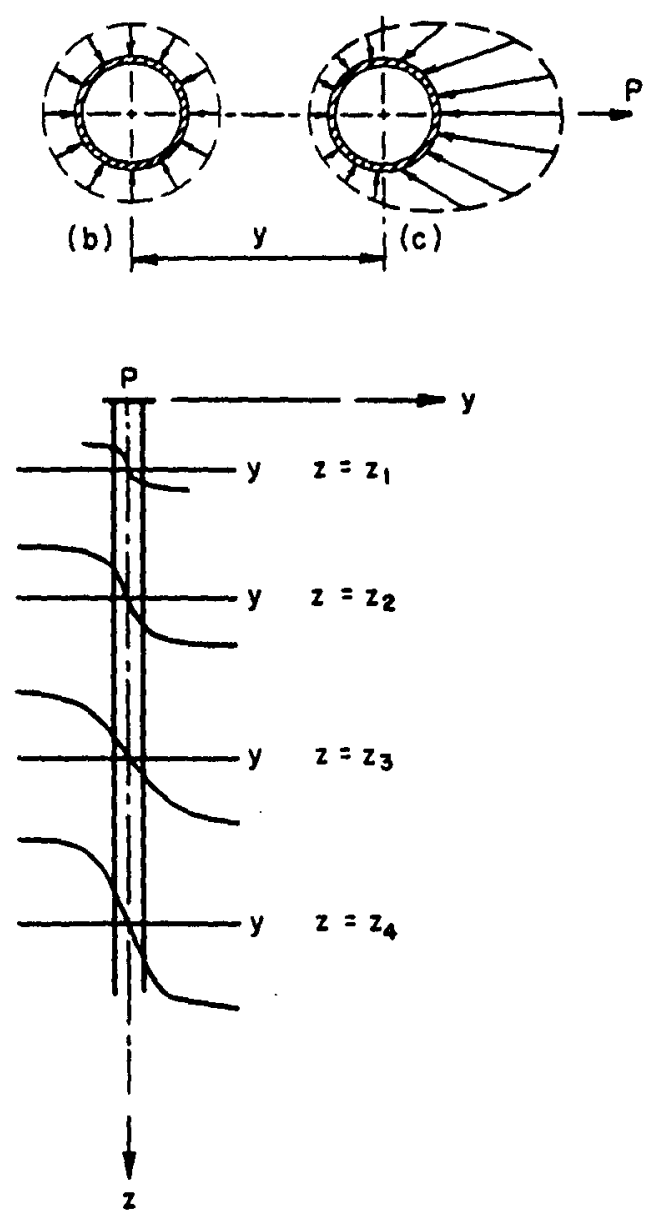

Graphical Definition of $P$ and $y$

(a) Side View

(b) A-A, Earth Pressure Distribution Prior to Lateral Looding

(c) A-A, Eorth Pressure Distribution After Lateral Looding

(d) Set of P-y Curves

Figure 3. Graphical definition of $p$ and $y$. 
Table 4

Soil Coefficients for Clays

$\begin{array}{cccc}\text { Clay } & \text { Stiff } & \begin{array}{c}\text { Very } \\ \text { Stiff }\end{array} & \text { Hard } \\ \mathrm{qu}_{\mathrm{u}(\mathrm{t}(\mathrm{n}) / \mathrm{sq} \mathrm{ft})} & 1-2 & 2-4 & >4 \\ \mathrm{k}(\mathrm{ton} / \mathrm{cu} \mathrm{ft}) & 50 & 100 & 200\end{array}$

3. Typical design situation - Under normal static operation conditions, the soil was represented by a very loose sand with $n_{h}=0.001 \mathrm{kips} / \mathrm{cu}$ in. $=1 \mathrm{ton} / \mathrm{cu}$ ft. Under normal dynamic operating conditions $(0.1 \mathrm{~g}$ earthquake acceleration), the soil was represented by a medium dense sand with $n_{h}=0.03 \mathrm{kips} / \mathrm{cu}$ in. $=26$ tons/cu ft.

Evaluation of Limit Pressures. The limit lateral pressure on a pile undergoing lateral displacement is equal to the difference between passive and active pressure. Sandy soils were assumed to be fully submerged $\left(\gamma^{\prime}=\right.$ buoyant unit weight). Clayey soils were assumed to respond 10 an undrained loading condition $(\phi=0$ analysis).

1. Sands The limit load per unit length of pile is given by

$$
P=\left(K_{P}-K_{A}\right) \gamma^{\prime} z B
$$

where

$$
\begin{aligned}
\mathrm{K}_{\mathrm{P}}= & \text { coefficient of passive earth pressure }=\tan \\
& \left(45^{\circ}+\phi / 2\right) \\
\mathrm{K}_{\mathrm{A}}= & \text { coefficient of active earth pressure }=\tan \left(45^{\circ}\right. \\
& -\phi / 2) \\
\gamma^{\prime}= & \text { buoyant unit weight }=\gamma_{\text {sat }}-\gamma_{\omega}=60 \mathrm{lb} / \\
& \text { cu } \mathrm{ft} \\
\%= & \text { depth } \\
\mathrm{B}= & \text { pile width. }
\end{aligned}
$$

The ratio $\mathrm{p} / \mathrm{z}=\left(\mathrm{K}_{\mathrm{P}}-\mathrm{K}_{\mathrm{A}}\right) \gamma^{\prime} \mathrm{B}$ is a characteristic of both soil and pile width. The limit elastic deformation $\left(y_{1 e}\right)$ is computed from the expression

\begin{tabular}{|c|c|c|c|c|c|}
\hline $\begin{array}{l}\text { Sandy } \\
\text { Soils }\end{array}$ & $\begin{array}{l}\text { Very } \\
\text { Loose }\end{array}$ & Loose & Medium & $\begin{array}{l}\text { Medium } \\
\text { Dense }\end{array}$ & Dense \\
\hline \multicolumn{6}{|l|}{$\begin{array}{l}\text { Typical } \\
\text { Design }\end{array}$} \\
\hline$n_{h}(t o n s / c u f t)$ & 0.864 & 4 & 14 & 26 & 34 \\
\hline$\phi(\mathrm{deg})$ & 30 & 30 & 37 & 40 & 45 \\
\hline$K_{P}$ & 3.0 & 3.0 & 4.0 & 4.6 & 5.83 \\
\hline $\mathrm{K}_{\mathrm{A}}$ & 0.33 & 0.33 & 0.25 & 0.22 & 0.17 \\
\hline \multicolumn{6}{|l|}{$\begin{array}{l}H P 14 \times 117 \\
b=14.9 \mathrm{in} .\end{array}$} \\
\hline$\frac{p}{L^{*}}(\mathrm{lb} / \mathrm{in})$. & 1.38 & 1.38 & 1.95 & 2.27 & 2.93 \\
\hline$y_{I_{e}}($ in.) & 1.38 & 0.298 & 0.120 & 0.076 & 0.074 \\
\hline \multicolumn{6}{|l|}{$\begin{array}{l}\text { HP } 14 \times 73 \\
b=14.6 \mathrm{in} .\end{array}$} \\
\hline$\frac{p}{z}(\mathrm{lb} / \mathrm{in})$. & 1.35 & 1.35 & 1.91 & 2.22 & 2.87 \\
\hline$y_{1 e}$ (in.) & 1.35 & 0.292 & 0.118 & 0.074 & 0.073 \\
\hline
\end{tabular}

$$
P=n_{h} z y
$$

which yields:

$$
y_{1 e}=\frac{P}{z} \frac{1}{n_{h}}=\left(K_{P}-K_{A}\right) \gamma^{\prime} B \frac{1}{n_{h}}
$$

The values of $y_{1 e}$ for various types of sands and two different piles (HP 14X73 and IIP 14X117) are shown in Table 5 .

Table 5

Limit Elastic Deformation $\left(y_{1 e}\right)$ for Sands

$*_{z}$ measured in inches. 
2. Clays - In an undrained loading condition $(\phi=$ 0 ), the difference between passive and active pressure $(\Delta)$ is equal to twice the unconfined compressive strength, $q_{u}$ :

$$
\Delta=2 q_{u}
$$

The limit load per unit length of pile is given by

$$
P=\Delta B
$$

where $B$ is the pile width.

The limit clastic deflection, $y_{1,}$, is computed from the expression

$$
P=K y_{10}
$$

or

$$
\mathrm{y}_{1 \mathrm{e}}=\frac{\mathrm{P}}{\mathrm{K}}
$$

or

$$
\mathrm{y}_{1 \mathrm{e}}=\frac{\Delta}{\mathrm{K}} \mathrm{B}
$$

Table 6 shows the values of $y_{1 \mathrm{e}}$ for various consistencies of clays and for two different piles.

Figure 4 shows typical load-deformation curves ( $\mathrm{p}-\mathrm{y}$ curves) for sands and clays.

\section{Determination of Concrete Spring Constant}

Two approaches were taken to evaluate the concrete spring constant :

\begin{tabular}{|c|c|c|c|}
\hline Clayey & & Very & \\
\hline Soils & Stiff & Stiff & Hard \\
\hline$q_{u}(\operatorname{ton} / s q \mathrm{ft})$ & 1 & 2 & $\begin{array}{l}3 \text { (low, } \\
\text { but used in } \\
\text { analysis) }\end{array}$ \\
\hline$k(t o n / c u f t)$ & 50 & 100 & 200 \\
\hline $\begin{array}{l}\mathrm{HP} 14 \times 117 \\
\mathrm{p}(\mathrm{lb} / \mathrm{in})\end{array}$ & 414 & 828 & 1242 \\
\hline$y_{1 e}$ (in.) & 0.597 & 0.596 & 0.447 \\
\hline $\begin{array}{l}\text { HP } 14 \times 73 \\
\mathrm{p}(\mathrm{lb} / \mathrm{in} .)\end{array}$ & 406 & 811 & 1,217 \\
\hline$y_{10}(i n)$. & 0.585 & 0.584 & 0.438 \\
\hline
\end{tabular}

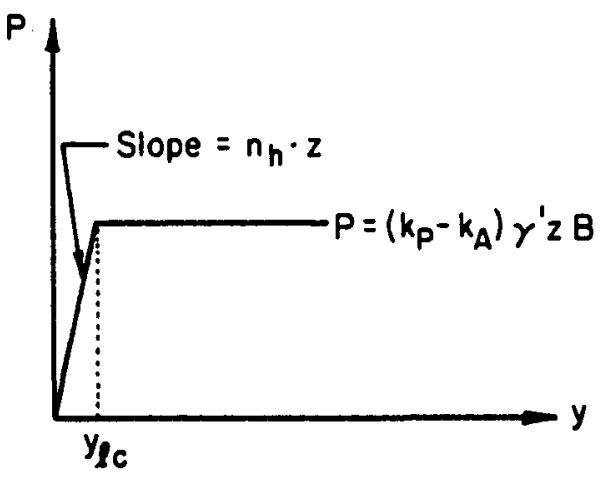

SAND
Table 6

Limit Elastic Deformation $\left(y_{1 e}\right)$ for Clays

1. Half-Space Solution-The equation yielding to compression of the surface layer of an elastic halfspace under the centerline of a strip load was derived. It is characterized by an influence coefficient, $\mathrm{I}_{\mathrm{HS}}$.

2. Elastic Layer over Rigid Base Solution-The numerical solution to this problem, obtained by Poulos, ${ }^{6}$ is characterized by an influence coefficient, $I_{R B}$.

It was found that both coefficients, $I_{H S}$ and $I_{R B}$, are approximately equal for a layer thickness at least equal to a width and a half of the loaded area. In other words, either solution can be used in evaluating the concrete spring constant as long as the representative

\footnotetext{
${ }^{6}$ H. G. Poulos, "Stresses and Displacements in an Elastic Layer Underlain by a Rough Rigid Base," Gcotechnique, Vol. 17, No. 4 (1967), pp 378-410.
}

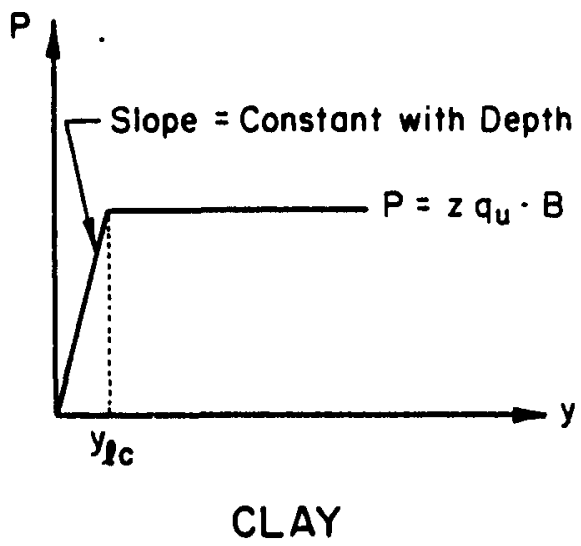

Figure 4. Typical load-deformation curves ( $\mathrm{p}-\mathrm{y}$ curves) for sands and clays. 
concrete thickness on either side of a pile is at least equal to one and a half times the width of the pile. The value $K_{S}=3084 \mathrm{kips} / \mathrm{sq}$ in. was selected for all the analyses. It was computed for a ratio of concrete thick. ness to pile width equal to 1.75 and was found to be approximately equal to the average spring constant for values of concrete thickness to pile width ratio ranging from one to five.

Detailed computations of $\mathrm{K}_{\mathrm{S}}$ for both approaches are given in the following pages.

Half-Space Solution. Stresses in an elastic half-space under a strip load are: ${ }^{7}$

$$
\begin{aligned}
& \sigma_{x}=\frac{q}{\pi}[\alpha+\sin \alpha \cos (\alpha+2 \delta)] \\
& \sigma_{x}=\frac{q}{\pi}[\alpha+\sin \alpha \cos (\alpha+2 \delta)] \\
& \sigma_{y}=\frac{2 q}{\pi} \nu \alpha \\
& \tau_{x z}=\frac{q}{\pi}[\sin \alpha \sin (\alpha+2 \delta)]
\end{aligned}
$$

where $\sigma_{x}, \sigma_{y}$, and $\sigma_{z}$ are normal stresses in $x, y$, and $z$ directions and $\tau_{x}$, is the shear stress acting in $z$ direction on a plane normal to the $x$ axis. Other variables involved in the above equations are defined in Figure 5. Strain in $z$ direction can be defined as:

$$
\epsilon_{z}=\frac{1}{\mathrm{E}}\left(\sigma_{z}-\nu \sigma_{\mathrm{x}}-\nu \sigma_{\mathrm{y}}\right)
$$

On the strip centerline $(\mathrm{x}=0) \sigma_{\mathrm{x}}, \sigma_{y}, \sigma_{z}, \tau_{\mathrm{x} z}$ simplify as follows:

$$
\begin{aligned}
& \sigma_{z}=\frac{\mathrm{q}}{\pi}(\alpha+\sin \alpha) \\
& \sigma_{\mathrm{x}}=\frac{\mathrm{q}}{\pi}(\alpha-\sin \alpha) \\
& \sigma_{\mathrm{y}}=\frac{2 \mathrm{q}}{\pi} \nu \alpha \\
& \tau_{\mathrm{x} \%}=0
\end{aligned}
$$

Substituting $\sigma_{x}, \sigma_{y}$, and $\sigma_{z}$ in the $\epsilon_{z}$ equation yields:

\footnotetext{
${ }^{7}$ Poulos and Davis (1974).
}

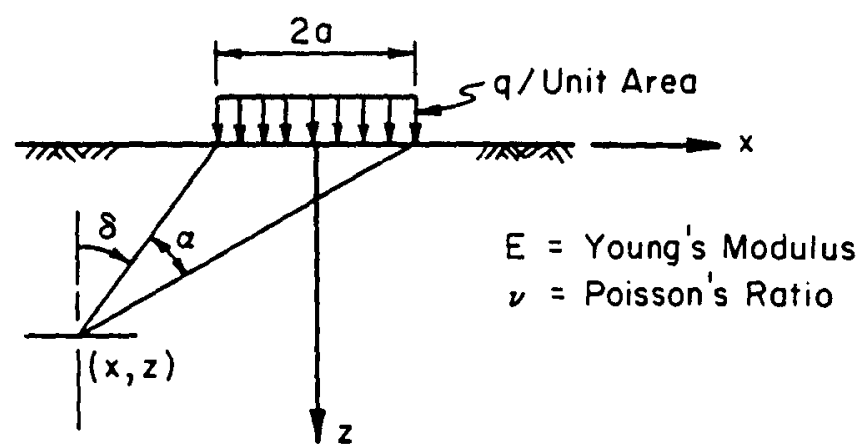

Figure 5. Elastic half-space under a strip load, generalized solution.

$$
\epsilon_{z}=\frac{1+\nu}{\mathrm{E}} \frac{\mathrm{q}}{\mathrm{n}}[\alpha(1-2 \nu)+\sin \alpha]
$$

From Figure 6, $z$ can be written as

$$
z=a \cot \frac{\alpha}{2}
$$

By differentiation

$$
\mathrm{d} z=-\frac{\mathrm{a}}{2} \frac{1}{\sin ^{2} \frac{\alpha}{2}} \mathrm{~d} \alpha
$$

and infinitesimal settlement $d w$ can be defined as

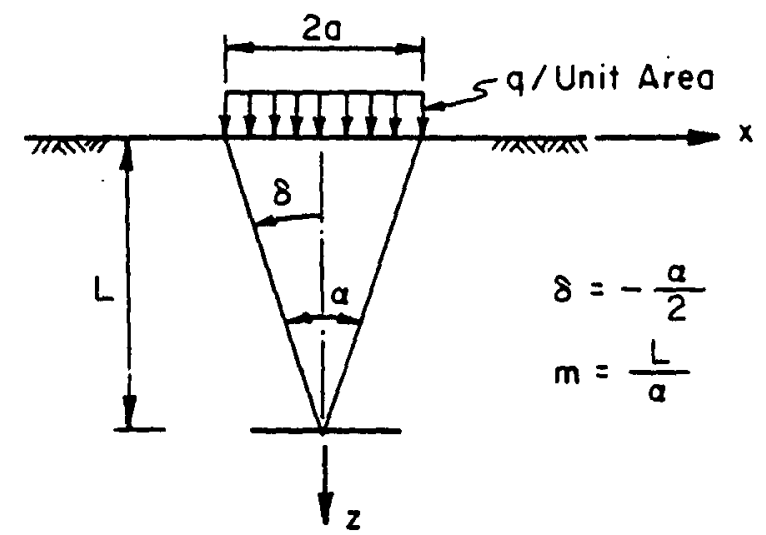

Figure 6. Elastic half-space under a strip load, centralized solution. 


$$
\mathrm{dw}=\epsilon_{\mathrm{z}} \mathrm{dz}
$$

Substituting $\epsilon_{z}$ and $\mathrm{dz}$ from the above equations, dw can be written as

$$
\mathrm{dw}=\frac{\mathrm{q}}{2 \pi} \frac{1+\nu}{\mathrm{E}} \mathrm{a} \frac{-[\alpha(1-2 \nu)+\sin \alpha]}{\sin ^{2} \frac{\alpha}{2}} \mathrm{~d} \alpha
$$

Integration of $d w$ between $\alpha=\pi(z=0)$ and $\alpha_{1}=$ 2 Arc cot $(m)$ yields:

$$
\begin{gathered}
w=\int_{\pi}^{\alpha_{1}} \mathrm{dw}=\frac{\mathrm{q}}{2 \pi} \frac{1+\nu}{\mathrm{E}} \mathrm{a}[(1-2 \nu) \\
\left.X\left[2 \alpha_{1} \cot \frac{\alpha_{1}}{2}-4 \ln \sin \frac{\alpha_{1}}{2}\right]-4 \ln \sin \frac{\alpha_{1}}{2}\right]
\end{gathered}
$$

replacing a by $L / m$ and simplifying,

$$
\begin{aligned}
w= & \frac{2 q}{\pi} \frac{1+\nu}{E} L[(1-2 v) \operatorname{Arccot}(m) \\
& \left.+(1-v) \frac{1}{m} \ln \left(1+m^{2}\right)\right]
\end{aligned}
$$

The equivalent spring constant, $\mathrm{K}_{\mathrm{S}}$, is

$$
\mathrm{K}_{\mathrm{S}}=\frac{2 \mathrm{qa}}{\mathrm{w}}
$$

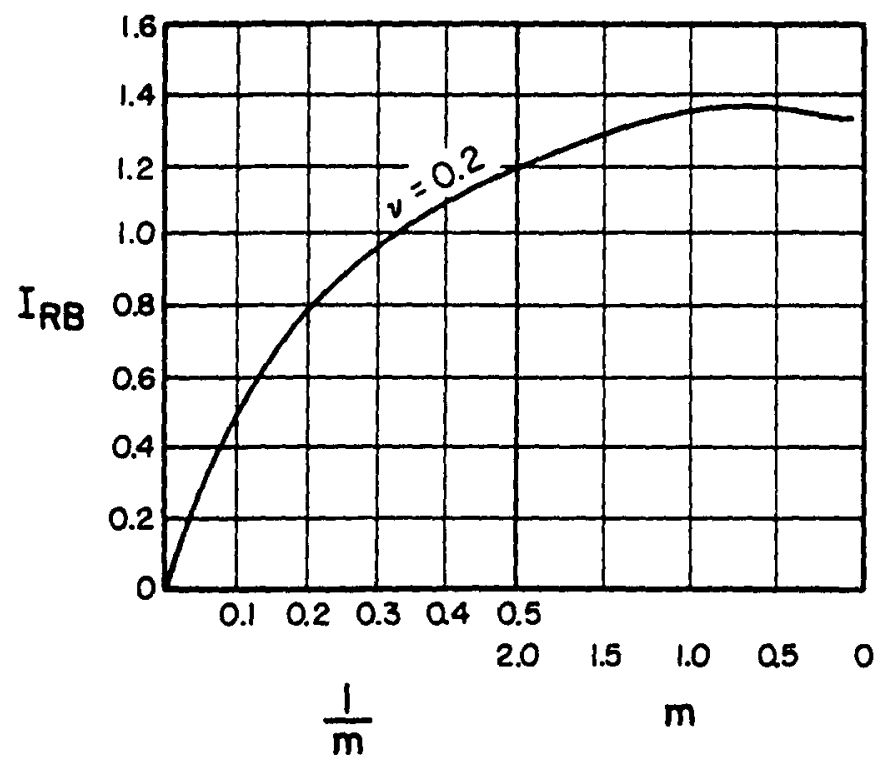

Figure 7. Plot of $I_{R B}$ in terms of $m=4 a$ and $v=0.2$.
Table 7

\section{Comparison Between}

$I_{H S}$ and $I_{R B}$

$\begin{array}{ccc}\mathbf{m}=\frac{\mathbf{L}}{\mathbf{a}} & \mathbf{I}_{\mathbf{H S}} & \mathbf{I}_{\mathbf{R B}} \\ 1.0 & 1.23 & 1.36 \\ 2.0 & 1.11 & 1.20 \\ 4.0 & 0.86 & 0.9 \\ 10.0 & 0.51 & 0.5\end{array}$

or

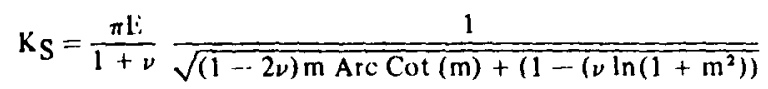

The settlement of the surface layer of an elastic half space can be expressed as

$$
w=\frac{2 q L}{\pi E} I_{H S}
$$

where

$$
\begin{aligned}
\mathrm{I}_{\mathrm{HS}} & =(1+\nu)[(1-2 \nu) \operatorname{Arc} \cot (\mathrm{m}) \\
& \left.+(1-\nu) \frac{1}{\mathrm{~m}} \ln \left(1+\mathrm{m}^{2}\right)\right]
\end{aligned}
$$

Elastic Layer over Rigid Base Solution. A numerical solution for the problem of the settlement of a finite layer over a rigid base has been obtained by Poulos. ${ }^{8}$ The solution can be expressed as

$$
w=\frac{2 q L}{\pi E} I_{R B}
$$

where $I_{R B}$ is shown in Figure 7 in terms of $m=L / a$ for a Poisson's ratio of 0.2 . Table 7 shows a comparison between $I_{H S}$ and $I_{R B}$ for various $m=L / a$ values. As can be seen from the table, both methods predict very similar settlements of the layer under a strip load for $m \geqslant 2.0$.

Calculation of Concrete Spring Constant. Using the half-space solution, the spring constant $K_{\mathrm{S}}$ is given as

$$
\mathrm{K}_{\mathrm{S}}=\frac{2 q \mathrm{a}}{\mathrm{w}}=\frac{2 \mathrm{qL}}{\mathrm{mw}}=\frac{\pi \mathrm{E}}{\mathrm{m}} \frac{1}{\mathrm{I}_{\mathrm{HS}}}
$$

\footnotetext{
${ }^{8}$ Poulos, pp 378-410.
} 
where

$$
\begin{aligned}
\mathrm{I}_{\mathrm{HS}} & =(1+\nu)[(1-2 \nu) \operatorname{Arccot}(\mathrm{m}) \\
& \left.+(1-\nu) \frac{1}{\mathrm{~m}} \ln \left(1+\mathrm{m}^{2}\right)\right]
\end{aligned}
$$

and

$$
\mathrm{m}=\frac{\mathrm{L}}{\mathrm{a}}
$$

and concretc's Young's modulus, from $\mathrm{ACI}:{ }^{9}$

$$
\mathrm{E}(\mathrm{lb} / \mathrm{sq} \text { in })=57000 \sqrt{\mathrm{f}_{\mathrm{c}}^{\prime}(\mathrm{lb} / \mathrm{sq} \text { in })}
$$

using $\mathrm{f}_{\mathrm{c}}^{\prime}=3000 \mathrm{lb} / \mathrm{sq}$ in., then $\mathrm{E}=3122 \mathrm{kips} / \mathrm{sq}$ in.; and concrete's Poisson's ratio

$$
\nu=0.2
$$

Thus, concrete spring constant $\mathrm{K}_{\mathrm{S}}$ with $\mathrm{m}=3.5$ is computed as

$$
\mathrm{I}_{\mathrm{HS}}=0.91
$$

\footnotetext{
${ }^{9}$ ACI $318-77$, Building Code Requirements for Reinforced Concrete (American Concrete Institute [ACI], June 1978).
}

$$
\mathrm{K}_{\mathrm{S}}=\frac{\pi(3122)}{3.5} \frac{1}{0.91}=3084 \mathrm{ksi}
$$

\section{Parametric Analysis}

An analysis was performed to investigate the effect of the following parameters on the degree of fixity of the pile section:

1. Embedment length in the cap

2. Soil stiffness and soil type

3. Shear force at the interface between the soil and cap

4. Pile stiffness.

Figures 8 and 9 show a typical analysis for specific parameters. The analysis was performed for variation of all the above parameters; the results are shown in Figures 10 through 19 and Table 8.

Figures 10 through 19 depict the rotation of pile at the soil-cap interface $(\Theta)$ versus the ratio of embed-

\begin{tabular}{|c|c|c|c|c|c|c|c|}
\hline Operation & Soil & Pile & $\begin{array}{l}\text { Embedded } \\
\text { Length } \\
\text { (in.) }\end{array}$ & $\begin{array}{c}\text { Shear at } \\
\text { Base of Cap } \\
\text { (kips) }\end{array}$ & $\begin{array}{c}\text { Cap } \\
\text { Displacement } \\
\text { (in.) }\end{array}$ & $\begin{array}{l}\text { Computed } \\
\text { Max. Moment } \\
\text { (in.-kips) }\end{array}$ & $\begin{array}{l}\text { Fixed End } \\
\text { Usual Design } \\
\text { Moment } \\
\text { (in.-kips) }\end{array}$ \\
\hline $\begin{array}{l}\text { Normal } \\
\text { Static }\end{array}$ & $\begin{array}{l}\text { Very Loose } \\
\text { Sand }\end{array}$ & HP $14 \times 73$ & $\begin{array}{l}12 \\
24 \\
36 \\
48\end{array}$ & $\begin{array}{l}2.8 \\
2.8 \\
2.8 \\
2.8\end{array}$ & $\begin{array}{l}0.27 \\
0.23 \\
0.23 \\
0.23\end{array}$ & $\begin{array}{l}240 \\
288 \\
291 \\
291\end{array}$ & 295 \\
\hline & $\begin{aligned} \mathrm{n}_{\mathrm{h}} & =0.001 \mathrm{kip} / \mathrm{cu} \text { in. } \\
& \cong 1 \mathrm{ton} / \mathrm{cu} \mathrm{ft}\end{aligned}$ & HP $14 \times 117$ & $\begin{array}{l}12 \\
24 \\
36 \\
48\end{array}$ & $\begin{array}{l}2.2 \\
2.2 \\
2.2 \\
2.2\end{array}$ & $\begin{array}{l}0.20 \\
0.16 \\
0.15 \\
0.15\end{array}$ & $\begin{array}{l}202 \\
259 \\
264 \\
264\end{array}$ & 260 \\
\hline $\begin{array}{l}\text { Normal } \\
\text { Dynamic } \\
0.1 \mathrm{~g} \\
\text { Earthquake }\end{array}$ & $\begin{array}{l}\text { Medium } \\
\text { Dense Sund }\end{array}$ & HP $14 \times 73$ & $\begin{array}{l}12 \\
24 \\
36 \\
48\end{array}$ & $\begin{array}{l}18 \\
18 \\
18 \\
18\end{array}$ & $\begin{array}{l}0.44 \\
0.36 \\
0.35 \\
0.35\end{array}$ & $\begin{array}{r}868 \\
1,140 \\
1,160 \\
1,160\end{array}$ & 954 \\
\hline & $\begin{aligned} \mathrm{n}_{\mathrm{h}} & =0.03 \mathrm{kip} / \mathrm{cu} \mathrm{in} \\
& \cong 26 \mathrm{ton} / \mathrm{cu} \mathrm{ft}\end{aligned}$ & HP $14 \times 117$ & $\begin{array}{l}12 \\
24 \\
36 \\
48\end{array}$ & $\begin{array}{l}15 \\
15 \\
15 \\
15\end{array}$ & $\begin{array}{l}0.26 \\
0.21 \\
0.20 \\
0.20\end{array}$ & $\begin{array}{l}605 \\
949 \\
983 \\
985\end{array}$ & 913 \\
\hline
\end{tabular}
ment length in the cap to pile width (Le/B). As can be seen from these figures, when Le/B is less than two, the rotation of the pile increases. When Le/B is more than two, the rotation of the pile reaches a minimum

Table 8

Computed Response to Typical Design Situations 
Medium Sond

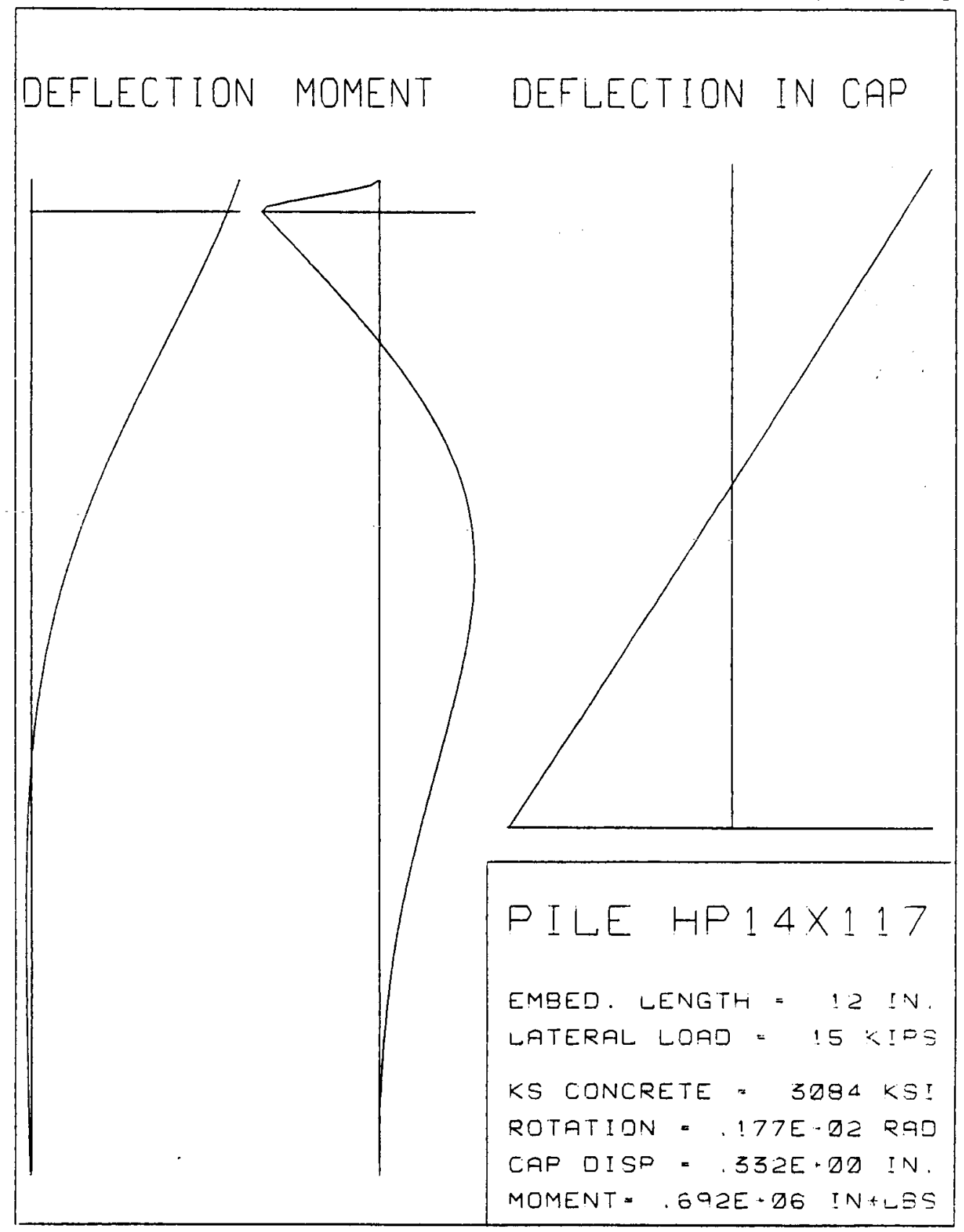

Figure 8. Typical moment and deflection curves for HP $14 \mathrm{X} 117$ pile with 12 in. embedment. 
Medium Sond

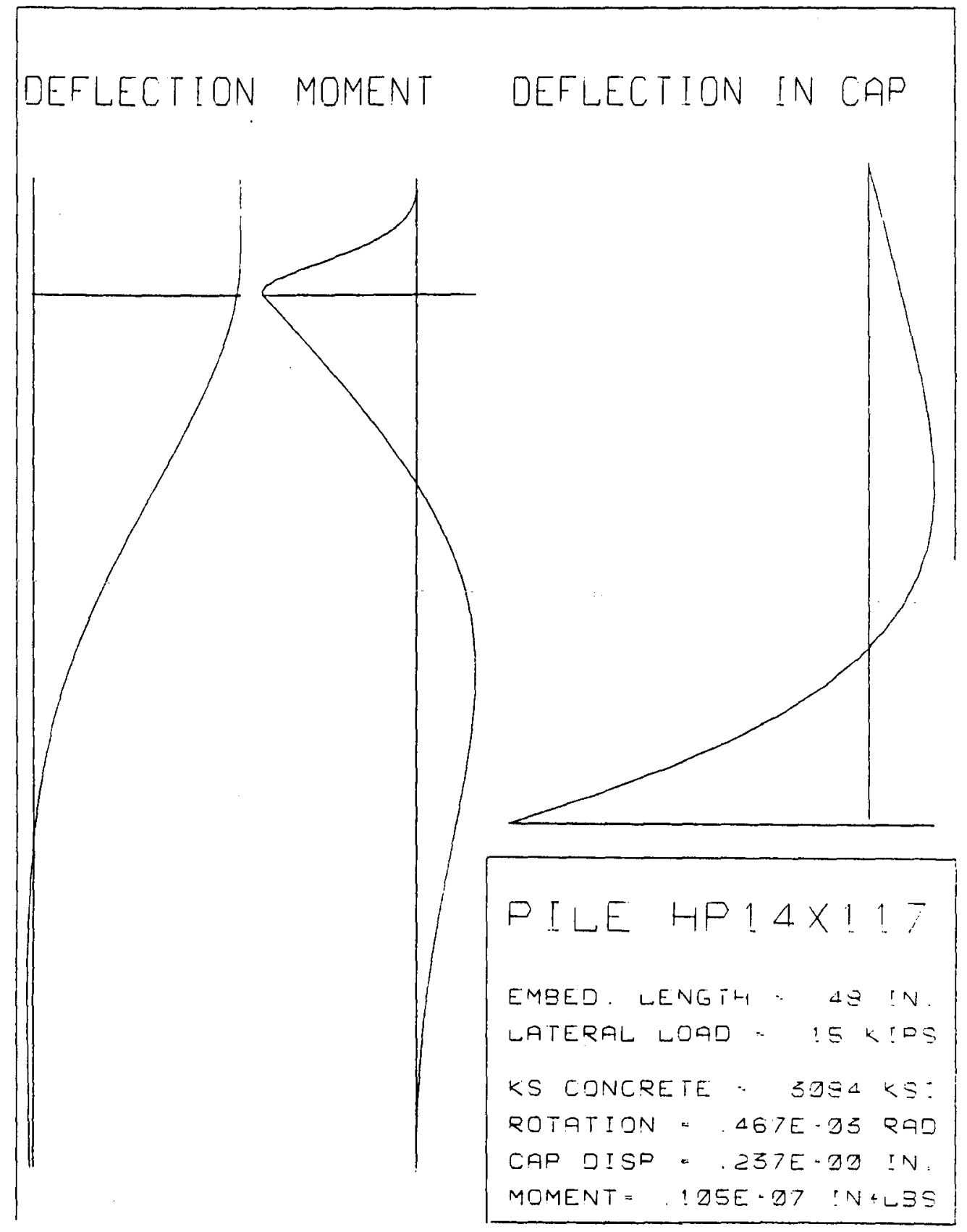

Figure 9. Typical moment and deflection curves for HP $14 \times 117$ pile with 48 in. embedment. 


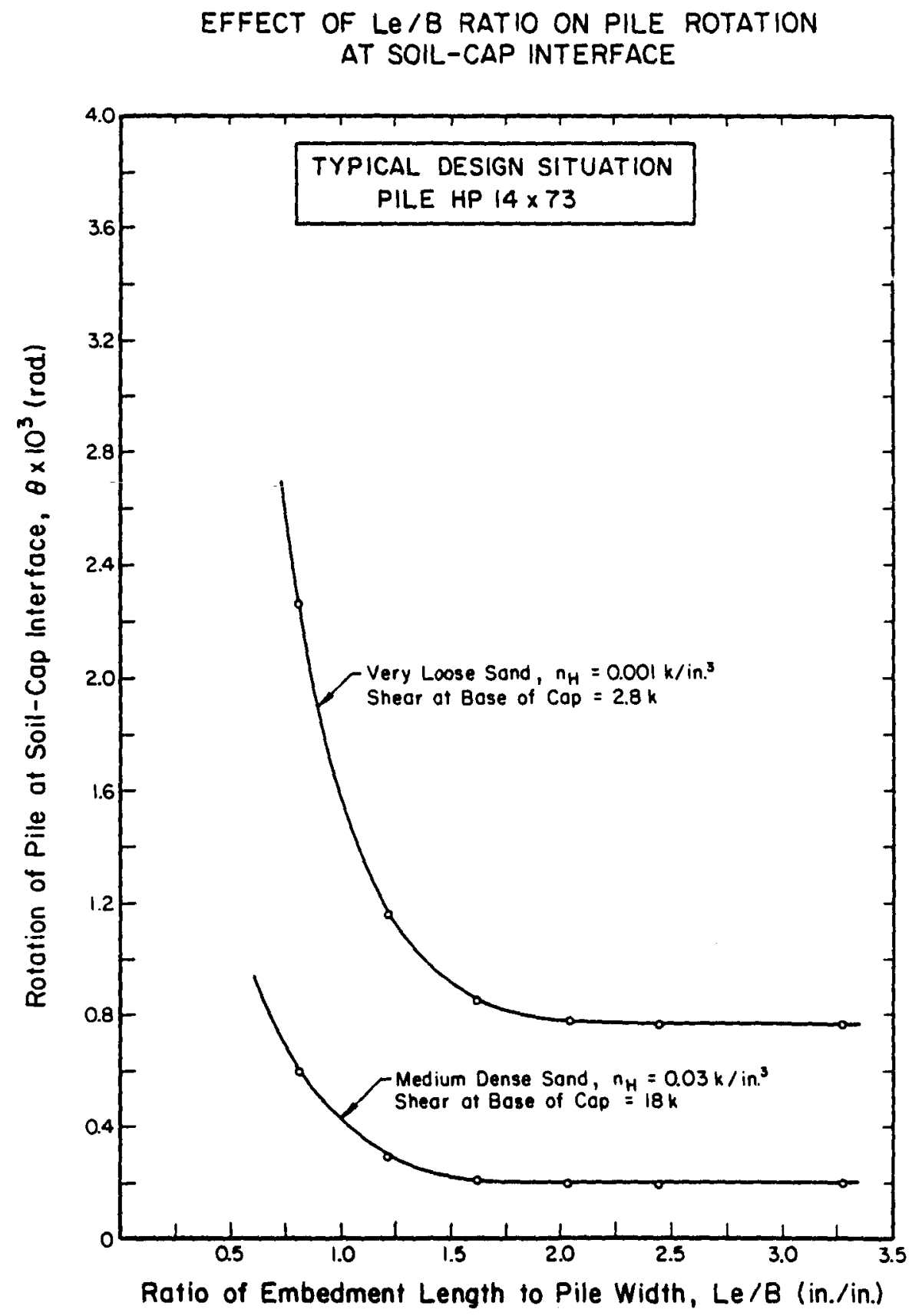

Figure 10. Effect of Le/B ratio on pile rotation at soil-cap interface, typical design situation for HP $14 X 73$ pile. 


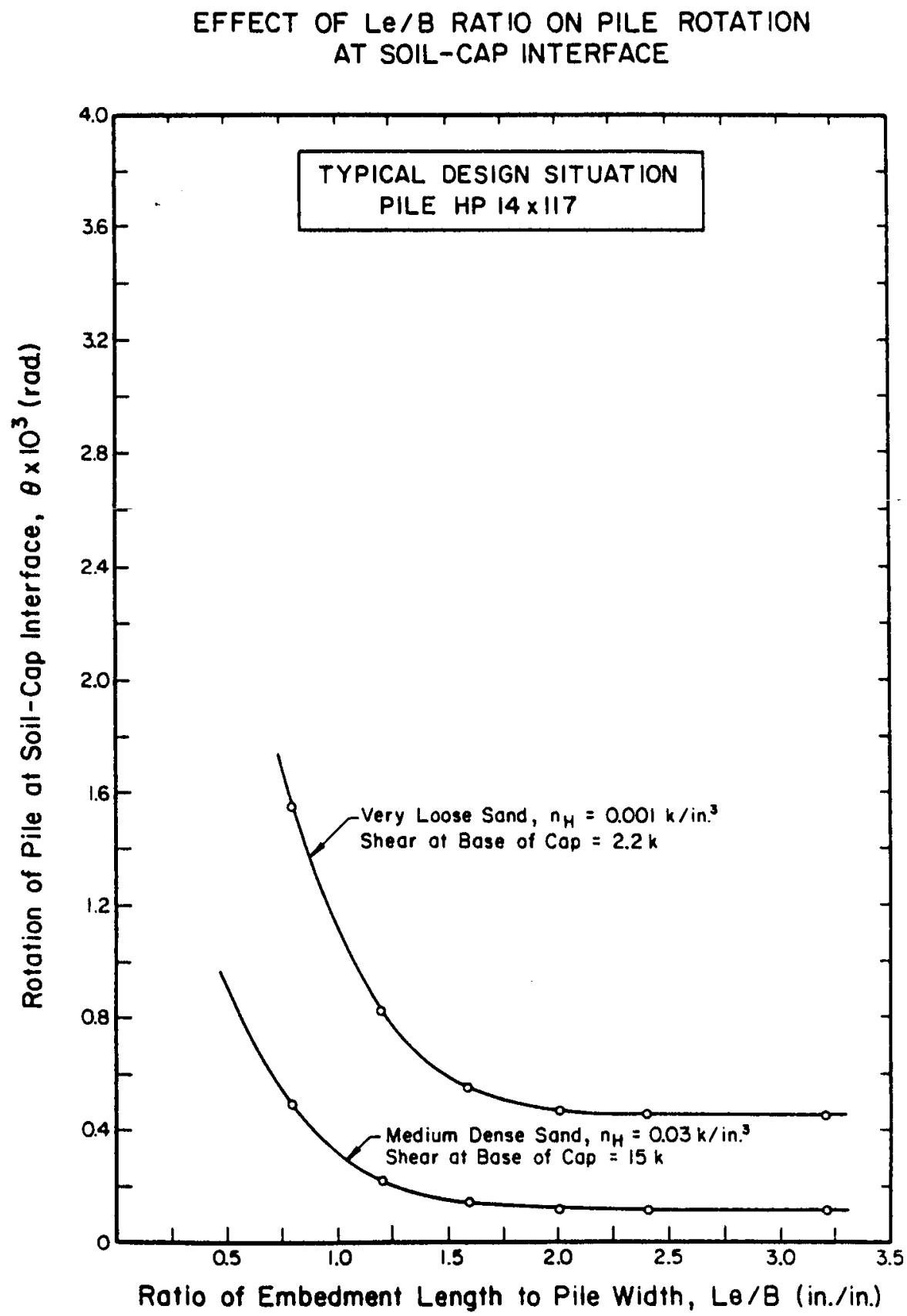

Figure 11. Effect of Le/B ratio on pile rotation at soil-cap interface, typical design situation for HP $14 X 117$ pile. 


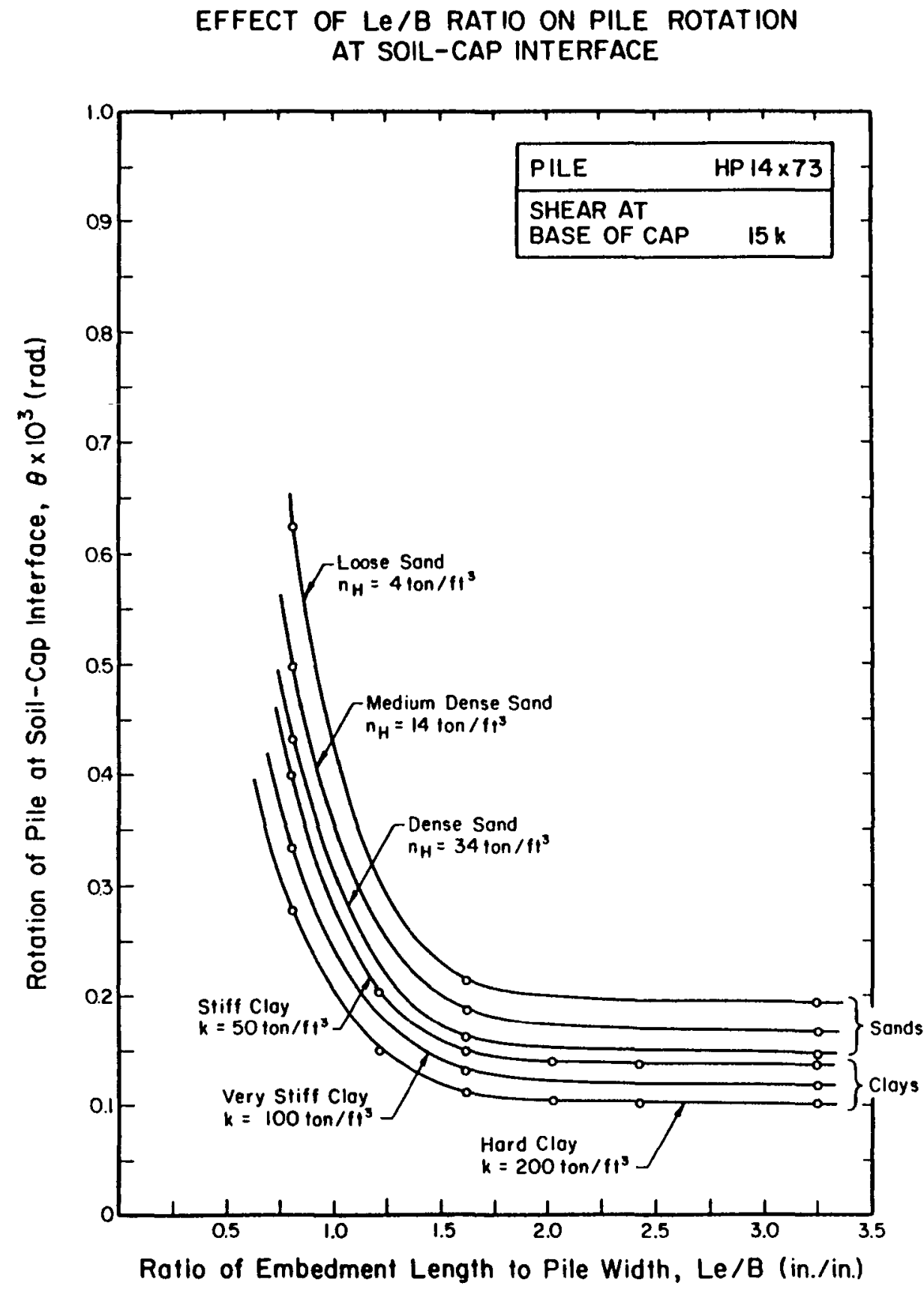

Figure 12. Effect of Le/B ratio on pile rotation at soil-cap interface, HP $14 X 73$ pile with 15 kip shear at base of cap. 


\section{EFFECT OF LE/B RATIO ON PILE ROTATION \\ AT SOIL-CAP INTERFACE}

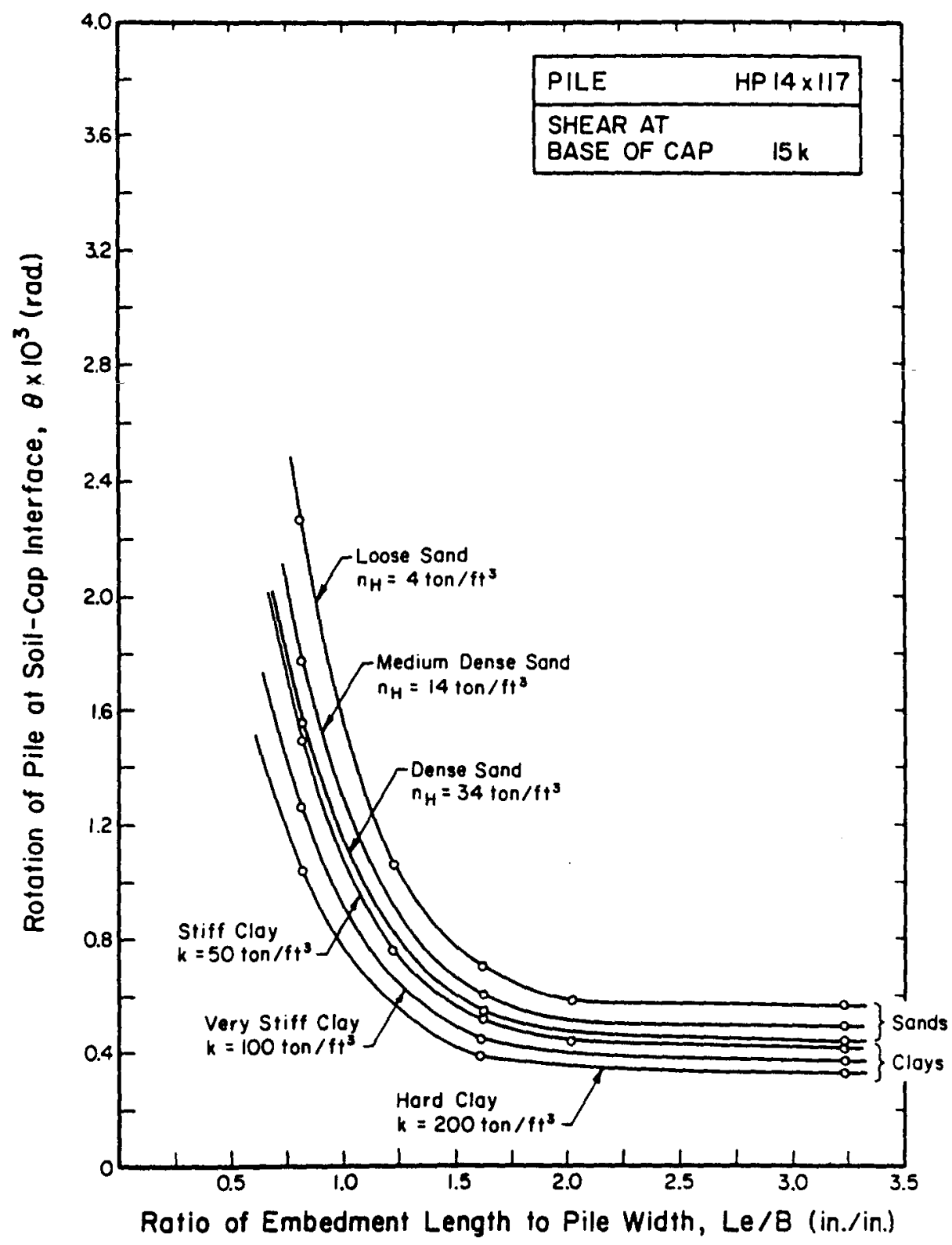

Figure 13. Effect of Le/B ratio on pile rotation at soil-cap interface, HP 14 X 117 pile with 15 kip shear at base of
cap. 


\section{EFFECT OF LE/B RATIO ON PILE ROTATION AT SOIL-CAP INTERFACE}

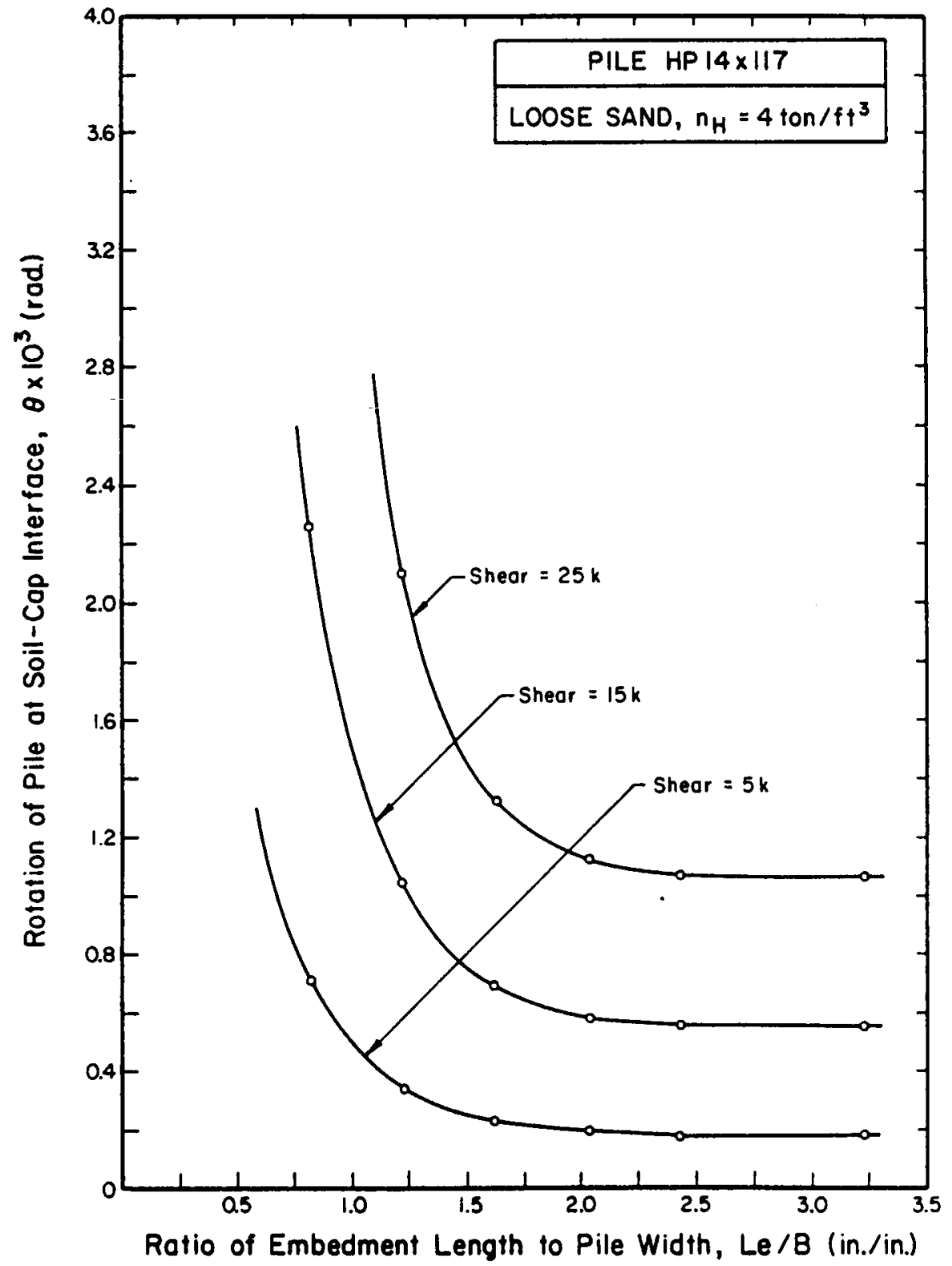

Figure 14. Effect of Le/B ratio of pile rotation at soil-cap interface, HP $14 \times 117$ pile in loose sand, $n_{h}=4$ ton/ cu ft. 


\section{EFFECT OF LE/B RATIO ON PILE ROTATION AT SOIL-CAP INTERFACE}

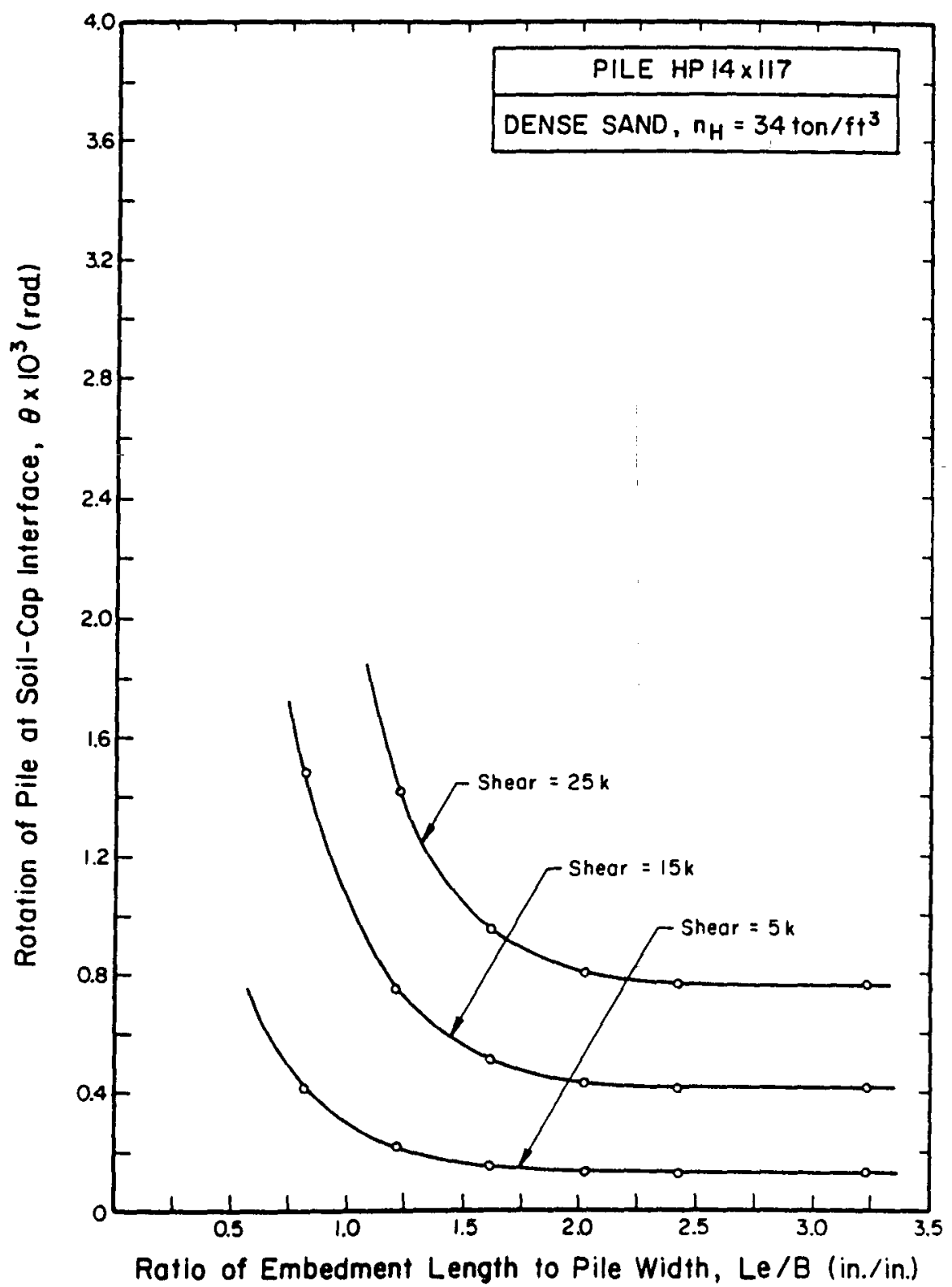

Figure 15. Effect of Le/B ratio on pile rotation at soil-cap interface, HP $14 X 117$ pile in dense sand, $\mathrm{n}_{\mathrm{h}}=34$ ton/ $\mathrm{cu} \mathrm{ft}$. 


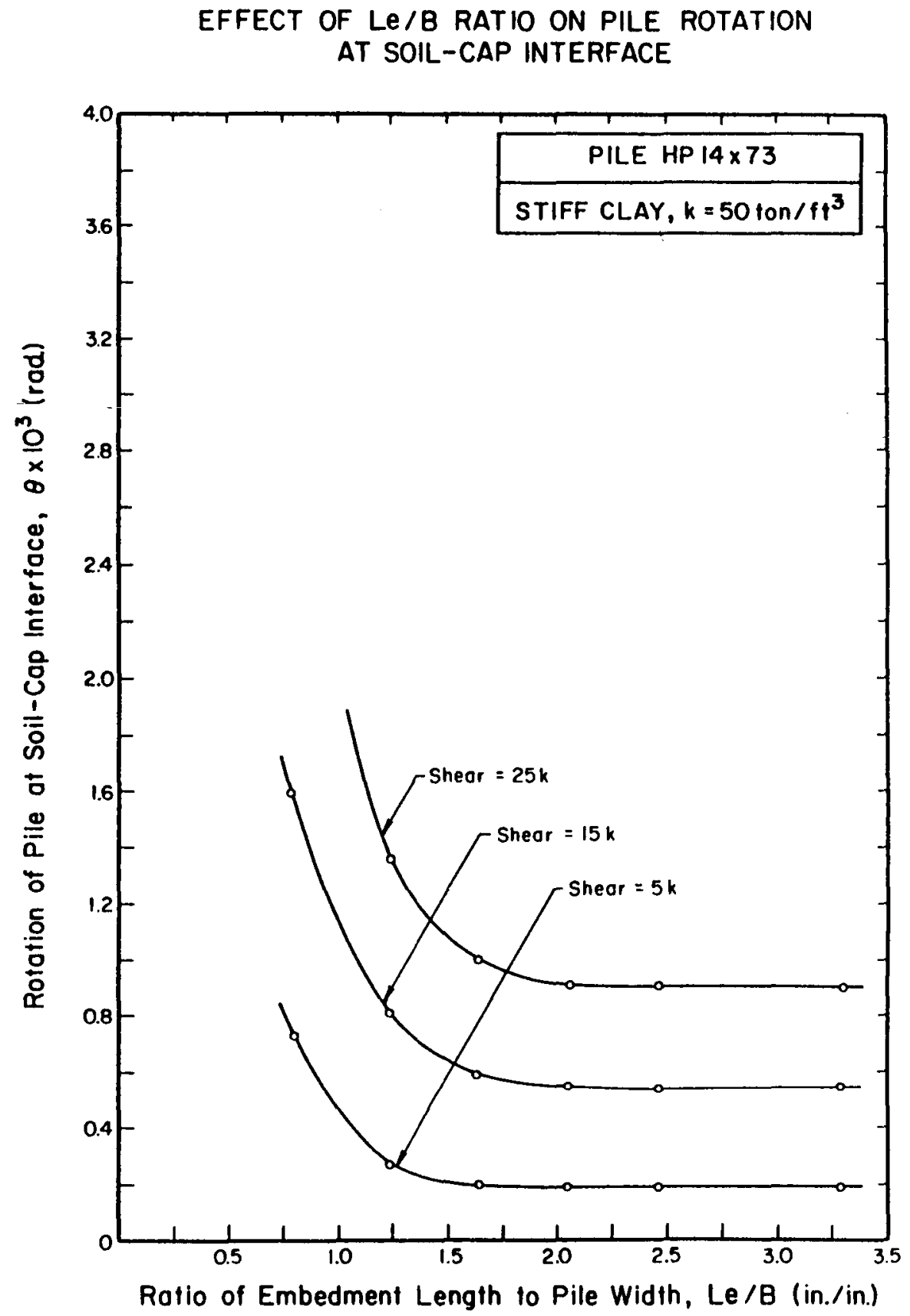

Figure 16. Effect of Le/B ratio on pile rotation at soil-cap interface, HP $14 X 73$ pile in stiff clay, $\mathrm{k}=50 \mathrm{tons} / \mathrm{cu} \mathrm{ft}$. 


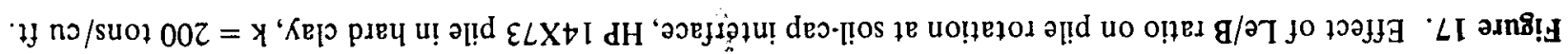

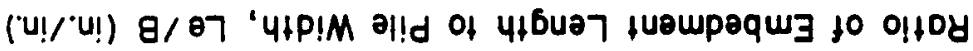

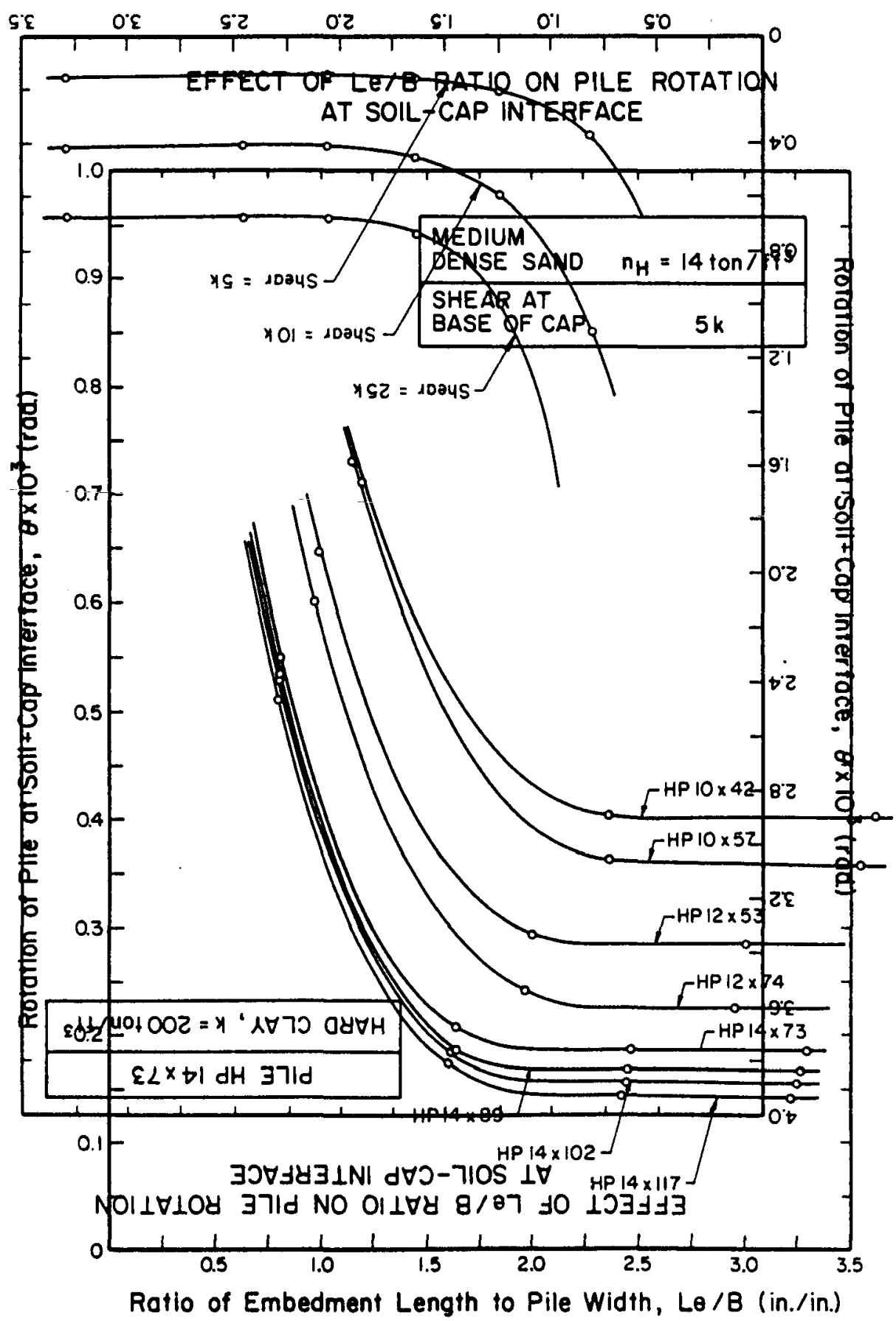

Figure 18. Effect of Le/B ratio on pile rotation at soil-cap interface, various pile sections in medium dense sand with 5 kip shear at base of cap. 


\section{EFFECT OF Le/B RATIO ON PILE ROTATION AT SOIL-CAP INTERFACE}

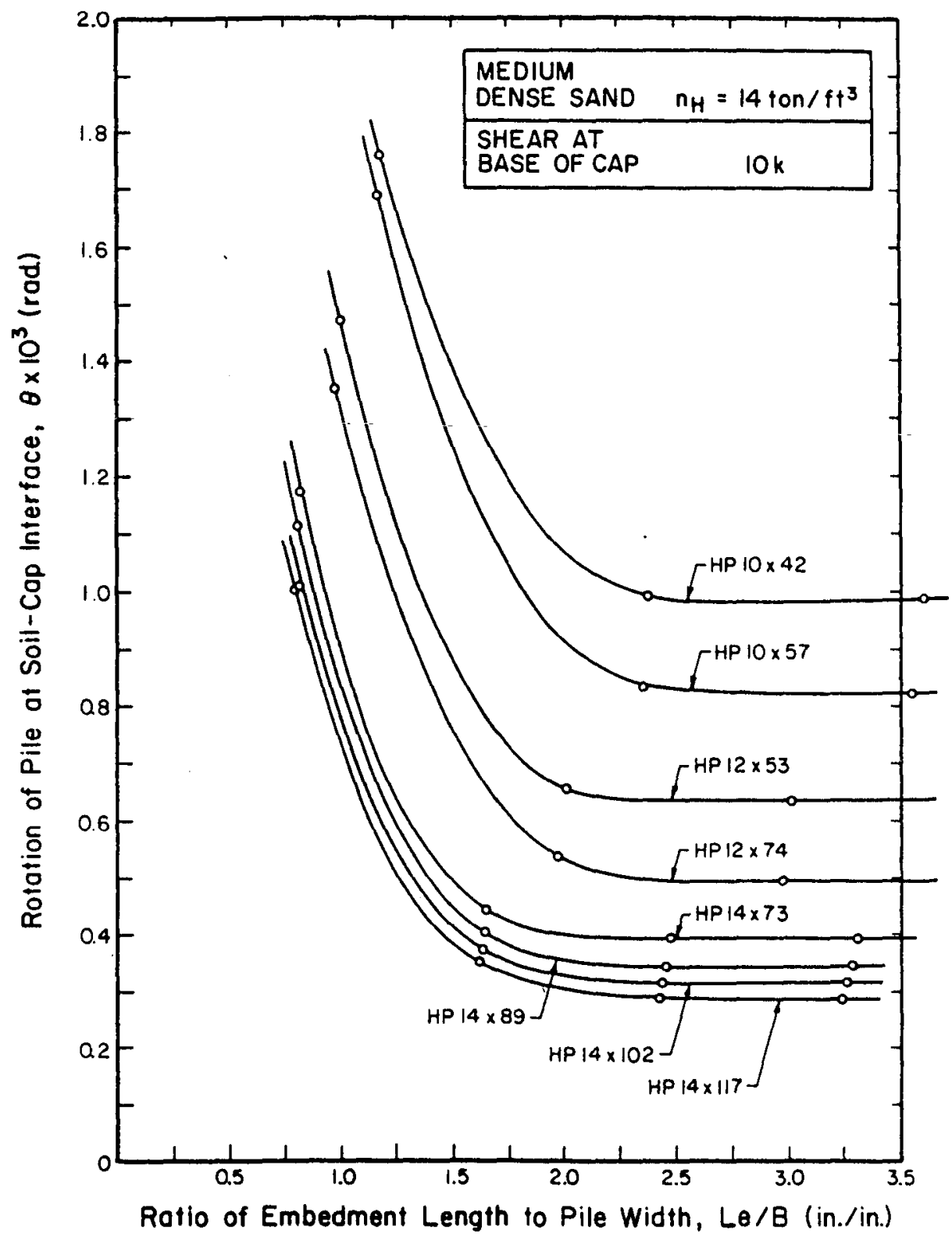

Figure 19. Effect of Le/B ratio on pile rotation at soil-cap interface, various pile sections in medium dense sand with 10 kip shear at base of cap. 
constant value independent of Le/B which indicates the fixed end condition is achieved.

Figures 10 through 13 show the effect of soil type and soil stiffness. As the stiffness of soil increases, the rotation of pile at the soil-cap interface decreases for a given value of Le/B. Figures 12 and 13 show that the rotation of the pile is less for clayey soil than sandy soil for a given value of $\mathrm{Le} / \mathrm{B}$.

Figures 14 through 17 show the effect of shear force at the interface between the soil and the cap. As the shear force increases for a given value of Le/B, the rotation of the pile at the soil-cap interface increases.

a)

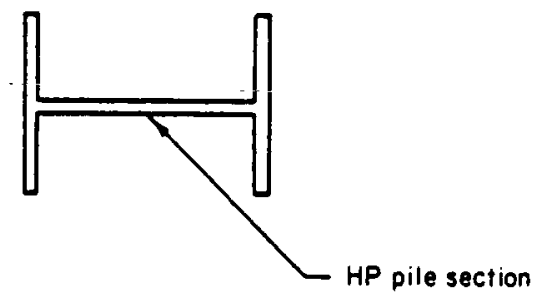

b)

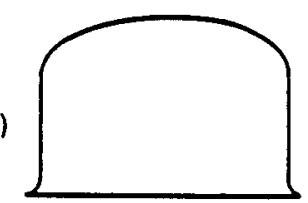

sheor stress distribution

c)

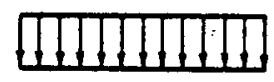

axial stress distribution

bending stress distribution

Figure 20. Stress distribution in an HP pile section.
The effect of pile stiffness is depicted in Figures 18 and 19. In both figures various HP pile shapes are examined. These two figures show that as the pile stiffness increases the rotation of the pile at the soil-cap interface decreases for a given value of $\mathrm{Le} / \mathrm{B}$.

Table 8 lists the computed response for a typical design situation. In this table, shear at the base of the cap was used as an input (from Table 2) to compute the maximum moment and cap displacement. The analysis was performed for 12 in., 24 in., 36 in., and 48 in. embedment length, and two different piles, HP $14 \times 73$ and HP 14X117. The last column of the table shows the fixed end design moments obtained from Table 2 in order to compare them with the computed maximum moments. It should be noted that the computed moments for the 12 in. embedment length ranged from 61 to 83 percent of the computed moments for the 48 in. embedment length. This suggests that the "rule of thumb" commonly used in the design of HP piles, i.e., an embedment length of $1 \mathrm{ft}$ or less into the concrete structure is considered pinned, may be unrealistic, and that past pile foundations designed using $1 \mathrm{ft}$ embedment length for the pinned assumption may not really be pinned, but partialty fixed.

In the parametric analyses, a fixed-end condition was achieved whenever the embedment length in the pile head equaled or exceeded twice the depth of the pile. This fixed-end condition occurs when the rotation at the pile-cap interface reaches a maximum value independent of any further increase in the embedment of the pile.

\section{CAP-MEMBER MODELS}

\section{Introduction}

CERL analyzed the degree of fixity of the pile embedded in a concrete cap from a purely structural standpoint, without considering the underlying soil and the interaction of the pile and the surrounding soil. CERL investigated the behavior of steel HP pile sections with several lengths of embedment in various concrete caps using two-dimensional linear and nonlinear finite element models. The moments, shears, and axial loads that would normally exist in the HP pile section at the concrete cap face were assumed to produce the stress distributions in the HP pile sections that are presented in Figure 20. These stress distributions were 
used to determine the nodal forces to apply to the appropriate nodal points in the finite element models.

\section{Exploratory Finite Element Models}

Before constructing the finite element models for the typical design loading conditions and the parametric analyses, four exploratory two-dimensional linear models of a concrete cap and embedded pile section were developed. The purpose was to (a) obtain a general understanding of the fundamental behavior of the concrete cap and embedded pile section, (b) locate zones of stress concentration, and (c) investigate the degree of detail required to adequately model the concrete cap and pile section. The four exploratory models represented an HP $12 \times 74$ pile embedded a depth of $2 \mathrm{ft}$ in a concrete cap with a nominal width of 36 in. (3D) and a depth of 48 in. (4D), where the symbol D represents the depth of the pile section. The thickness normal to the two-dimensional plane was 12.2 in., i.e., the width of the flange of a HP $12 \times 74$ pile. Quadrilateral nonconforming elements were used to represent the embedded pile section and the concrete cap. The aspect ratio for the elcments was chosen to ensure that the resultant aspect ratios were not greater than 5:1 and that the majority of the elements had ratios no greater than 2:1. The finite element meshes for the four models ranged from coarse to fine in an effort to determine an optimum mesh. The optimum mesh would be the coarsest mesh that would yield rea. sonable results as compared with the results from the finest finite mesh. The four finite element models are shown in Figures 21. The total number of elements in each of the four models ranging from coarsest to finest was $12,48,350$, and 800 , respectively. In the two finer mesh models, the thickness of the flange of the HP $12 \times 74$ pile was modeled as a single row of elements. The boundary conditions at the right and left boundaries of the model were restrained in both the vertical and horizontal directions, simulating a condition of fixity at these boundaries.

The behavior of both the concrete cap and the steel HP pile sections were assumed to be governed by linear elasticity, although it was recognized that the behavior of concrete is nonlinear. A perfect bond was assumed to exist between the pile section and the concrete cap, i.e., displacements at the interface between the concrete cap and the pile were identical in each material. The cross sectional area of the pile section was transformed to an equivalent concrete thickness using the ratio of the modulus of elasticity for steel and concrete. The nodal forces applied to the nodal points for the embedded pile represented a constant horizontal shear force of 1 kip and an applied moment of 720 in.-kips.

The four two-dimensional finite element models were analyzed using the ANSYS finite element computer program. Displacement fields for these models appeared to coincide very closely, suggesting that the model with the coarsest mesh would be appropriate. The stress distribution, however, did not substantiate the same conclusion. For a nonconforming quadrilateral element, the stresses are constant within the boundaries of the element. Therefore, the more refined the mesh, the more detailed the stress distribution. When the mesh becomes very fine the distribution of stresses reflects "peak" stresses, and when the mesh becomes coarse the stress distribution reflects "average" stresses. Based on a comparison of the stress distribution for the four models, it was concluded that the second model (see Figure $21 \mathrm{~b}$ ) was adequate for the present study.

In addition, a series of analyses was performed with the mesh shown in Figure $21 \mathrm{c}$ to gain a basic understanding of the effect of embedment depth on the magnitude of the rotation of the pile section at the face of the concrete cap. The depths_of embedment of the pile were $0.5 \mathrm{D}, \mathrm{D}, 2 \mathrm{D}$, and $4 \mathrm{D}$ or 6 in., 12 in., 24 in., and 48 in., respectively. The nodal forces applied to the model represented a horizontal shear force of $1.0 \mathrm{kip}$ and applied moments of 240,480 , and 720 in.-kip. The rotation of the pile section at the face of the concrete cap is listed in Table 9 as a function of the applied loads and the depth of embedment. The lateral displacement curves for the centerline of the HP $12 \times 74$ pile under the three loading conditions with embedment depths of $0.5 \mathrm{D}, \mathrm{D}, 2 \mathrm{D}$, and $4 \mathrm{D}$ are presented in Figure 22.

As the depth of pile embedment is increased for a given pile section and loading conditions, the angular rotation at the concrete cap face should gradually decrease until full fixity is achieved. This condition will occur when a limiting value of angular rotation is reached for which there is no further reduction in angular rotation associated with additional increases in the depth of pile embedment. For the rotational results in Table 9, the largest decrease in angular rotation at the concrete cap face occurred when the pile embedment depth was increased from 0.5 to $1 \mathrm{D}$ and ranged from 12 to 25 percent depending on the loading condition. When the pile embedment depth was increased from 1 to $2 \mathrm{D}$, only about a 5 percent decrease in the angular rotation was observed for all the loading conditions. These results indicate that for each of the three 
a.
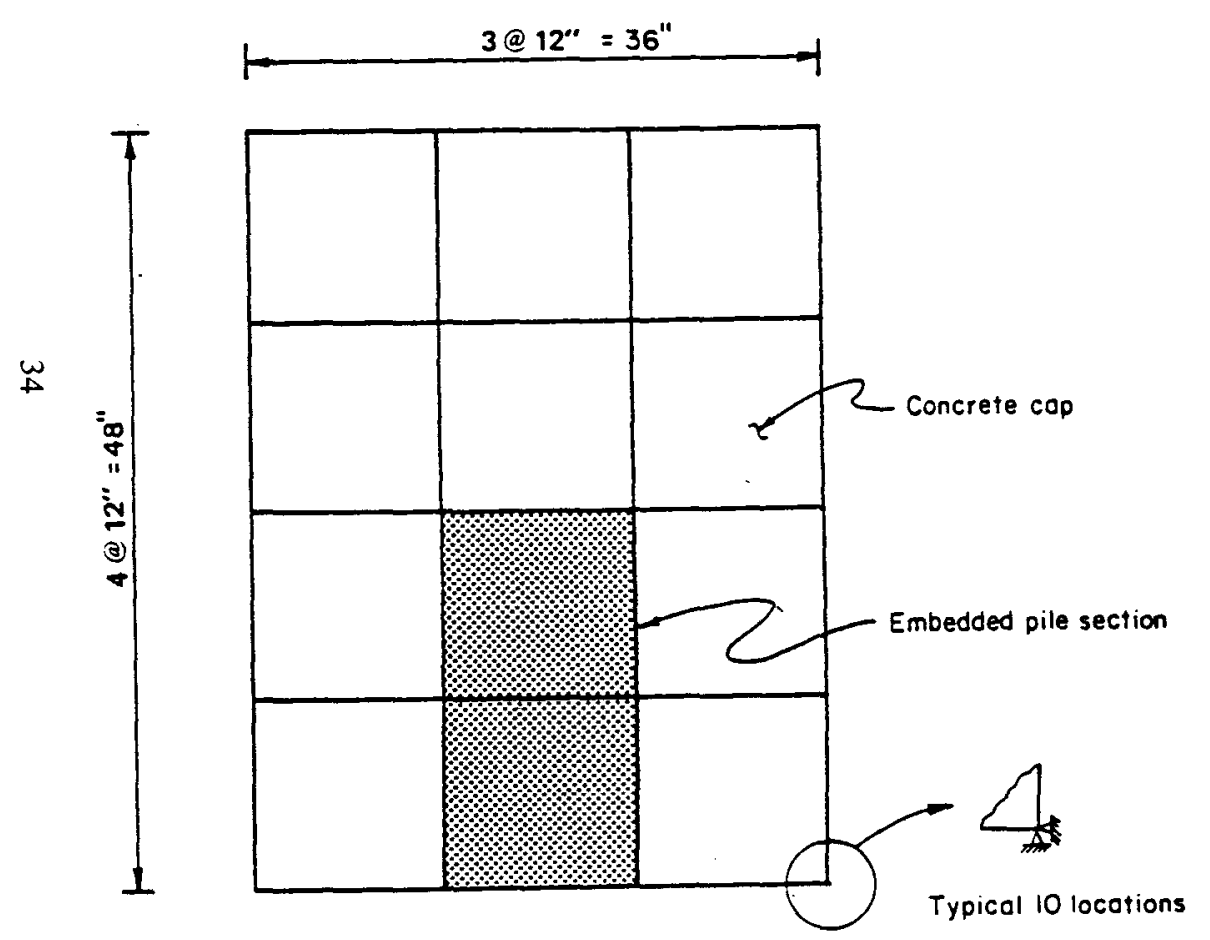

b.
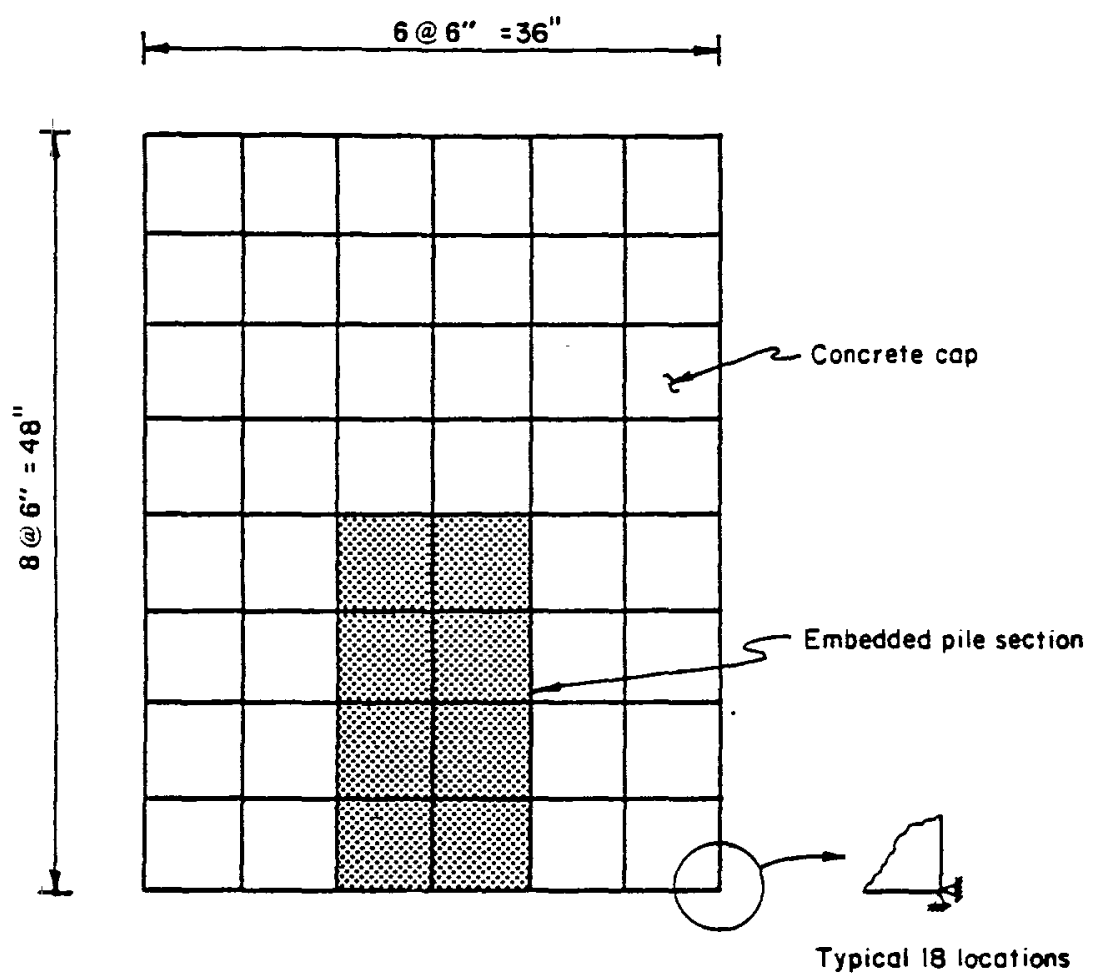

Figure 21. Exploratory finite element models. 
c.

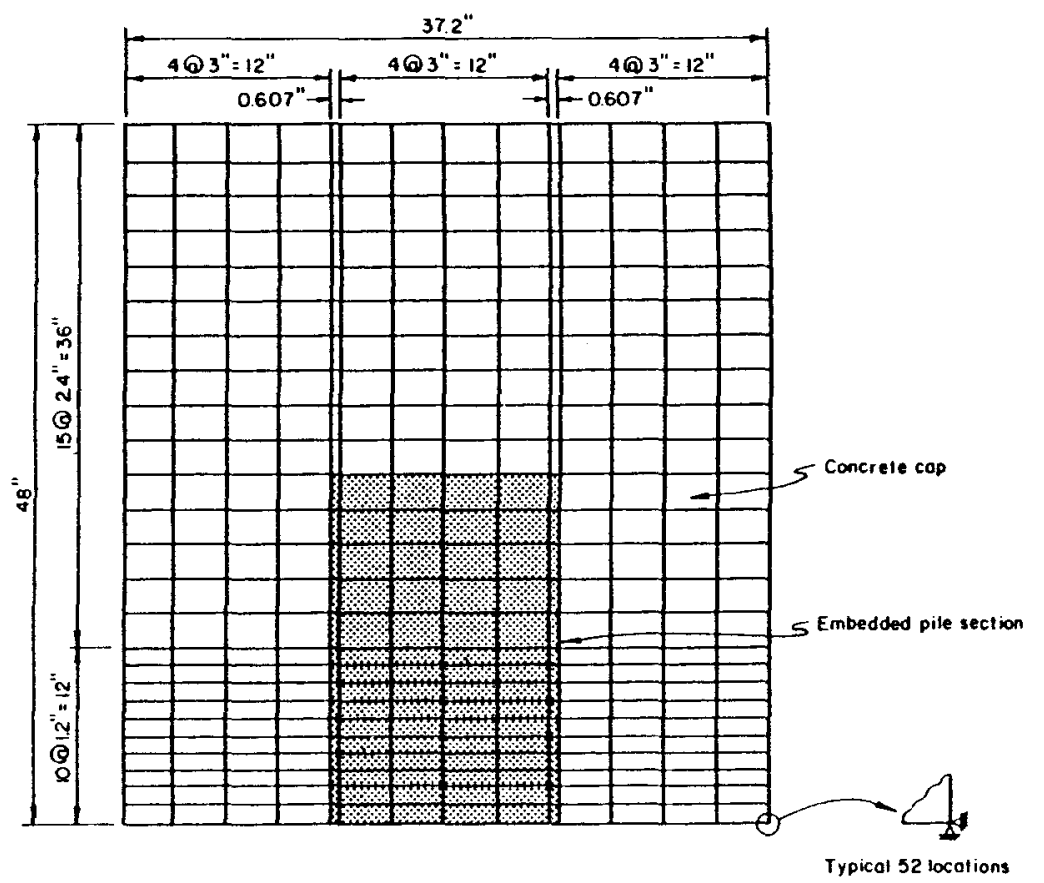

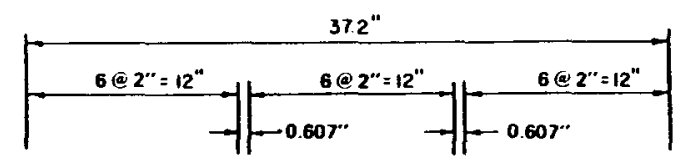

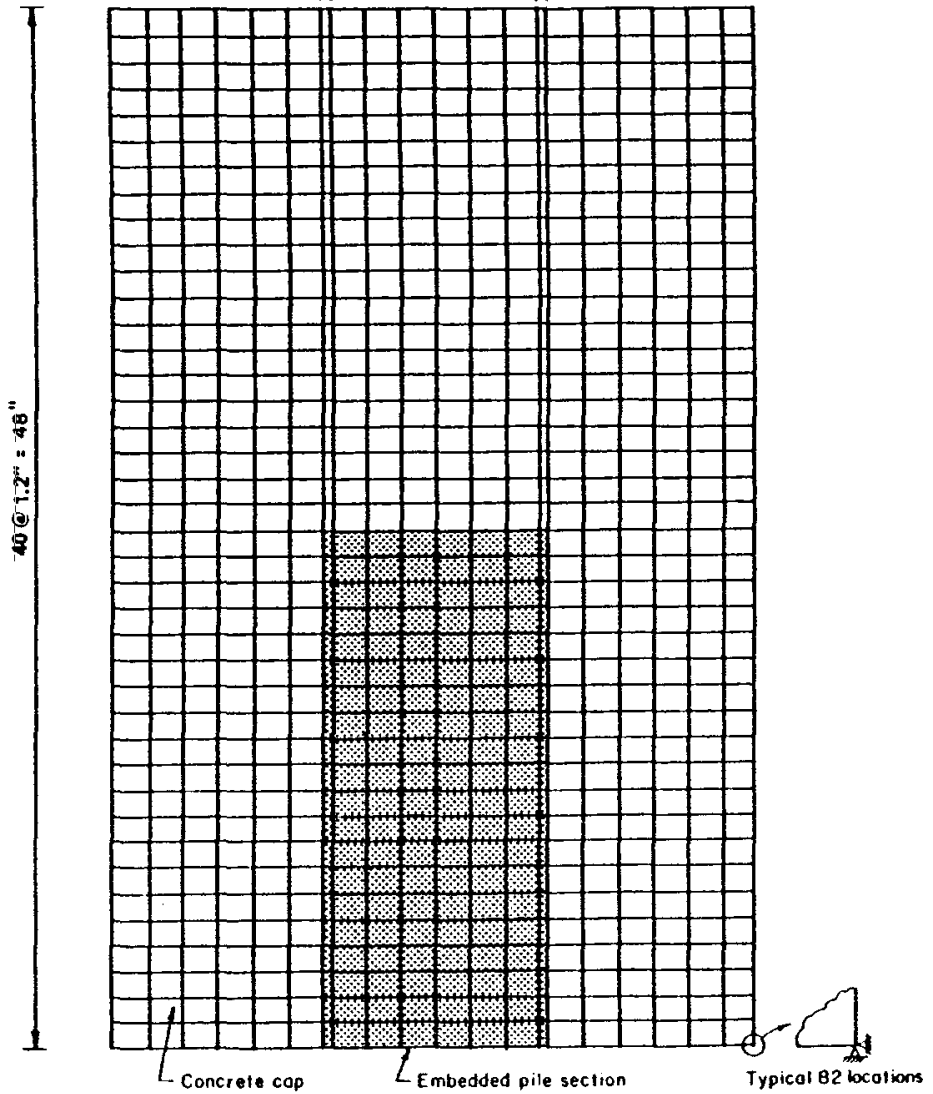

Figure 21. (Cont'd). 


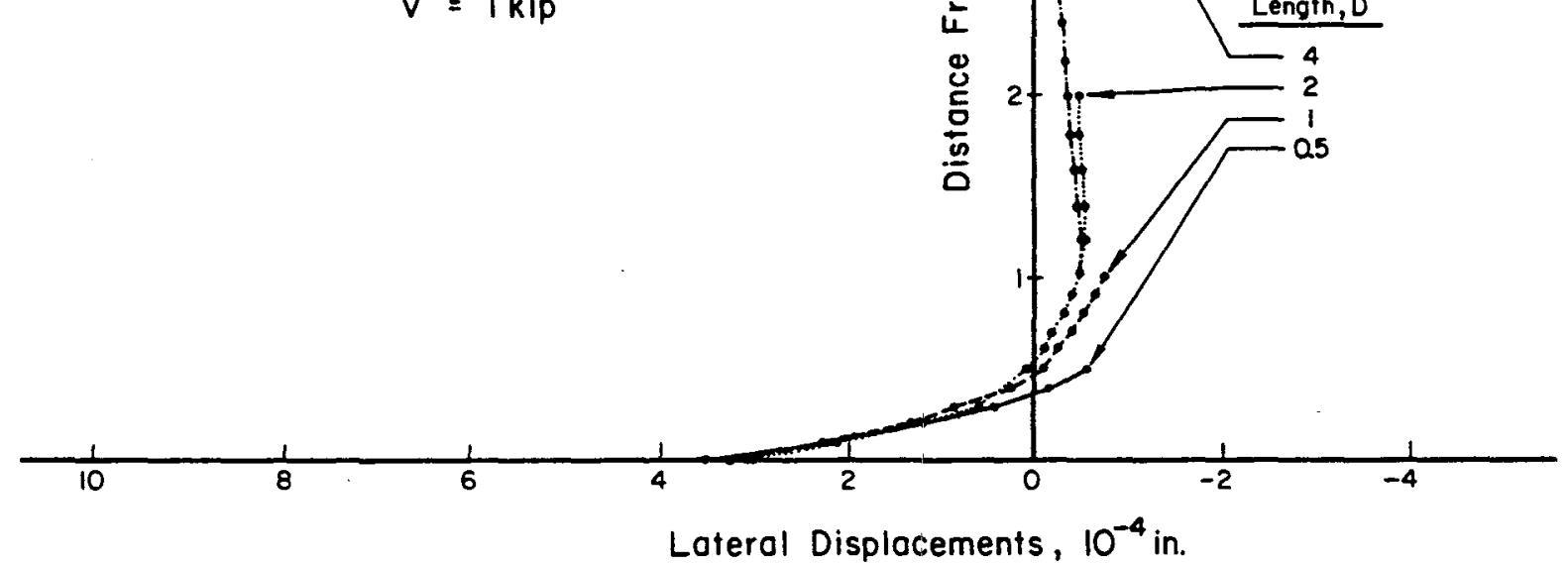

Figure 22. Lateral displacement curves for HP $12 \times 74$ pile with $0.5 \mathrm{D}, \mathrm{D}, 2 \mathrm{D}$, and $4 \mathrm{D}$ embedments. 


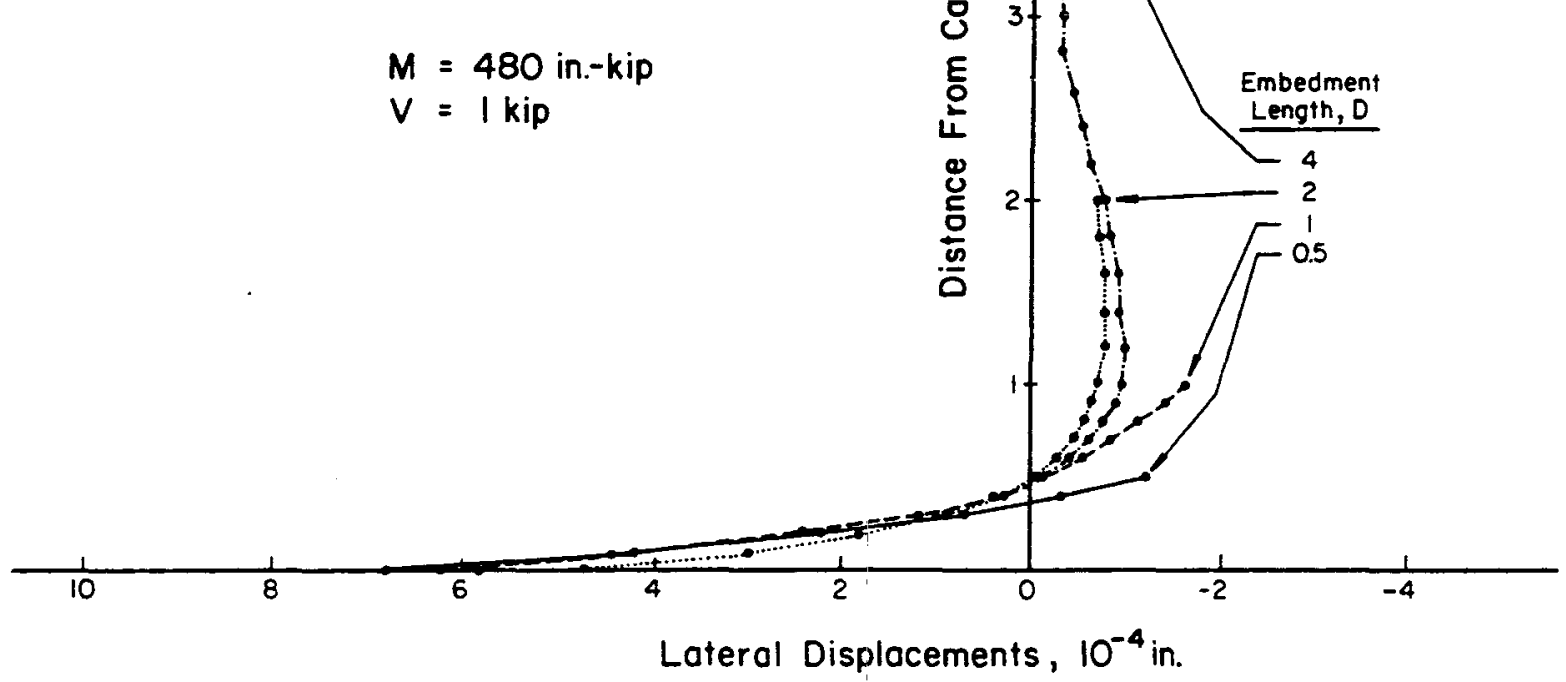

Figure 22. (Cont'd). 


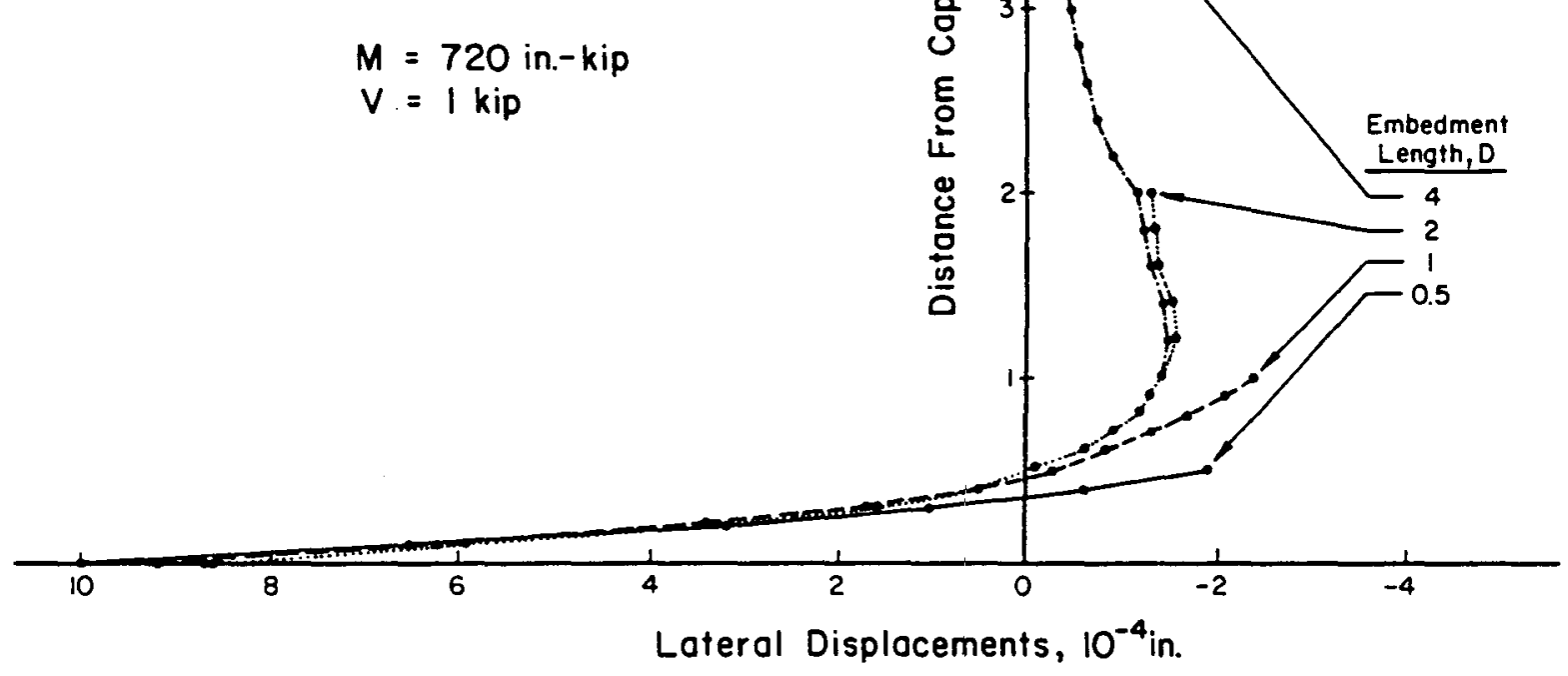

Figure 22. (Cont'd) 
loading conditions, the angular rotation has reached some limiting value at an embelment depth of approximately 2D or greater. For pile embedment depths less than approximately $2 \mathrm{D}$, only partial fixity was achieved.

Because concrete cracks at low tensile stress levels and degradation occurs under cyclic loading, it was decided that the current models did not represent the load transfer mechanism at the interface between the concrete cap and the pile section. Therefore, an interface element was incorporated into the model presented in Figure $21 \mathrm{~b}$ before proceeding with the additional investigation discussed below.

\section{HP 14X117 Typical Design Loading Analyses}

After the analyses of the exploratory finite element models were completed, the St. Louis District asked CERL to model an HP $14 \times 117$ pile embedded in a concrete cap with $2-\mathrm{ft}$ and 4 -ft embedments (nominal $2 \mathrm{D}$ and $4 \mathrm{D}$ embedments). These models were to be subjected to the typical loading from an actual design condition as presented in Table 2. The knowledge gained from the exploratory analyses, in particular the need to incorporate an interface element, was factored into the development of the finite element models. Specific details regarding the models are summarized below:

1. Pile-Quadrilateral, nonconforming elements were used to model the web of the pile; plane bar elements, STIF1, were used to model the flanges of the pile. The thickness of the finite elements was equivalent to the thickness of web of the pile-0.805 in. To simulate the flanges, plane bar elements with an area equal to the area of the flange-11.982 sq in.were connected to the vertical nodes on the extreme right and left sides of the finite elements representing the web (Figure 23). Linear elastic properties were assumed for the steel. The modulus of elasticity and Poisson's ratio were assumed to be $29.6 \times 10^{6} \mathrm{lb} / \mathrm{sq}$ in. and 0.3 , respectively.

2. Concrete cap-Quadrilateral nonconforming elements were also used to model the concrete cap. The thickness of the elements outside the region of the pile was taken as the width of the flange of the HP 14X117 pile-a conservative assumption for this analysis. The width of the flange was 14.885 in. The thickness of the elements representing the concrete between the flanges of the HP pile section was reduced by the thickness of the web of the HP pile section-0.805 in. In essence, the elements representing the concrete between the flanges and the elements representing the web of the
HP pile section overlaid each other and had common nodal points at the corners of the elements; the concrete between the flanges of the pile would deform in the same manner as the HP pile section. Linear elastic propertics were also assumed for the concrete. The modulus of elasticity and Poisson's ratio were assumed to be $3.0 \times 16^{6} \mathrm{lb} / \mathrm{sq}$ in. and 0.15 , respectively.

3. Pile and concrete cap interface-To simulate the load transfer mechanisms between the external surfaces of the flanges of the HP pile section and the concrete cap, as well as with the end of the HP pile section and the concrete cap, a two-dimensional interface element (see Figure 24) was introduced into the model. This element is designated STIF12 in the ANSYS program. It represents two plane surfaces which may maintain or break physical contact and may slide relative to each other. The element is capable of supporting compression in the direction normal to the surfaces and shear (Coulomb friction) in the tangential direction. The basic features and force deflection relationships of the interface elements are illustrated in Figure 25.

The force deflection relationships for the interface elements can be separated into the normal and tangential directions as shown in Figure 25. The element operates bilinearly and requires an iterative solution. The stiffness matrix is reformulated after each itera. tion for static convergence.

The 'element status at the beginning of the first iteration was assumed to be closed; the stiffness, $k$, was used for computing both gap and sliding effects. The element status at the beginning of each succeeding iteration was based on the status at the end of the previous iteration. In the normal direction, if the normal force $\left(F_{n}\right)$ was negative, the interface remained in contact and responded as a linear spring. If the normal force became positive, contact was broken and no force was transmitted across the interface. In the tangential direction, if $F_{n}<0$ and the absolute value of the tangential forces, $F_{s}$, was less than or equal to the interface coefficient of friction $(\mu)$, times the absolute value of $f_{n}\left(\mu\left|F_{n}\right|\right)$, the interface did not slide and responded as a linear spring in the tangential direction. However, if $F_{n}<0$ and $F_{s}>\mu F_{n}$, sliding occurred. If $F_{n}>0$, contact was broken and the tangential force was reduced to zero. Convergence occurred whenever the status of the bilinear elements remained unchanged from the previous iterations.

The only material property required for the interface element is the coefficient of friction, $\mu$. The Prestressed Concrete Institute (PCI) specifies a coefficient 
Table 9

Angular Rotation of HP $12 \times 74$ Pile

Angular Rotation, rad $\times 10^{4}$

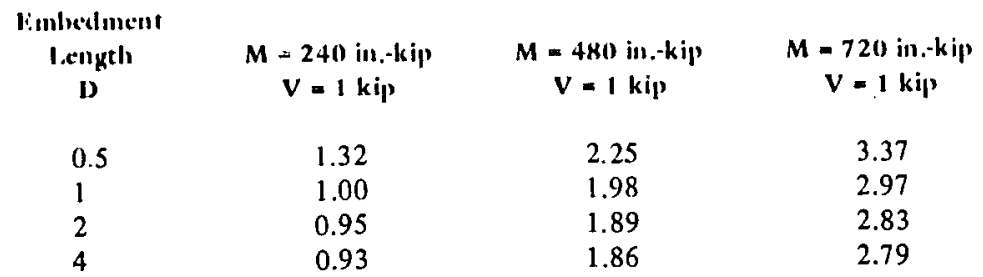
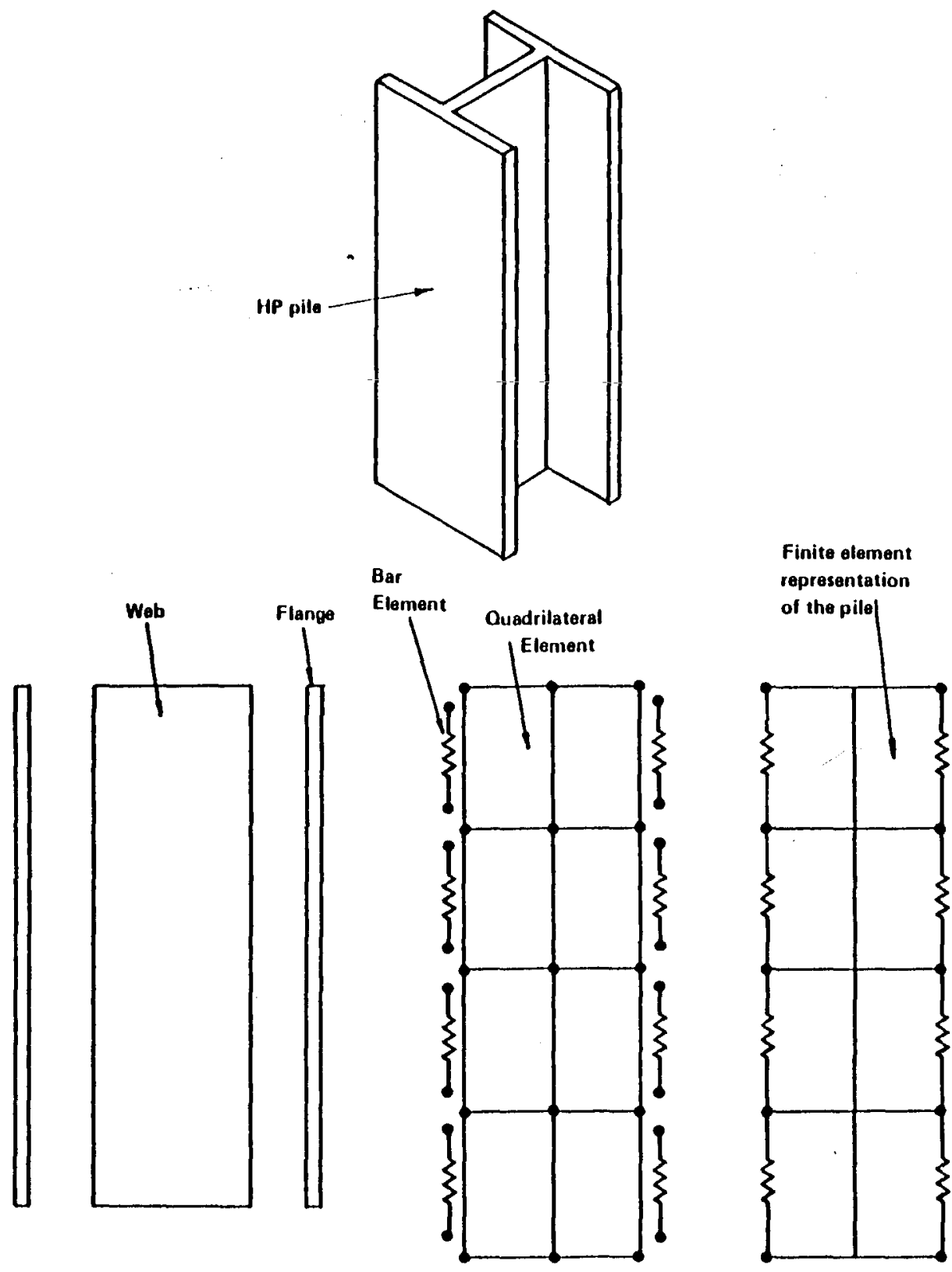

Figure 23. Finite element representation of HP pile. 


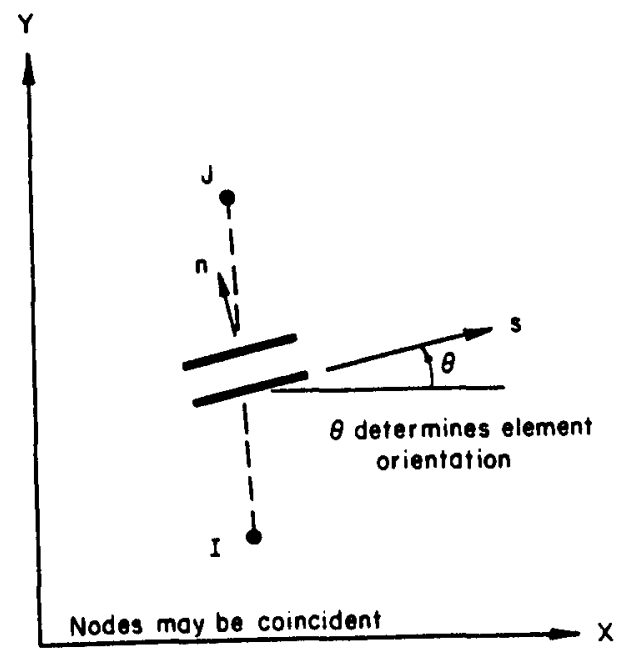

Figure 24. Two-dimensional interface element.

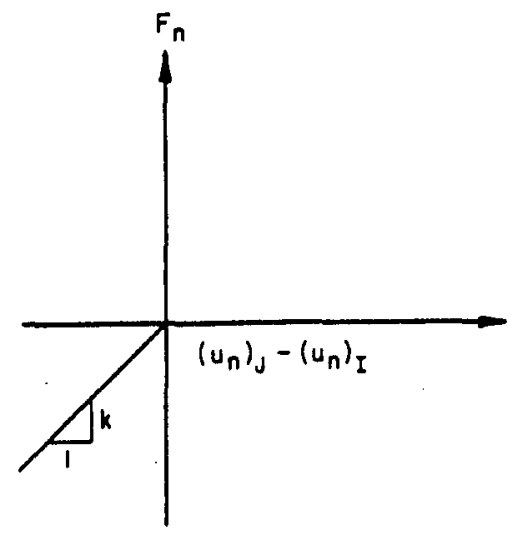

(a) Normal

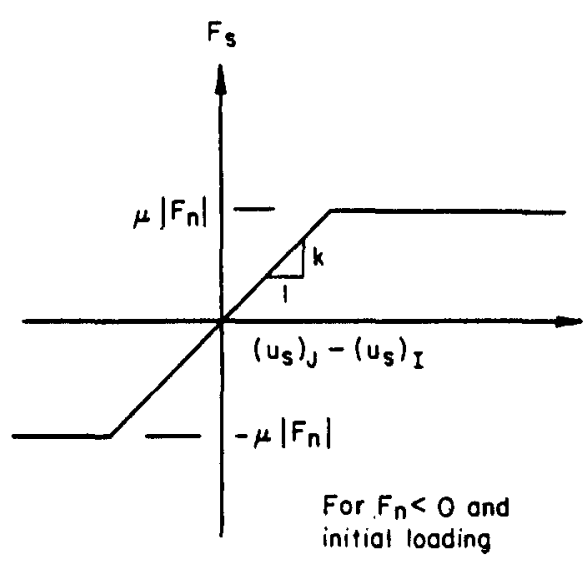

(b) Sliding

Figure 25. Force-deflection relationship for the interface element. 
of friction of 0.4 for a concrete and steel interface..$^{10}$ The American Concrete Institute (ACI) specifies a coefficient of friction of 0.7 when surfaces of rolled steel and concrete are interacting. ${ }^{11}$ The $\mathrm{ACI}$ also specifies a coefficient of friction of 1.4 for concrete placed monolithically, which is an upper limit for the coefficient of friction. A coefficient of friction of 0.4 was selected for the initial analyses, because it represented a lower limit.

4. Boundary conditions - The same boundary conditions were used for the HP 14 X 117 pile model as for the HP $12 \times 74$ pile model.

5. Loading-The loading conditions for the HP $14 \mathrm{X} 117$ pile section are shown in Table 2 . The introduction of the interface element required that the loads be gradually applied to the model to ensure convergence of the solution. Consequently, the shear, axial load, and moment for each of the loading conditions were gradually applied to the model in a series of load steps so that large corrections in succeeding iterations would not be required. After each load step the solution was allowed to iterate until convergence was obtained-as represented by the unchanged status of the bilinear elements from the previous iteration.

In the analysis of the HP $14 \times 117$ pile section with 2D and 4D embedments and the subseçuent parametric analysis (discussed below), the effects of various parameters were analyzed. Table 10 is an index correlating the analysis case number and the specific model parameters for the analyses summarized in this report. Table 10 should be used as a reference when reviewing and comparing some of the figures which follow.

A typical displacement field and stress contour plots for the HP $14 \times 117$ pile under normal operations with a $0.1 \mathrm{~g}$ earthquake condition and an embedment depth of $2 \mathrm{D}$ are presented in Figures 26 through 32 . The displacement field (Figure 26) indicates that although the maximum displacement was only about 0.004 in., the pile section and concrete cap separated at the right side of the pile section. Consequently, relative displacements occurred between the concrete cap and pile section along both vertical interfaces, as shown by the offset boundaries of the finite elements along these interfaces.

\footnotetext{
${ }^{10}$ PCI Manual on Design of Connections for Precast, Prestressed Concrete (Prestressed Concrete Institute, 1973).

${ }^{11} \mathrm{ACI} 318-77$.
}

Stress contour plots for $\sigma_{x}, \sigma_{y}, t_{x y}, \sigma_{\max }, \sigma_{\text {min }}$, and $t_{\max }$ are presented in Figures 27 through 32. In each normal stress contour plot (Figs. 27, 28, 30, 31), maximum tensile and compressive stress levels and their points of occurrence are indicated with an " $X$ " and " 0 ," respectively. In the shear stress contour plots (Figs. 29, 32), the maximum and minimum stress levels and their points of occurrence are similarly marked. The stress contour interval is indicated near the lower left corner of the plot. A dash line is used to represent the zero stress contour line. Figures 27 and 28 indicate that the maximum $\sigma_{\mathrm{x}}$ and $\sigma_{\mathrm{y}}$ stresses were $-308 \mathrm{lb} / \mathrm{sq}$ in. and $-371 \mathrm{lb} / \mathrm{sq}$ in., respectively. These stresses occurred at the concrete cap face at the interface between the concrete cap and pile on its left side. Along the interface between the concrete cap and the left side of the pile, the $\sigma_{x}$ stresses gradually decreased to a stress level approaching zero near the end of the embedded pile. Along this same interface, the $\sigma_{y}$ stresses (see Figure 28) decreased much more slowly because additional load was transferred from the pile section to the concrete cap through the interface elements.

Figures 30 through 32 indicate that the maximum and minimum principal stresses occurred at the left side of the pile section at the concrete cap face and that the maximum shear force occurred along the left boundary of the concrete cap. The maximum tensile stress was $199 \mathrm{lb} / \mathrm{sq}$ in. and the maximum shear stress was $254 \mathrm{lb} / \mathrm{sq}$ in. The latter is slightly greater than $3.5 \sqrt{f_{c^{\prime}}^{\prime}}$ which is the maximum allowed by the $\mathrm{ACI}$ code for members subjected to shear and flexure only. ${ }^{12}$ Since it is standard construction practice to provide concrete steel reinforcement only in the region above the top of the embedded pile, consideration should be given to placement of a nominal percentage of concrete steel reinforcement in the region of pile embedment to increase the structural integrity of the concrete.

The lateral displacements of the centerline of the pile sections with $4 \mathrm{D}$ and $2 \mathrm{D}$ embedment in the concrete cap (Case 1 and Case 2, respectively) are shown in Figure 33. The displacement curve for 2D embedment nearly coincided with the displacement curve for 4D embedment between 0 and $2 \mathrm{D}$. In addition, the displacement curve for $4 \mathrm{D}$ embedment experienced a change in slope at a distance slightly greater than $2 \mathrm{D}$ from the concrete cap facc, which indicates that the 
Table 10

Index Correlating Analysis Case and Model Parameters

\section{Model Parameters}

$\begin{array}{cccccc}\begin{array}{c}\text { Analysis } \\ \text { Case }\end{array} & \begin{array}{c}\text { Pile } \\ \text { Embedment }\end{array} & \begin{array}{c}\text { Pile } \\ \text { Spacing }\end{array} & \begin{array}{c}\text { Cap } \\ \text { Thickness }\end{array} & \begin{array}{c}\text { Cap } \\ \text { width (in.) }\end{array} & \begin{array}{c}\text { Coefficient } \\ \text { of Friction }\end{array} \\ \text { 1 } & \text { 4D } & \text { 3D } & \text { 6D } & 14.9 & \\ 2 & \text { 2D } & \text { 3D } & \text { 4D } & 14.9 & 0.4 \\ 3 & \text { 2D } & \text { 3D } & \text { 4D } & 14.9 & 0.4 \\ 4 & \text { 2D } & \text { 3D } & \text { 4D } & 14.9 & 1.4 \\ 5 & \text { 2D } & \text { 3D } & \text { 4D } & 44.7 & 0.4 \\ 6 & \text { 2D } & \text { 5D } & \text { 4D } & 14.9 & 0.4 \\ 7 & \text { 2D } & \text { 5D } & \text { 5D } & 14.9 & 0.4 \\ 8 & \text { 2D } & \text { 5D } & \text { 6D } & 14.9 & 0.4 \\ 9 & \text { 2D } & \text { 5D } & \text { 7D } & 14.9 & 0.4\end{array}$

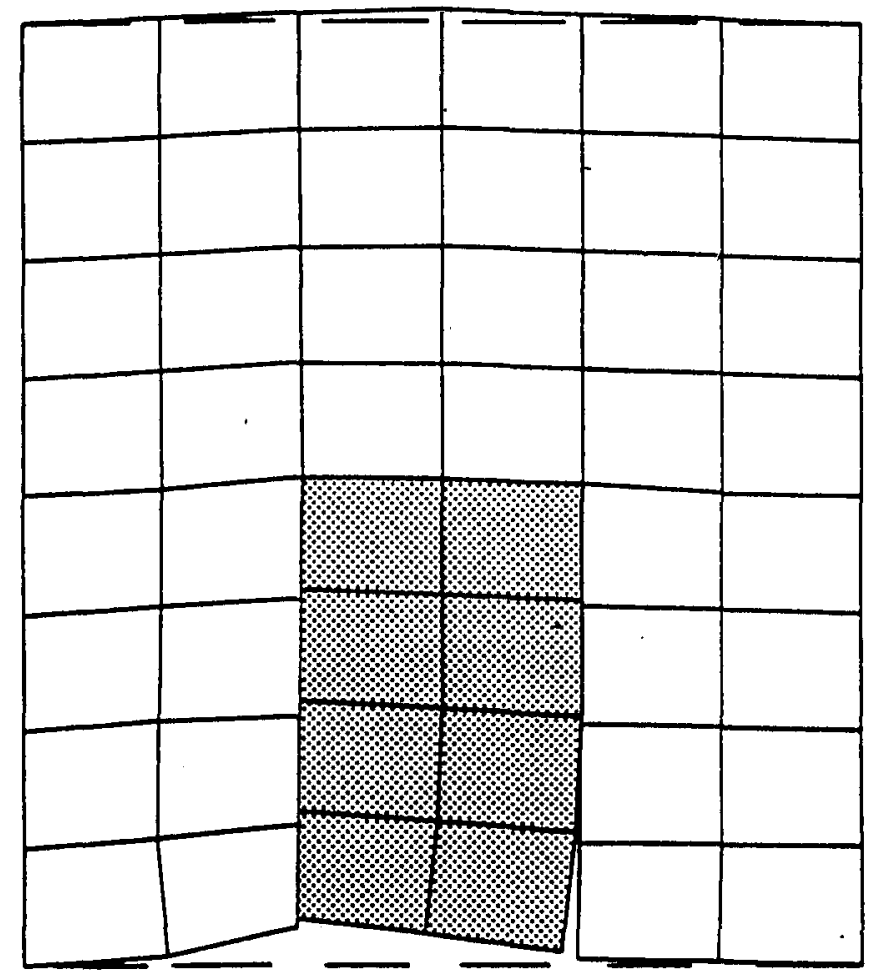

MAXIMUM DISPLACEMENT $=0.00445^{\prime \prime}$

Figure 26. Typical displacement field for HP $14 X 117$ pile. 


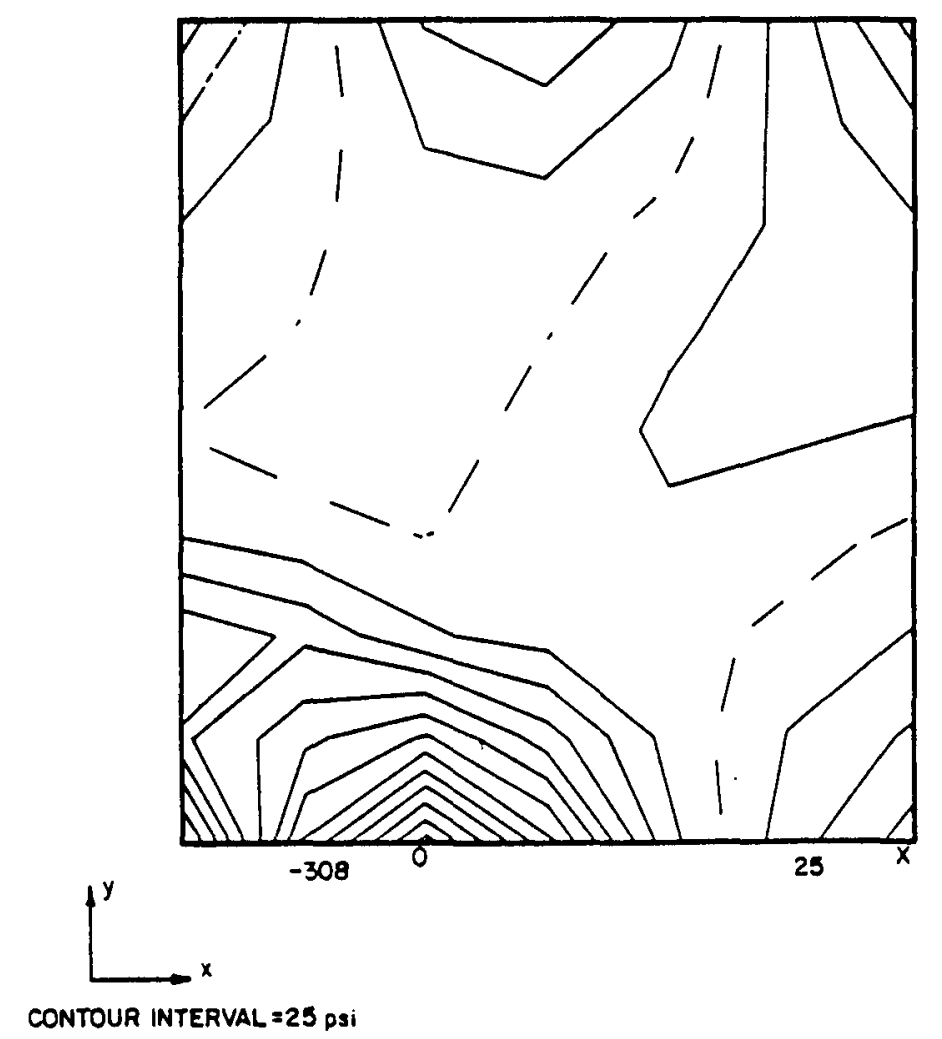

Figure 27. Typical Stress Contour Plot for $\sigma_{\mathrm{x}}$.

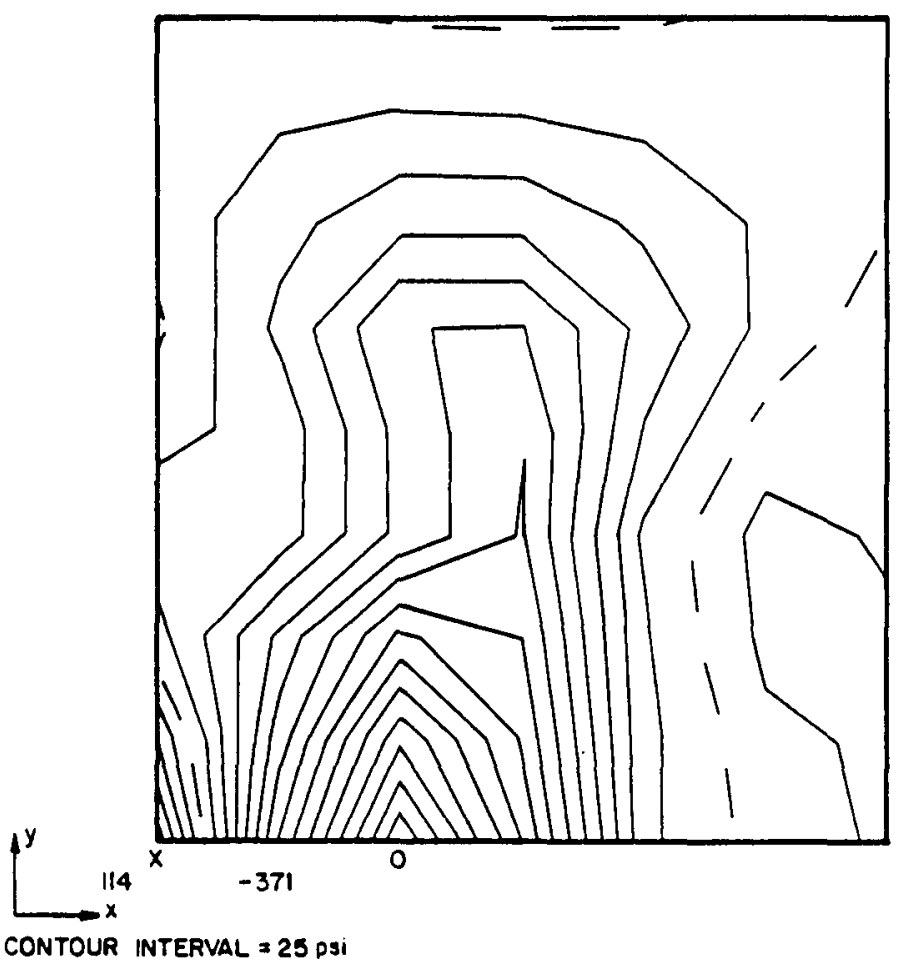

Figure 28. Typical Stress Contour Plot for $\sigma_{y}$. 


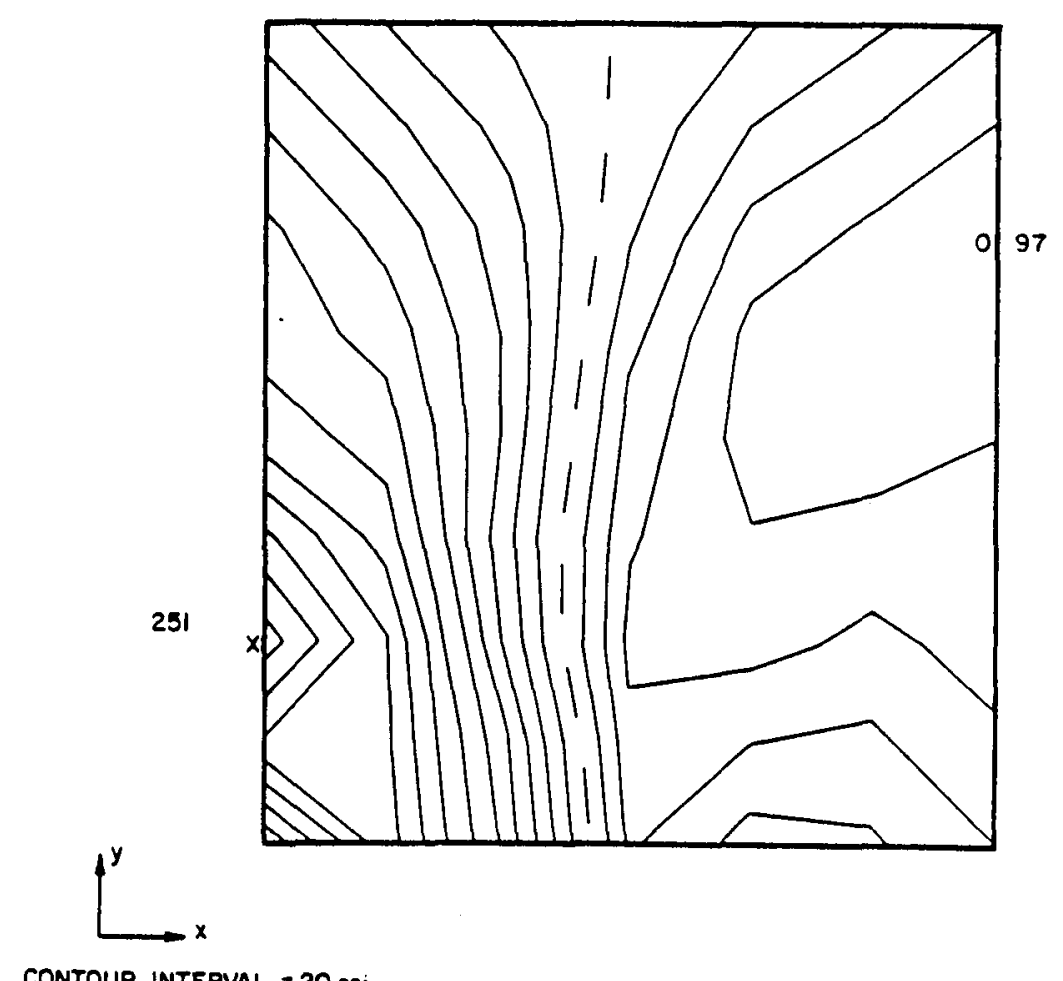

CONTOUR INTERVAL $=20$ psi

Figure 29. Typical Stress Contour Plot for $\tau_{\mathbf{x y}}$.

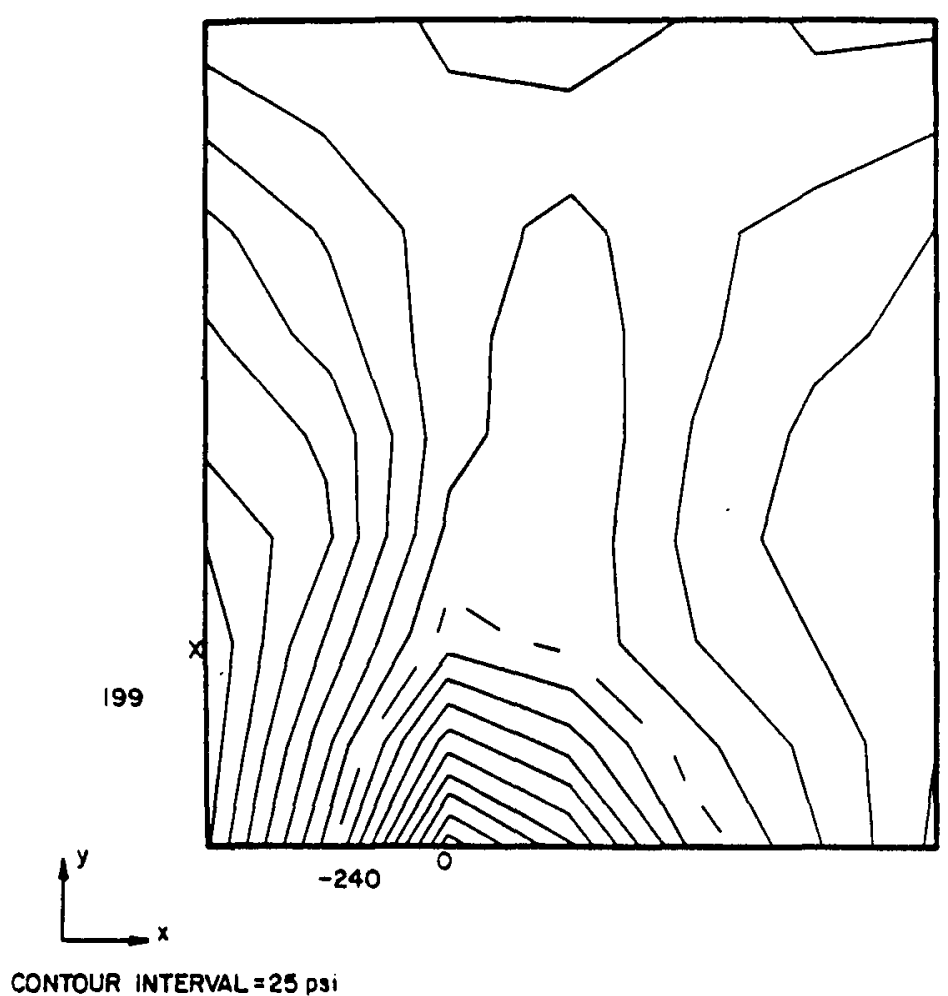

Figure 30. Typical Stress Contour Plot for $\sigma_{\max }$. 


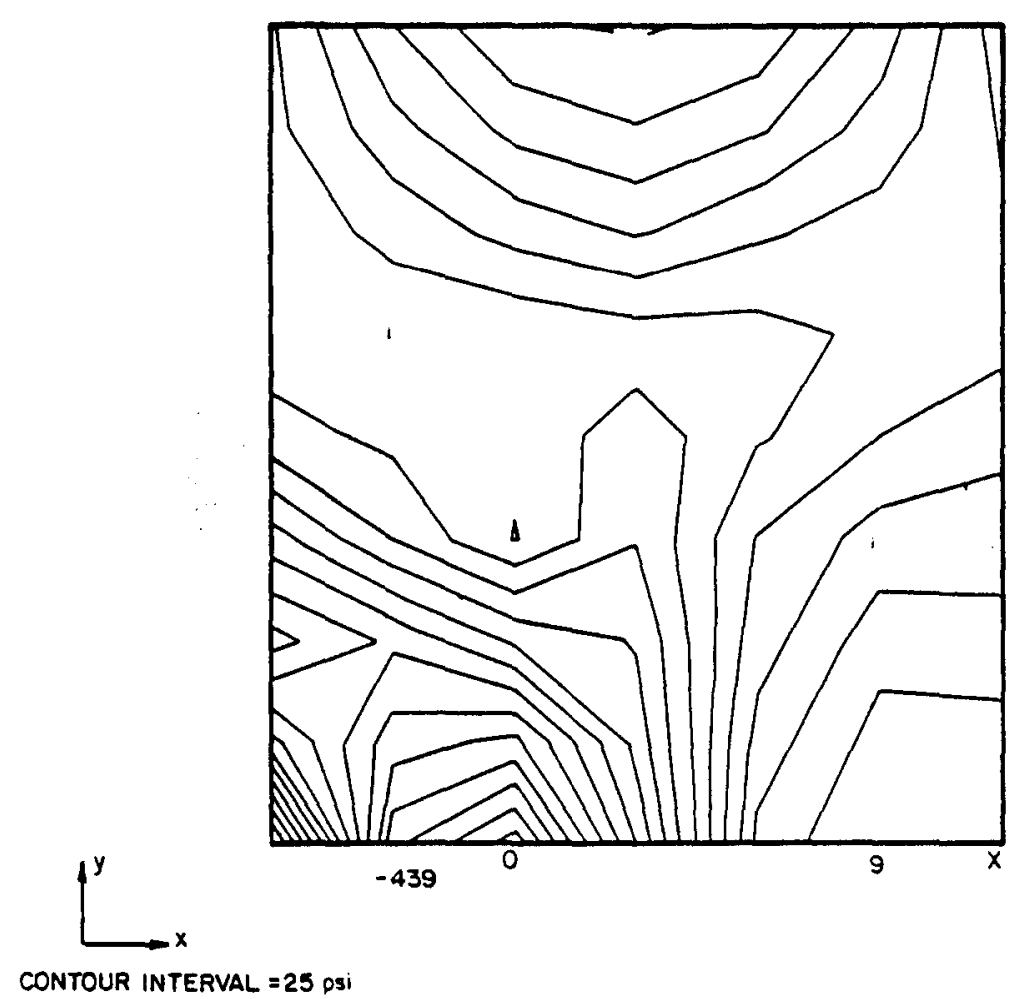

Figure 31. Typical Stress Contour Plot for $\sigma_{\min }$.

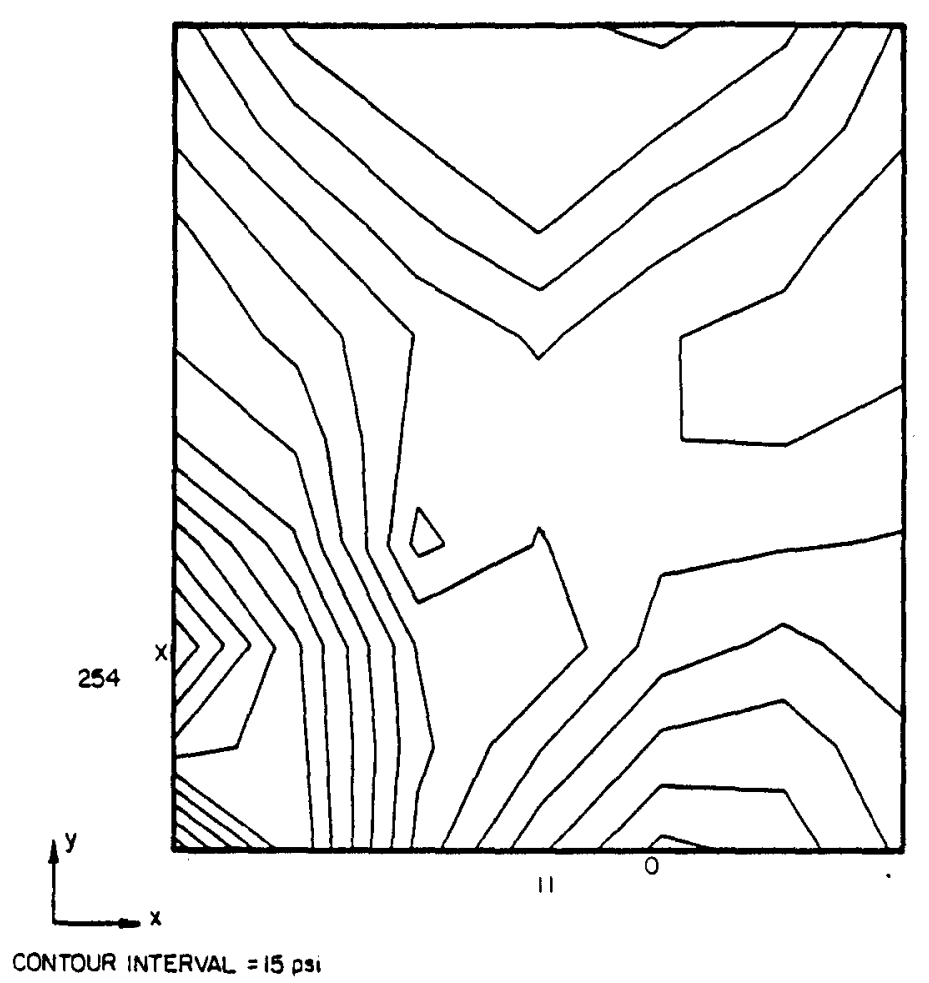

Figure 32. Typical Stress Contour Plot for $\tau_{\max }$. 
pile section has achieved a condition of full fixity. The maximum lateral displacement at the face of concrete cap for the pile section with 4D embedment was slightly greater than the pile section with $2 \mathrm{D} \mathrm{em}$ bedment. Considering the nonlinear aspects of the concrete pile system, this difference is not considered significant.

The rotations of the pile section at the face of the concrete cap, $\phi_{\max }$, for these same conditions of $2 \mathrm{D}$ and $4 \mathrm{D}$ embedment were computed to be $3.22 \times 10^{-4}$ rad and $3.29 \times 10^{4} \mathrm{rad}$, respectively. A difference of about 2 percent between the maximum rotations for the 2D and 4D embedments was not considered significant. Also, the magnitudes of these rotations were quite similar to those obtained in the analysis of the exploratory finite element models for the case of 2D embedment and a bending moment of 720 in.-kip.

The compression and shear forces developed in the interface elements in the models are shown in Figures 34 and 35 for the 2D and 4D embedments, respectively, together with the nodal forces simulating the applied loads. The forces transmitted by the first two interface elements on the lower left side of the pile section were nearly identical for the 2D and 4D embedments. Forces in the other interface elements along the left side of the pile section tended to degenerate to zero, thus indicating that contact between the pile section and the concrete cap had been broken. This suggests that the pile section attempts to pivot about the edge of the concrete cap and thereby reduce the forces acting on the upper portion of the left side of the pile section: this increases the fores acling on the upper portion of the right side of the pilc.

Due to the nonlinear aspects of the interface elements and the solution convergence criteria, the forces acting at the interface elements do not fully satisfy statics. However, the estimated error was less than 4 percent.

\section{HP 14X117 Parametric Analysis}

A parametric analysis of the HP $14 \times 117$ pile embedded $2 \mathrm{D}$ in a concrete cap was performed to determine if other parameters would significantly affect the degree of fixity of the pile section. The loadings applied to the pile were those associated with normal operations with $0.1 \mathrm{~g}$ earthquake conditions. The basic parameters for the models were the same as those used in previous analysis and are summarized in Table 11. The following parameters were investigated:
1. Coefficient of friction between the concrete cap and the pile section

\section{Effective width of the concrete cap}

\section{Pile spacing}

\section{Concrete cap thickness.}

Different finite element models were developed and analyzed based in part on the range of parameters presented in Table 1. Table 10 is an index which correlates the model parameters with a specific analysis case.

The following is a summary of the results from the parametric analysis:

1. Coefficient of friction between the concrete cap and the pile section. A degree of adhesion exists between the concrete cap and the pile section. This adhesion occurs at the interface between the concrete cap and the exterior surface of the flanges of the pile section, and at the concrete cap and the end of the pile. Consequently, three different values for the coefficient of friction were investigated: $0.4,0.7$, and 1.4. Three analyses were performed and identified as_Case $2(\mu=$ $0.4)$, Case $3(\mu=0.7)$, and Case $4(\mu=1.4)$.

The lateral displacement curves for the centerline of the embedded pile section for the three analysis are shown in Figure 36. The shapes of the three displacement curves are basically similar. However, as the coefficient of friction was increased from 0.4 to 1.4 , the maximum displacement of the centerline of the pilc section at the concrete cap face decreased from $2.49 \times 10^{-3}$ in. to $1.62 \times 10^{-3}$ in., or about 35 percent. The maximum rotation decreased from $3.22 \times$ $10^{-4} \mathrm{rad}$ to $2.23 \times 10^{-4} \mathrm{rad}$, or about 30 percent. These effects were due to the transfer of forces in the pile section to the concrete cap due to the increase in the coefficient of friction. Comparison of the interface element forces in Figures 34 (Case 2), 37 (Case 3), and 38 (Case 4) clearly indicated this to be the load transfer mechanism.

Stresses in the concrete cap were also compared at the sections indicated in Figure 39. As a result of the nonconforming quadrilateral element used to represent the concrete cap, the stress obtained from the analyses was average stress at the center of the element. The distribution of forces in the horizontal direction $\left(f_{x}\right)$ and the vertical direction $\left(f_{y}\right)$ were calculated using the normal stress, $\sigma_{x}$; the shear stress, $t_{x y}$; and the thickness of the concrete cap, $14.9 \mathrm{in}$. These forces 


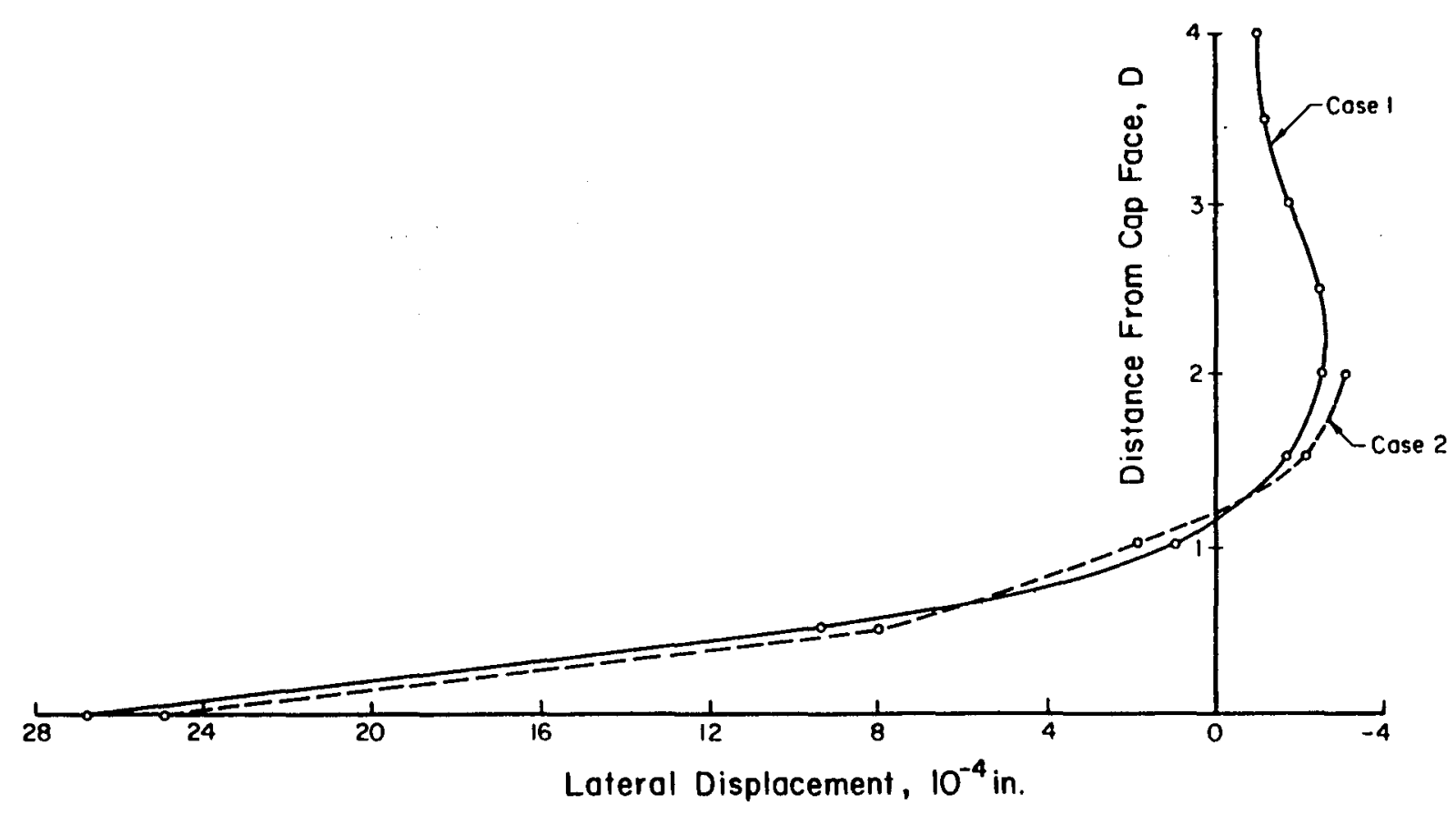

Figure 33. Lateral displacement curves for centerline of HP $14 \mathrm{X} 117$ pile with $2 \mathrm{D}$ and $4 \mathrm{D}$ embedments, $\mu=0.4$.

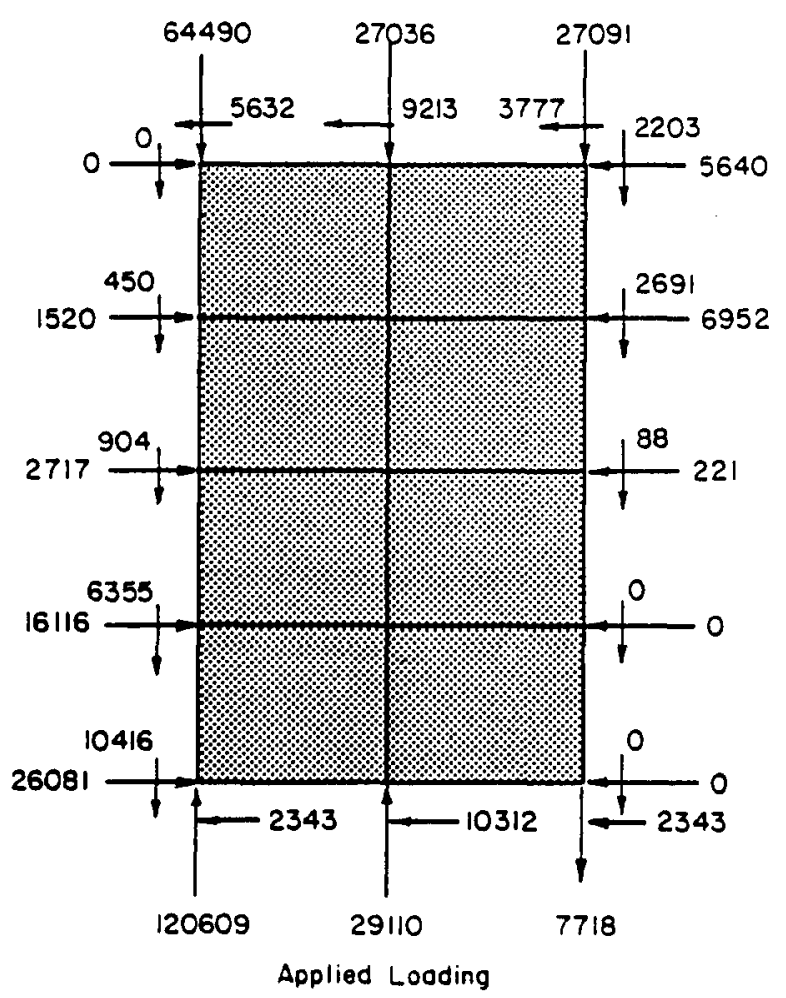

Figure 34. Interface element forces for HP 14 X117 pile with 2D embedment, $\mu=0.4$. 


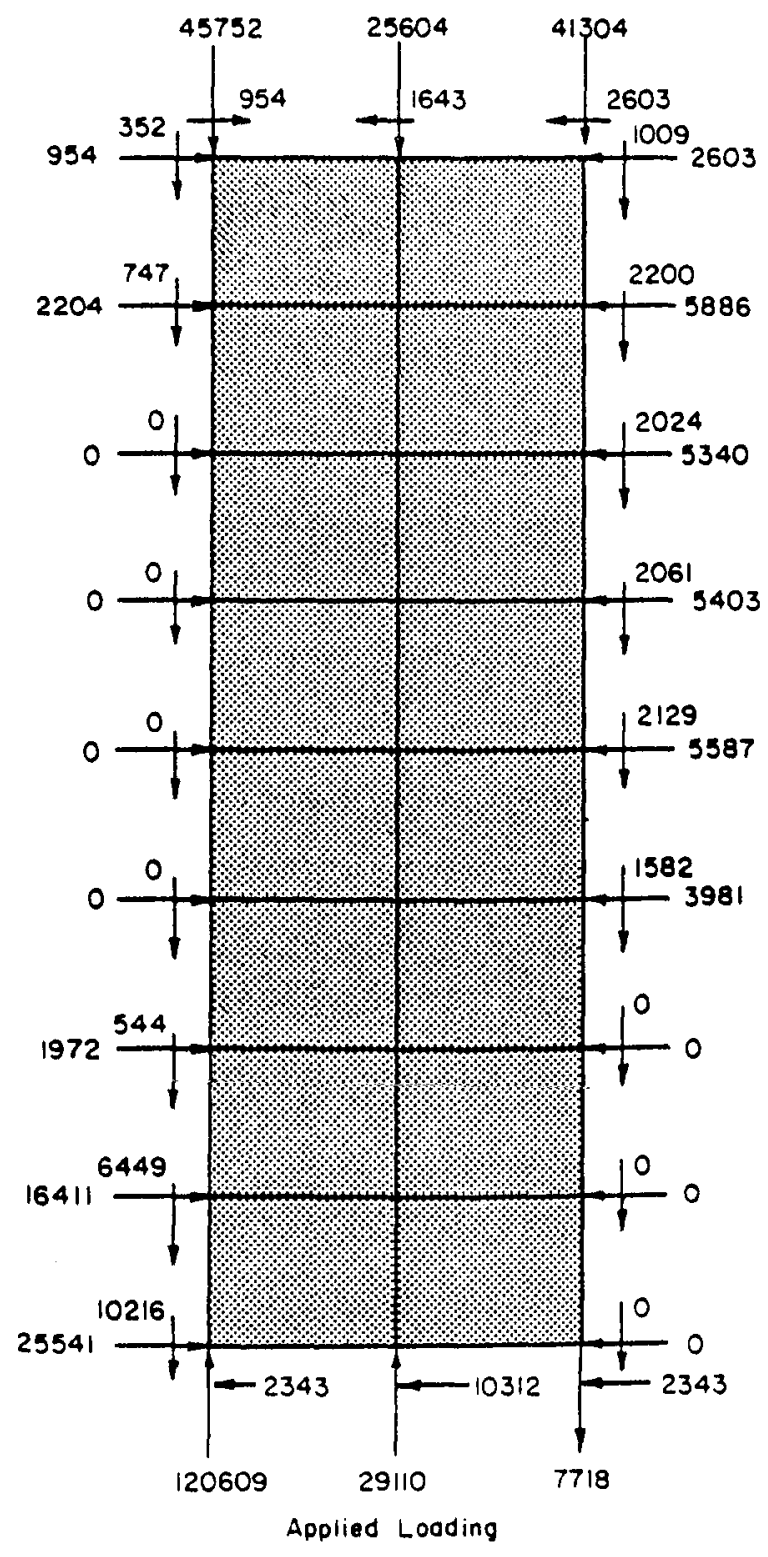

Figure 35. Interface element forces for HP $14 \times 117$ pile with $4 \mathrm{D}$ embed ment, $\mu=0.4$.

were plotted in Figures 40 through 43 . In general, the force distributions are similar to each other, which indicates that the concrete cap stresses were not significantly influenced by the cocfficient of friction, at least for the range of values that were investigated.

2. Effective width of the concrete cap. The effective width of the concrete calp was increased from $14.9 \mathrm{in.}$ to $44.7 \mathrm{in.}$ to determine if the effective width of the concrete cap significantly affected the behavior of the cap-member system. To model this condition, the thickness of the elements representing the concrete cap outside the region of the pile was increased to $44.7 \mathrm{in}$. while the thickness of the clements representing the concrete between the flanges of the pile section was increased to $43.9 \mathrm{in}$. The latter number represents the eflective width of $44.7 \mathrm{in}$. less lla lhickness of the web of the pile section. Analysis Case 5 was performed and compared with the results from Case 2. The lateral displacement curves for the centerline of the embed. ded pile section with an effective width of concrete cap of 14.9 in and 44.7 in. are presented in Figure 44. The maximum displacement at the centerline of the pile section at the concrete cap face was reduced from $2.49 \times 10^{-4}$ in. to $1.16 \times 10^{-4}$ in., or about 50 percent. The maximum rotation at the concrete cap face was reduced from $3.22 \times 10^{-4} \mathrm{rad}$, to $1.76 \times 10^{-4}$ rad or about 45 percent, with the increase in the effective width of the concrete cap. The shape of the Case 5 displacement curve was different in that the slope of the curve changed sign at an embedment depth of about 1.75D. Likewise the distributed forces shown in Figures 40 through 43 for Case 2 and Case 5 do not indicate significant differences.

3. Pile spacings. Pile spacings varying between 3D and 5D were specified in Table 1. Analysis Case 6 was performed to reflect the specified variation in the pile spacing parameter and compared with the results from Case 2.

The lateral displacement curves for the embedded pile section with pile spacings of $3 \mathrm{D}$ (Case 2) and 5D (Case 6) are presented in Figure 45. The displacement curves are essentially identical. When the pile spacing was increased, the maximum lateral displacement increased from $2.49 \times 10^{-4}$ in. to $2.76 \times 10^{-4}$ in., or about 10.5 percent, and the maximum rotation increased from $3.22 \times 10^{-4} \mathrm{rad}$ to $3.31 \times 10^{-4} \mathrm{rad}$, or about 2.6 percent. Comparison of the distributed force plots for $f_{x}$ and $f_{y}$ in Figures 40 through 43 and Figures 46 through 49 revealed that there were only minor differences between the two analyses.

4. Concrete Cap Thickness. A series of analyses was performed in which the pile section was embedded 2D in the concrete cap and the thickness of concrete cover above the pile section was varied from $4 \mathrm{D}$ to $7 \mathrm{D}$ (represented as Case 7, Case 8, and Case 9). Comparisons of the distributed forces calculated from the results of these analyses are presented in Figures 46 through 49, respectively. These plots show that the thickness of concrete cover above the pile section does not alter the distribution of forces in the region of the depth of embedment for the pile section. 
Table 11

Basic Parameters for HP 14X117

Pile Parametric Analysis

Parameter

Member Spacing

Member Embedment

Cap Thickness

Cap Effective Width

Member Configuration

Modulus of Lilasticity

Concrete

Steel

Poisson Ratio

Concrete

Steel

Coefficient of liriction
Valuc

2D

4D

$14.9 \mathrm{in}$.

HP 14X117

$3.0 \times 10^{6} \mathrm{lb} / \mathrm{sq}$ in.

$29.6 \times 10^{6} \mathrm{lb} / \mathrm{sq}$ in.

0.15

0.3

0.4

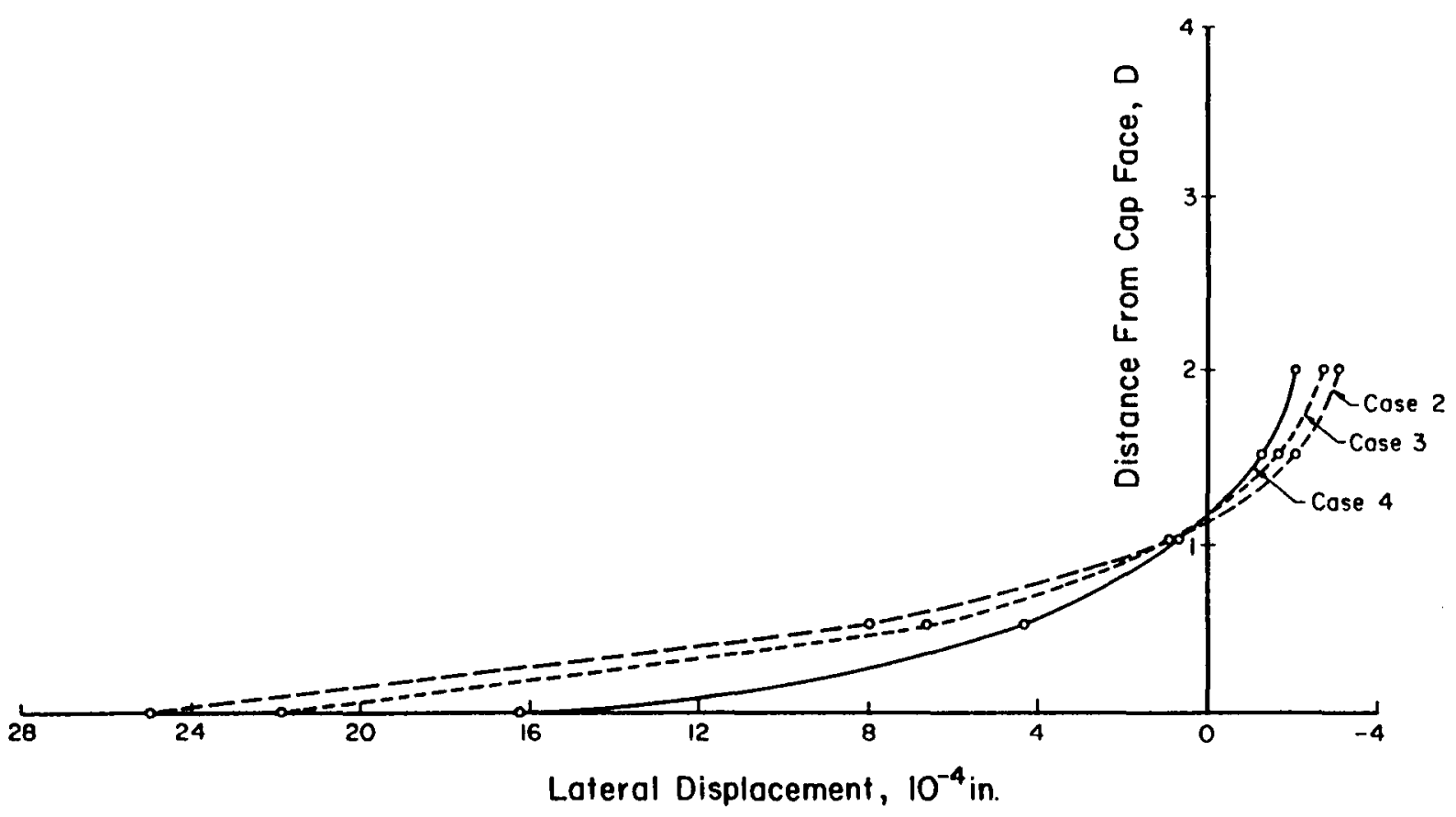

Figure 36. Lateral displacement curves for centerline of HP $14 \mathrm{X} 117$ pile with $2 \mathrm{D}$ embedment, $\mu=0.4,0.7$, and 1.4 . 


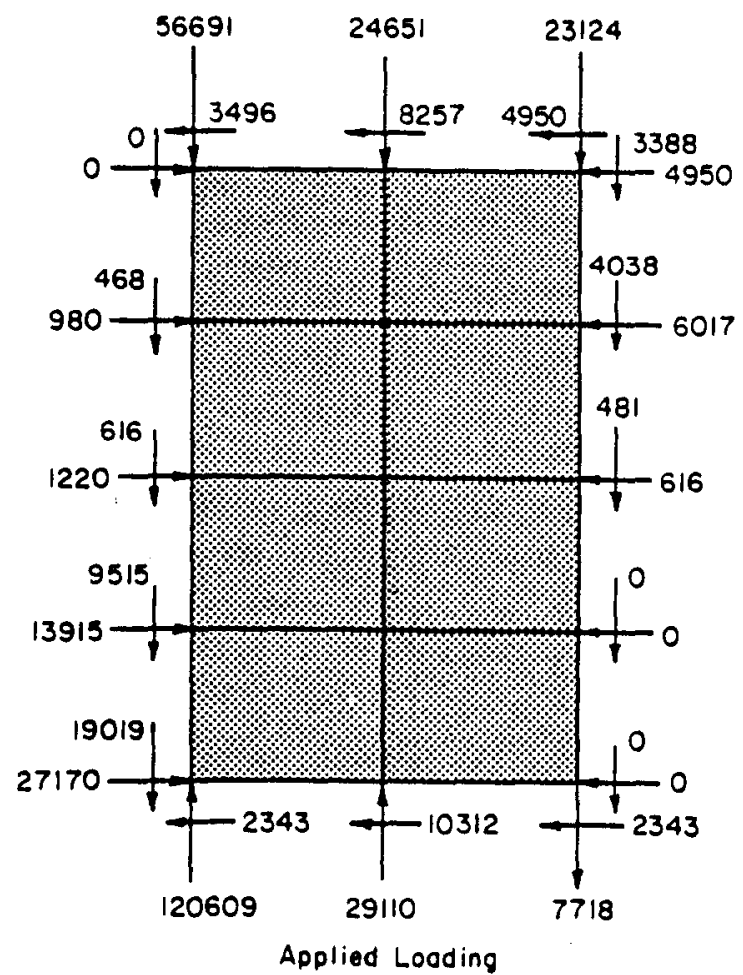

Figure 37. Interface clement forces for IIP $14 X 117$ pile with $2 \mathrm{D}$ embedment, $\mu=0.7$.

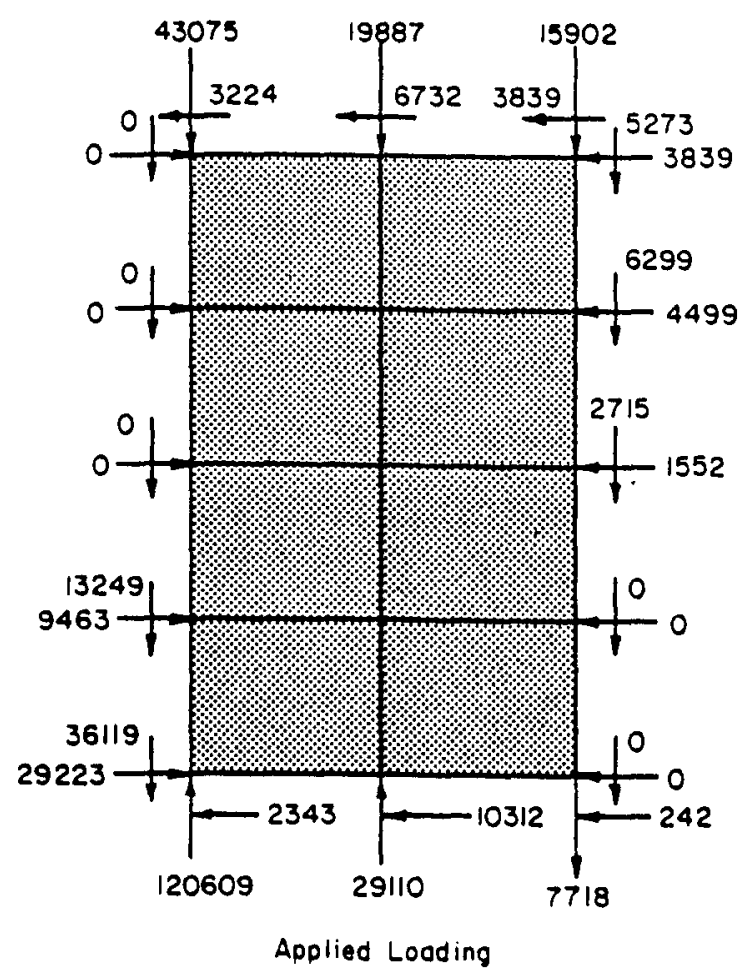

Figure 38. Interface element forces for HP 14 X 117 pile with $2 \mathrm{D}$ embedment, $\mu=1.4$. 


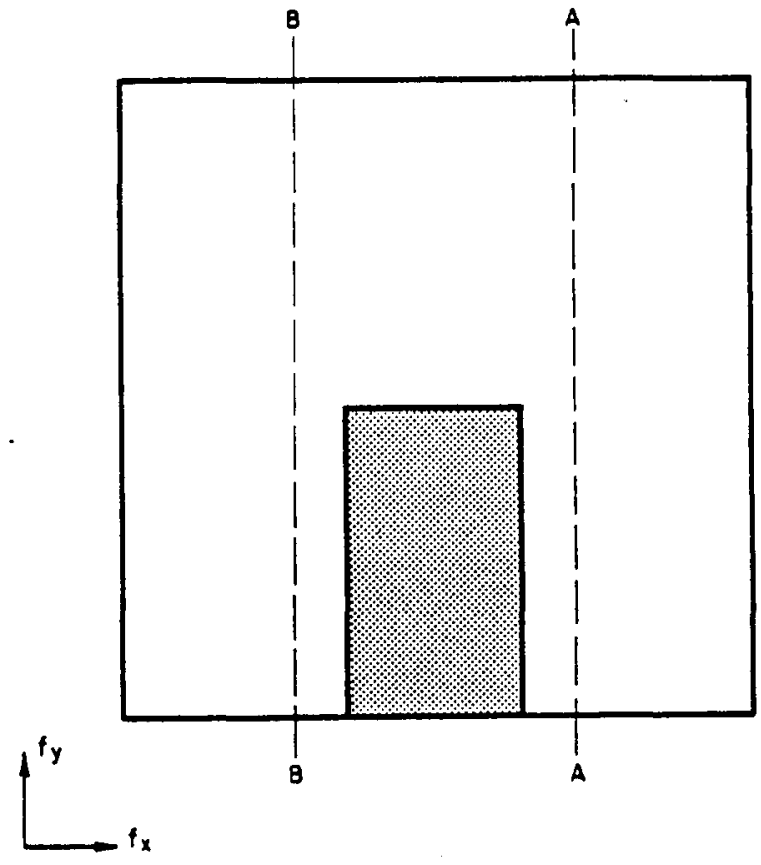

Figure 39. Sections in concrete cap used for normal and shear force distribution comparisons.

\section{CONCLUSIONS}

Based on the results from the analytical studies by UIUC and CERL on the cap-member-soil system and the cap-member system, a pile embedment length equal to or greater than twice the pile depth or diameter is required to develop a condition approximating full fixity for a pile embedded in the base of the structure. Moreover, the "rule of thumb" commonly used in the design of HP piles that $1 \mathrm{ft}$ embedment length into the concrete structure is considered pinned may be unrealistic. The computed response of the cap-membersoil model for the typical design situations indicated a $1 \mathrm{ft}$ embedment length would develop 61 to 83 percent of the moments for a $4 \mathrm{ft}$ embedment length. Therefore existing pile foundations designed using $1 \mathrm{ft} \mathrm{cm-}$ bedment length into the concrete structure for the pinned assumption may not really be pinned, but partially fixed.

\section{REFERENCES}

ANSYS User's Manual, Revision 3 (Swanson Analysis System, Inc., Houston, Pennsylvania).

ACI 318-77, Building Code Requirements for Reinforced Concrete (American Concrete Institute, June 1978).

PCI Manual on Design of Connections for Precast, Prestressed Concrete (Prestressed Concrete Institute, 1973).

Poulos, H. G., "Stresses and Displacements in an Elastic Layer Underlain by a Rough Rigid Base," Geotechnique, Vol. 17, No. 4 (1967), pp 378-410.

Poulos, H. G., and E. H. Davis, Elastic Solutions for Soil and Rock Mechanics (John Wiley and Sons, 1974).

Reese, L. C., "Laterally Loaded Piles: Program Documentation," ASCE Proceedings, Vol. 103, No. GT4, April 1977.

Terzaghi, K., "Evaluation of Coefficients of Subgrade Reaction," Geotechnique, Vol. 5, No. 4 (1955), pp 297-326. 
Distance from cop face, $D$

(D)
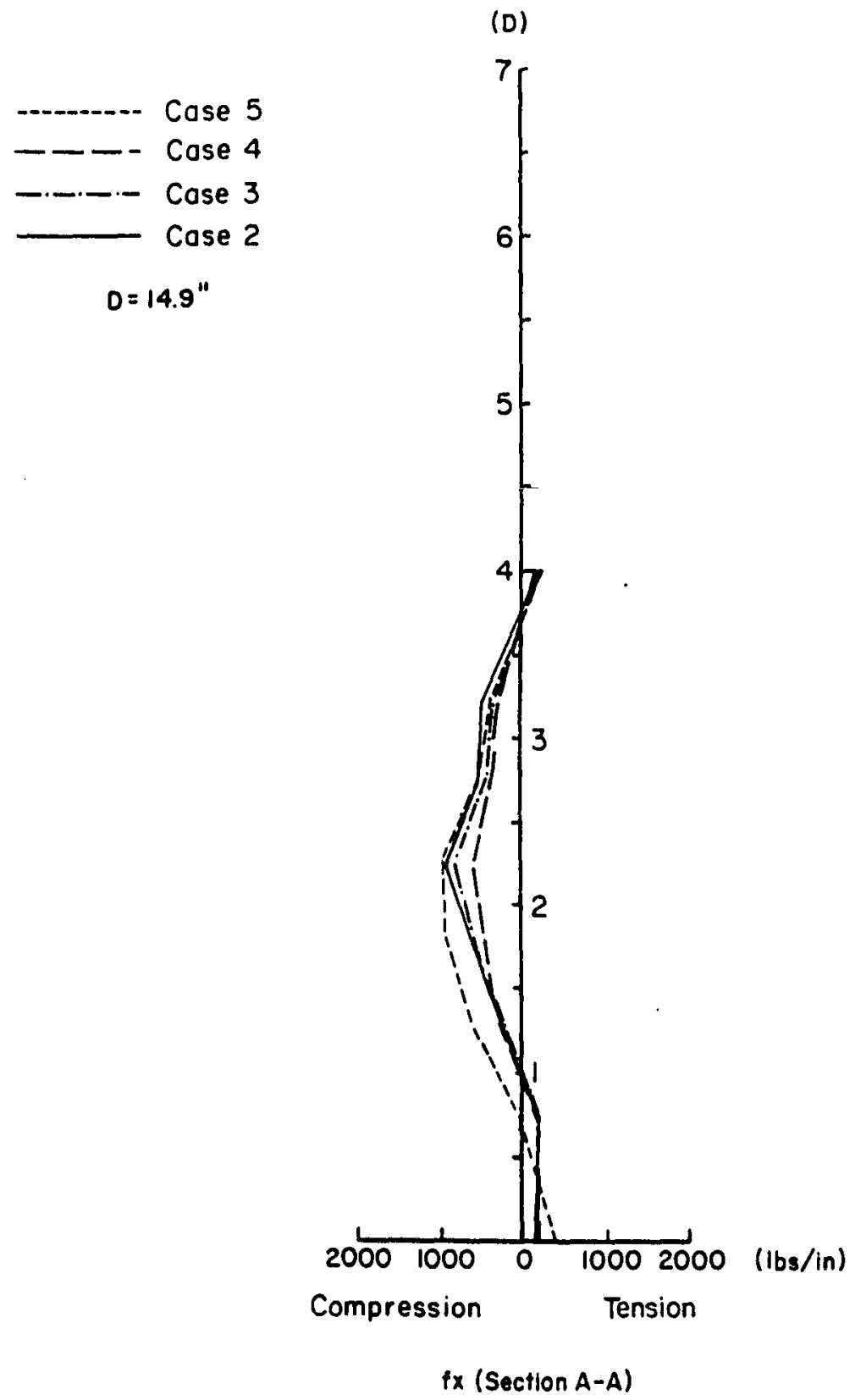

Figure 40. Normal force distribution at Section A-A for cap thickness of 4D. 


\section{Distonce from cap face, $D$}

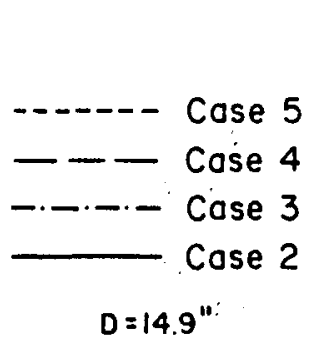

(D)

7

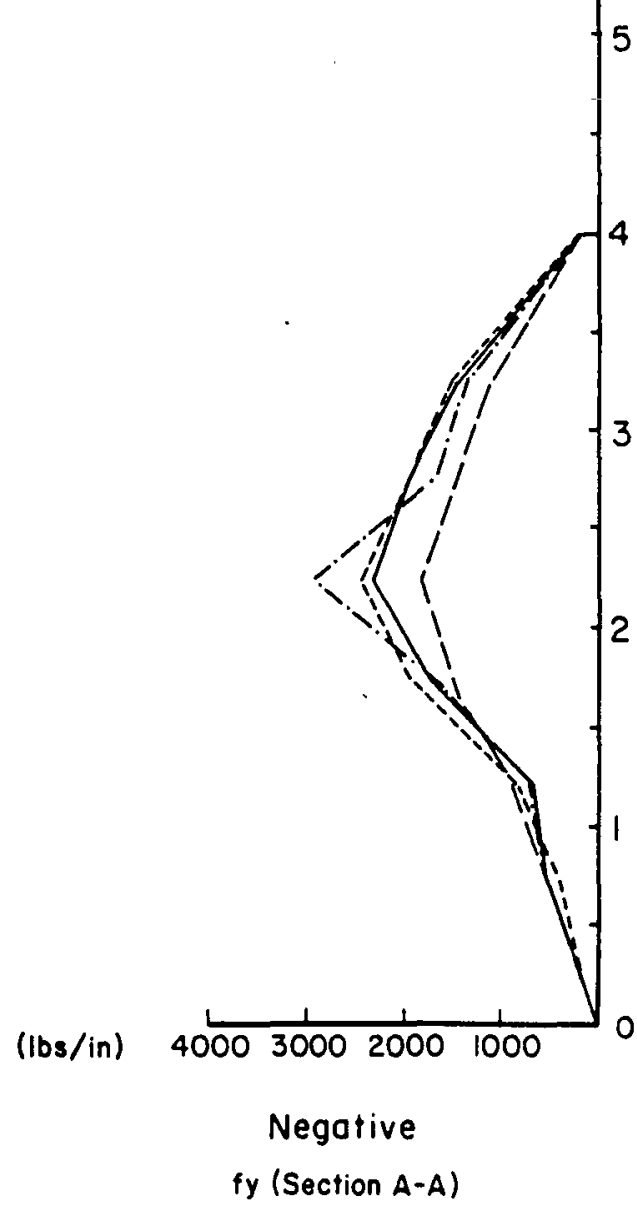

Figure 41. Shear force distribution at Section A-A for cap thickness of 4D. 


\section{Distance from cop face, $D$}

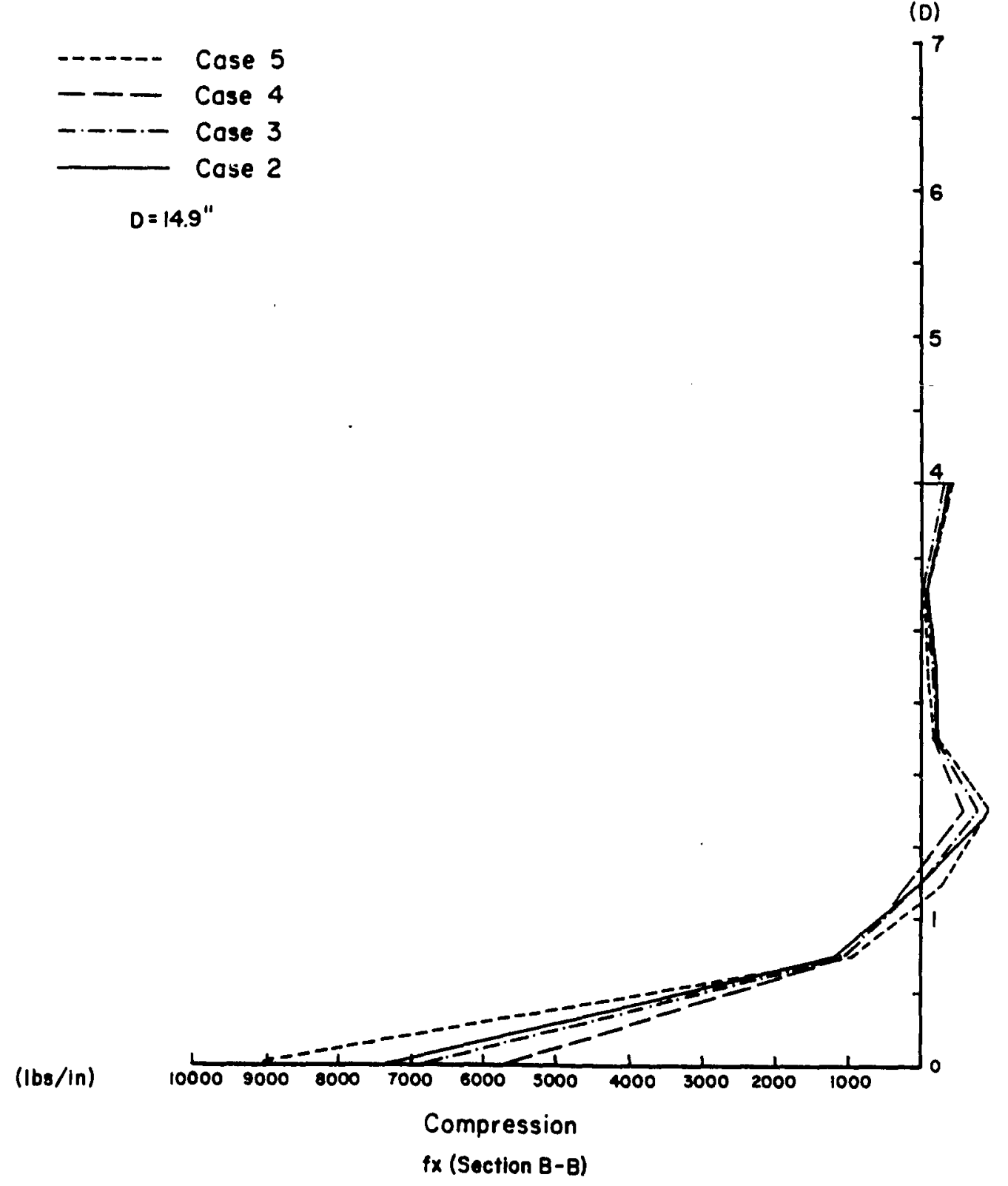

Figure 42. Normal force distribution at Section B-B for cap thickness of 4D. 


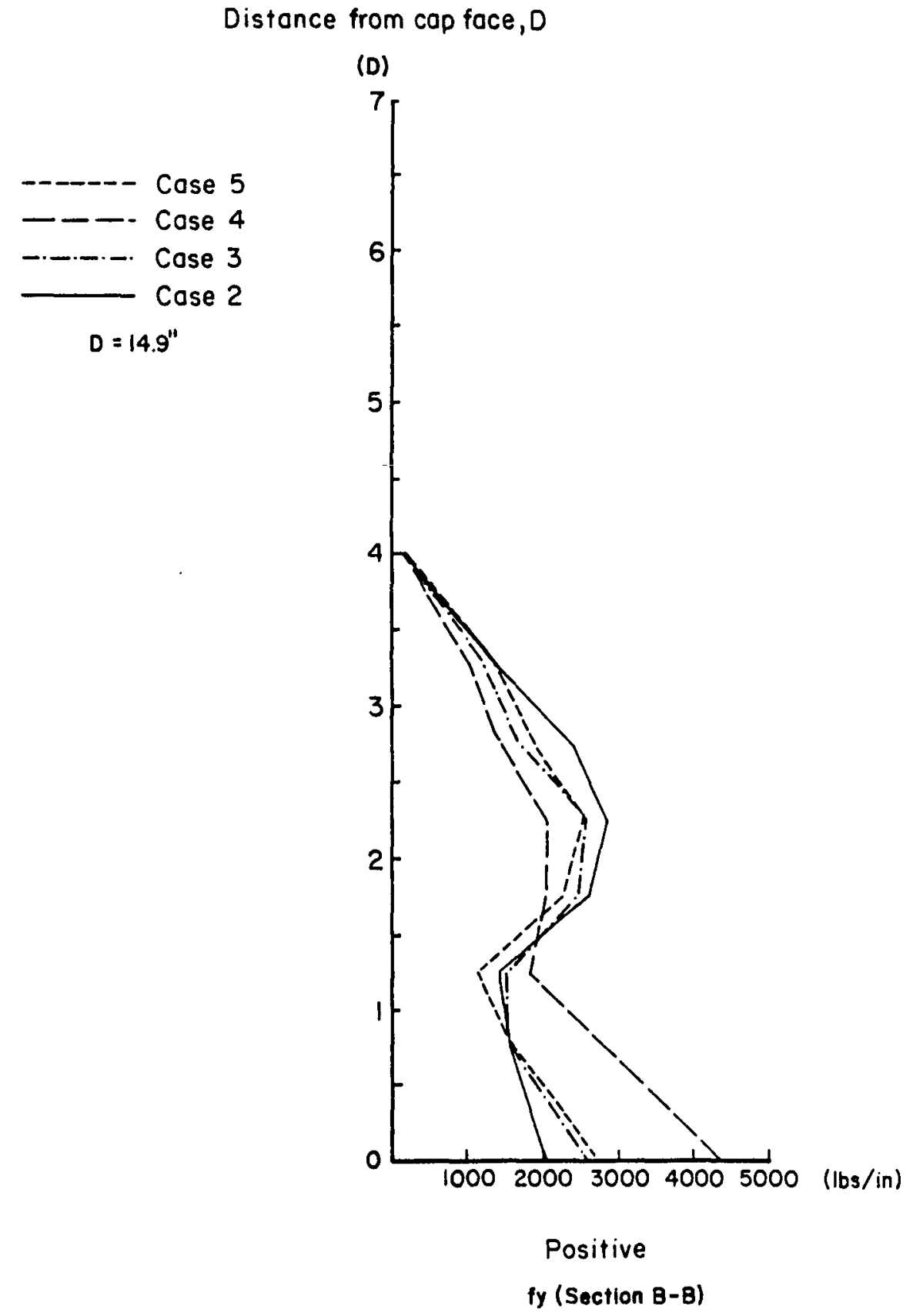

Figure 43. Shear force distribution at Section B-B for cap thickness of 4D. 


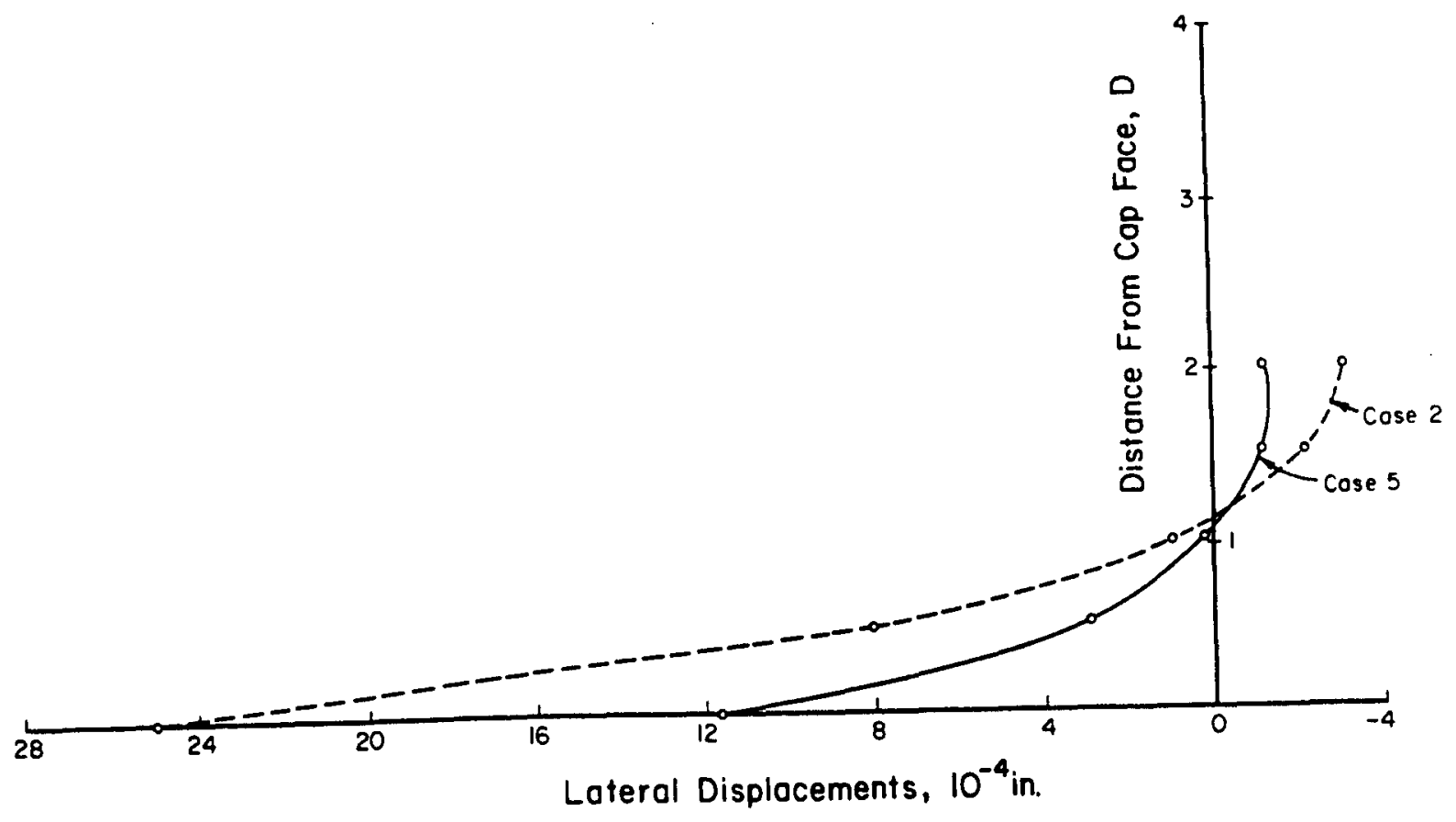

Figure 44. Lateral displacement curves for centerline of HP $14 \mathrm{X} 11.7$ pile for effective widths of concrete cap of 14.9 in. and 44.7 in.

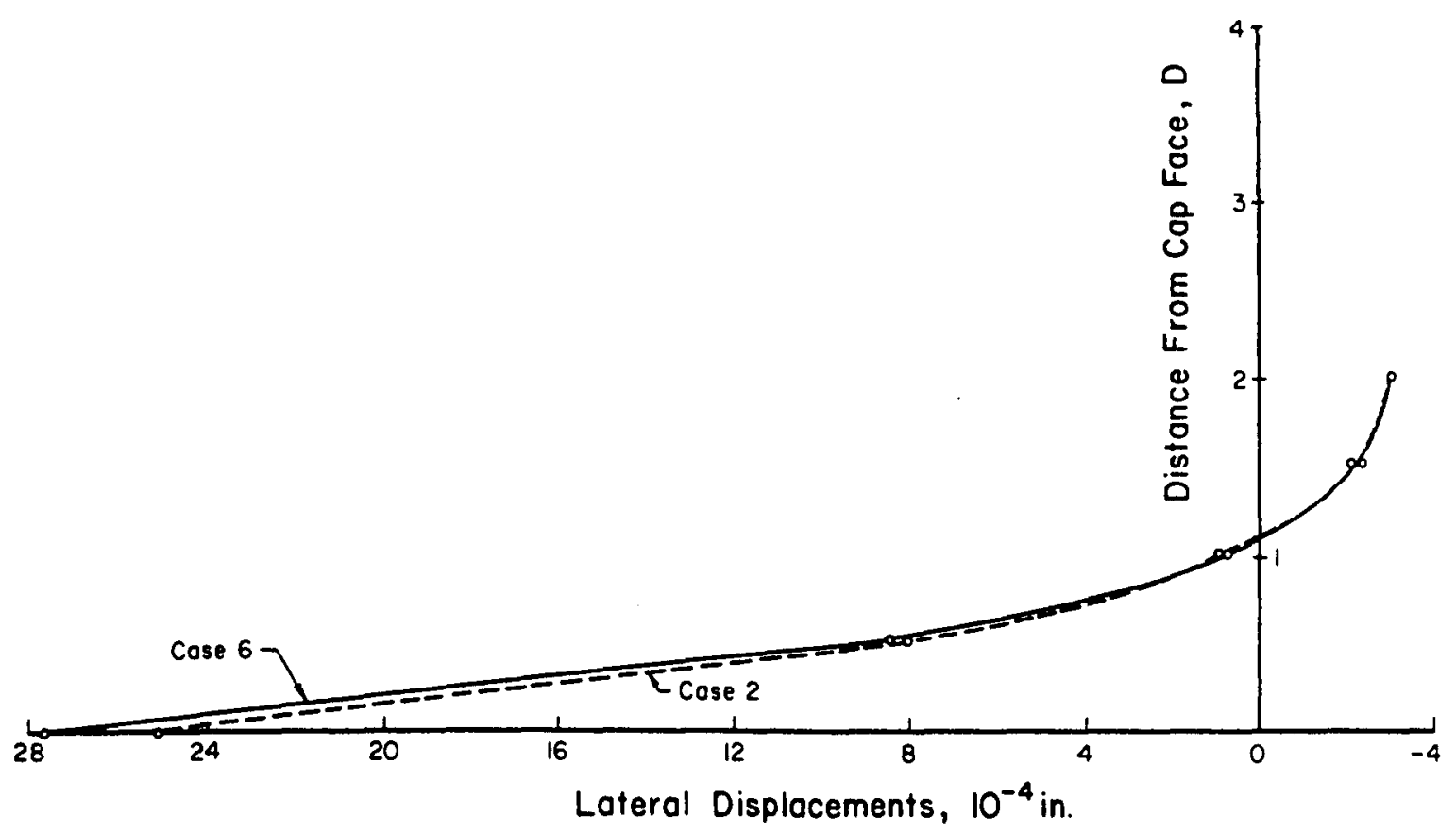

Figure 45. Lateral displacement curves for centerline of HP $14 \mathrm{X} 117$ pile for pile spacings of 3D to 5D. 


\section{Distance from cop face, $D$}

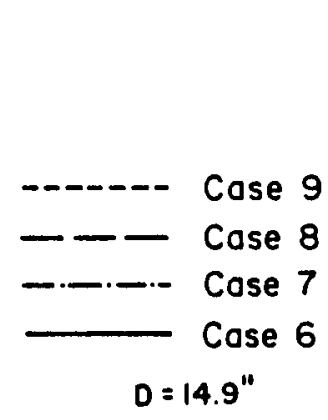

(D)

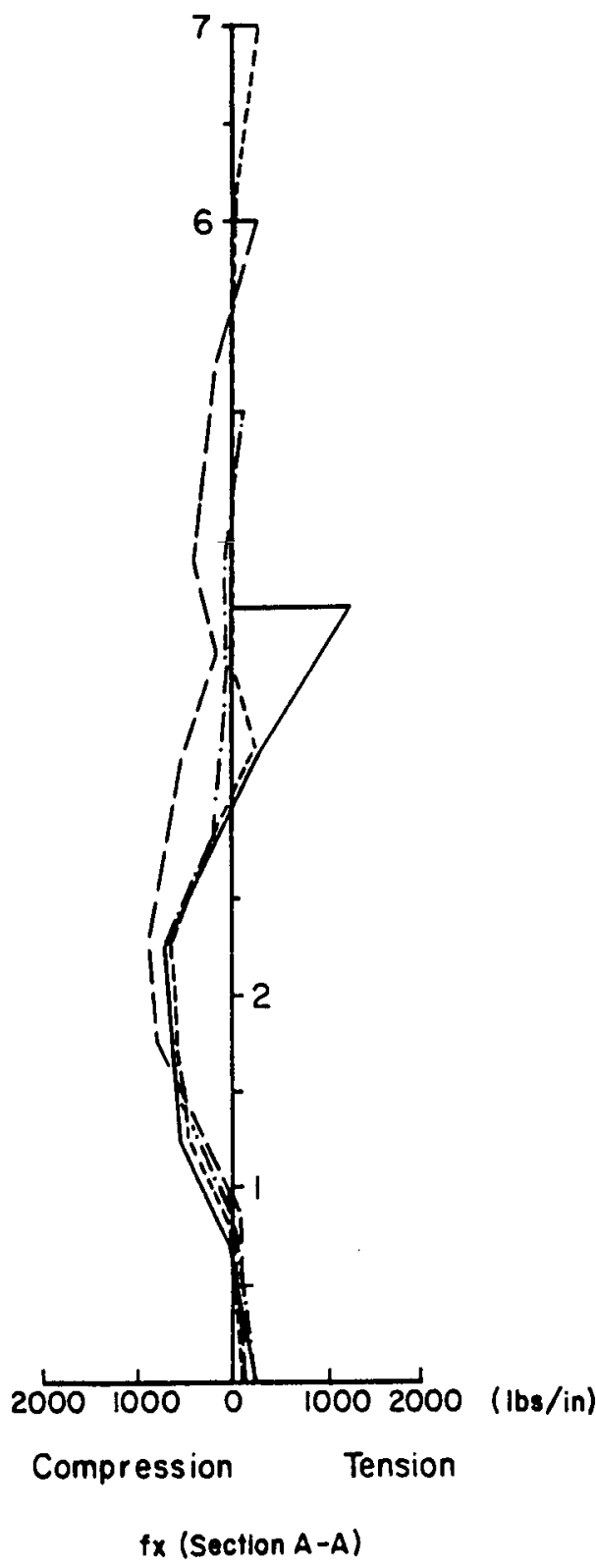

Figure 46. Normal force distribution at Section A-A for cap thicknesses of 4D to 7D. 


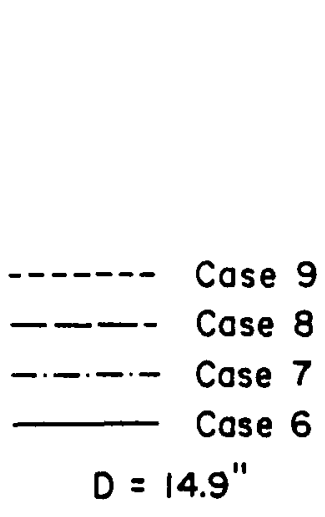

Distance from cap face, $D$

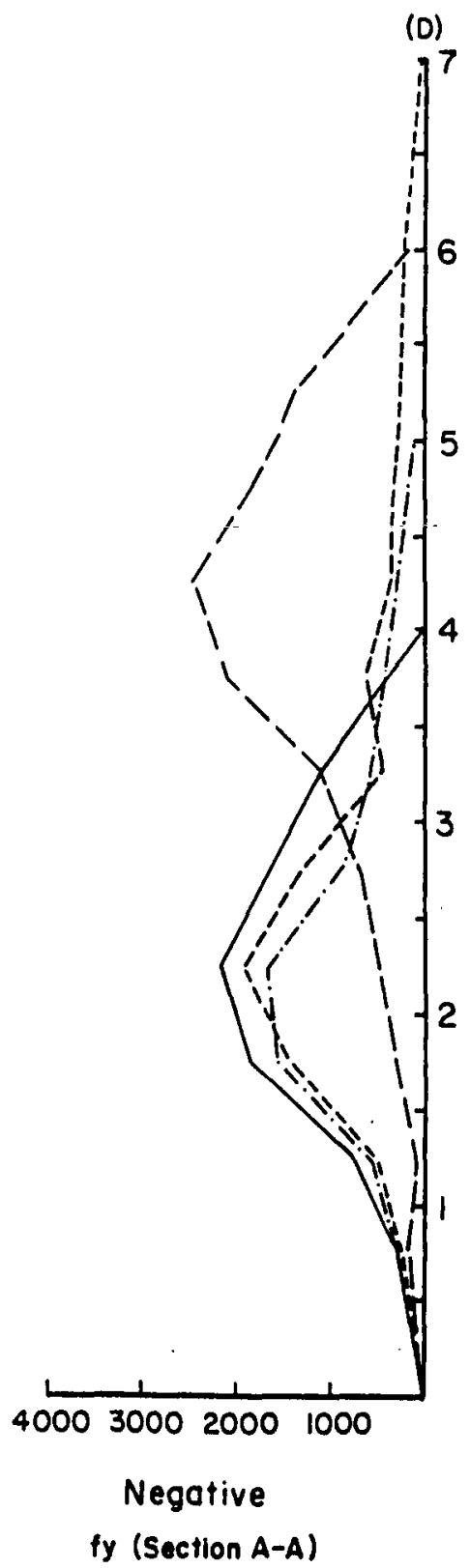

Figure 47. Shear force distribution at Section A-A for cap thicknesses of 4D to 7D. 
(D)

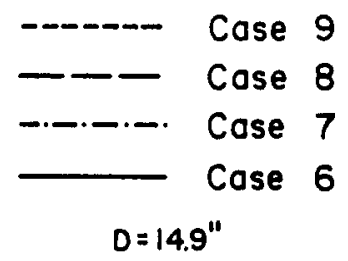
9

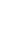

\section{Distance from cap face, $D$ \\ Distance from cap foce, D}

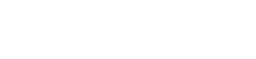

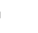




\section{Distance from cap face, $D$}

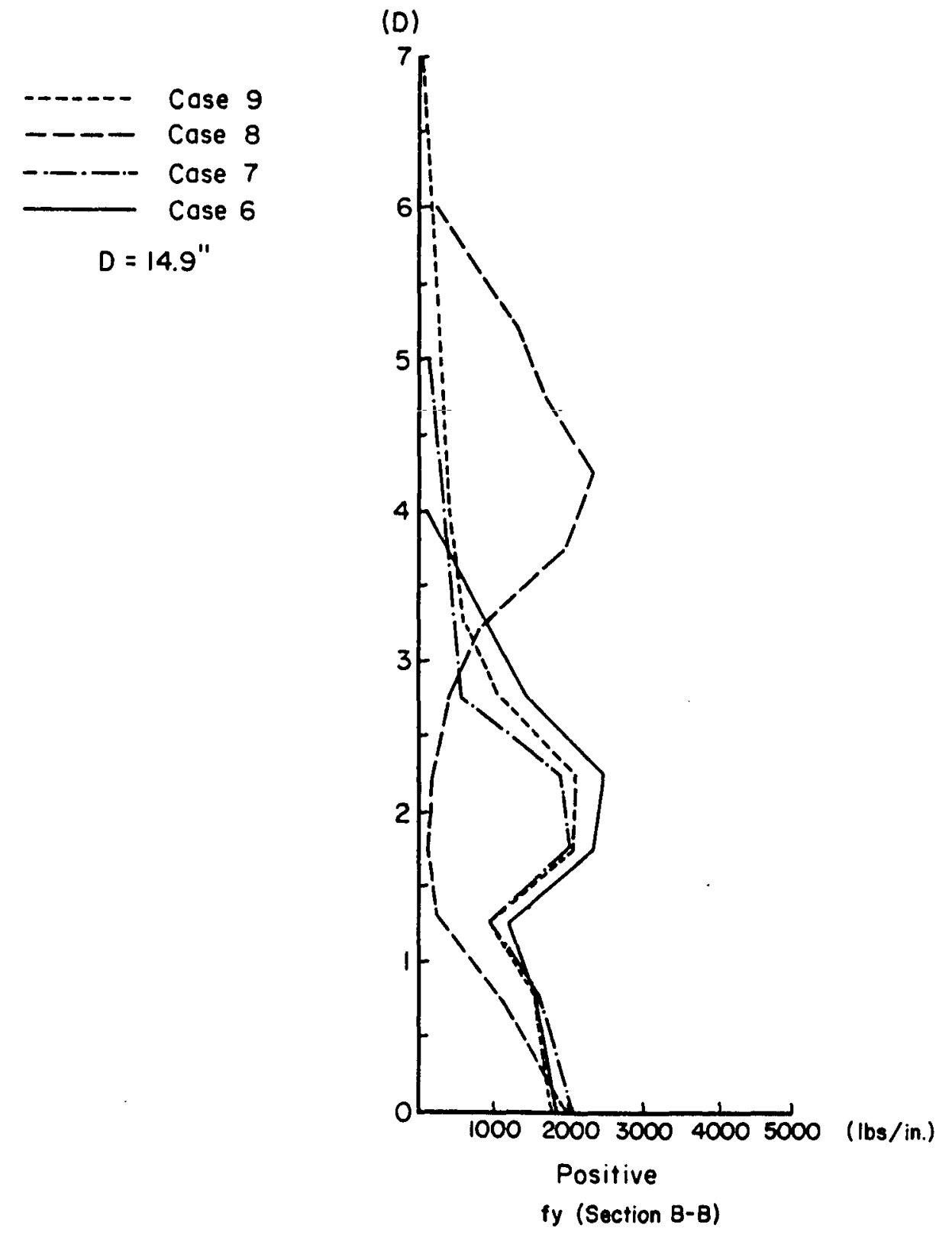

Figure 49. Shear force distribution at Section B-B for cap thicknesses of 4D to 7D. 


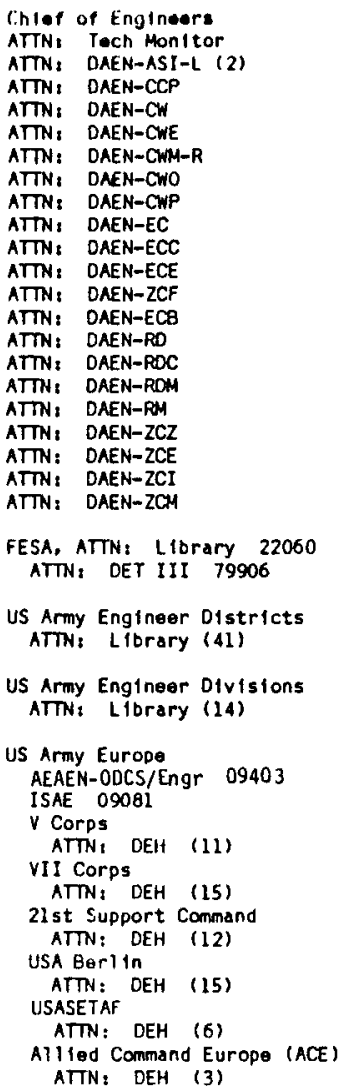

8th USA, Kored (14)

ROK/US Combined Forces Command 96301 ATTN: EUSA-HAC-CFC/Engr

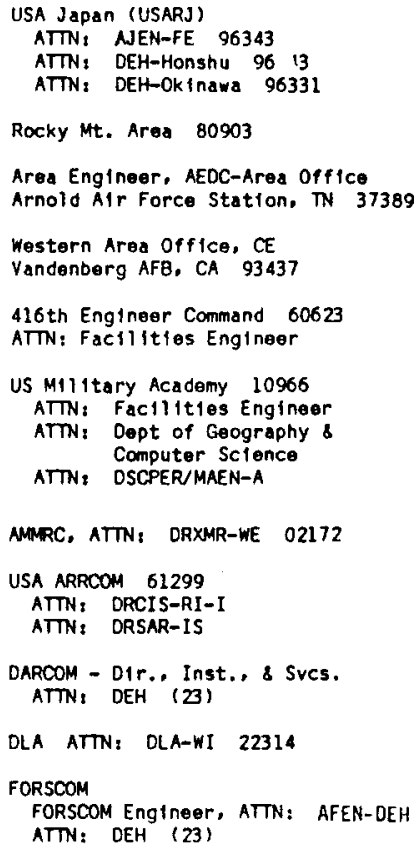

HSC

ATTN, HSLO-F IA23a

ATTN: Facilitios Englneor

Fitisimans AMC 80240

Walter Reed AMC 20012

INSCOM - Ch, Instl. Div.

ATTN: Factlities Englneer (3)

MOW

ATTN: DEH (3)

MTMC

ATTN: MTMC-SA 20315

ATTN: Facilities Eng1neer (3)

NARADCOM, ATTN: DRONA-F 071160

TARCON, Fac. DIV. 48090

TRADOC

HQ. TRADOC, ATTN: ATEN-DEH

ATTN: DEH (19)

TSARCOM, ATTN: STSAS-F 63120

USACC

ATTN: Facflities Engineer (2)

WESTCOM

ATTN: DEH

Fort Shafter 96858

ATTN: APEN-IM

SHAPE 09055

ATTN: Survivabllity Section, CCB-OPS Infrastructure Branch, LANOA

HQ USEUCOM 09128

ATTN: ECJ 4/7-LOE

U.S. Army, Fort Belvoir 22060

ATTN: Canadian Liaison Officer

AIIN: Water Resources Support Center

ATTN: -Engr Studies Center

ATTN: Engr Topographic Lab

ATTN: ATZA-DTE-SU

ATIN: ATZA-DTE-EM

ATTA: R\&D Command

CRREL, ATTN: L1Drary 03755

ER, ATTN: LIbrary 22060

WES, ATTN: Library 39180

HQ, XVIII Alrborne Corps and

Ft. Bragg 28307
ATTN: AFZA-FE-EE

Chanute AFB, IL 61868

3345 CES/DE, Stop 27

Norton AFB CA 92409

ATTN: AFRCE-MX/DEE

Tyndall AFB, FL 32403

AFESC/Engineering \& Service Lab

NAFEC

ATTN: ROTSE Lialson Off 1 ce (6)

ATTN: Sr. Tech. FAC-03T 22332

ATTN: Asst. CDR R\&D, FAC-03 22332

NCEL 93041

ATTN: L L rary (Code LOBA)

Defense Technical Info. Center 22314 ATTN: DOA (12)

Englneering Socleties Library

New York. NY 10017

National Guard Bureau 20310

Installation Division

US Government Printing offlce 22304 Receiving Section/Depository Coples (2)

National Bureau of Standards 20760 


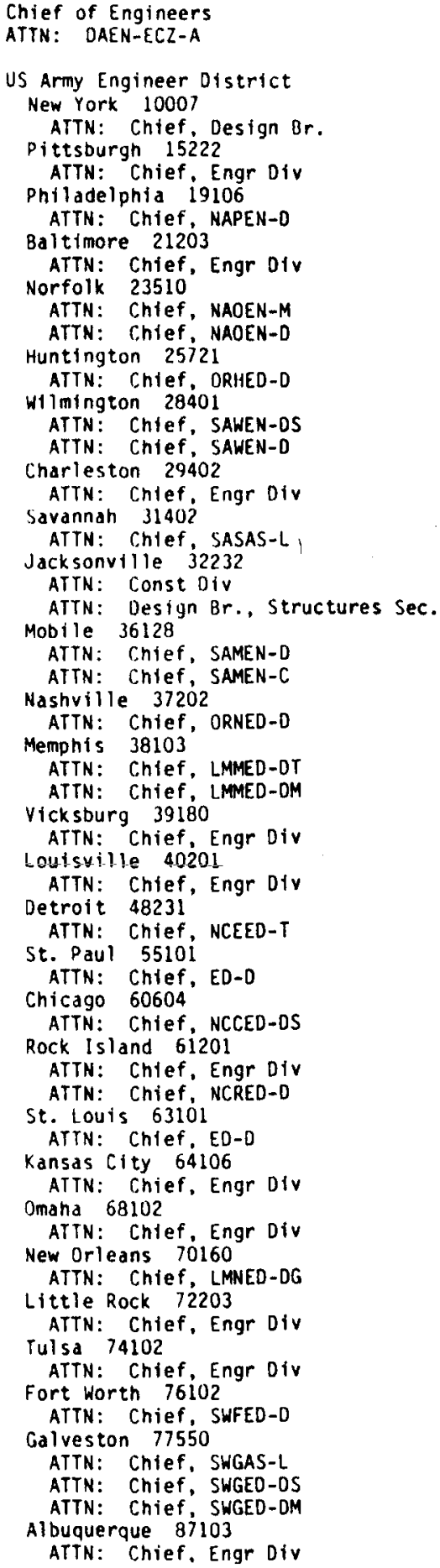

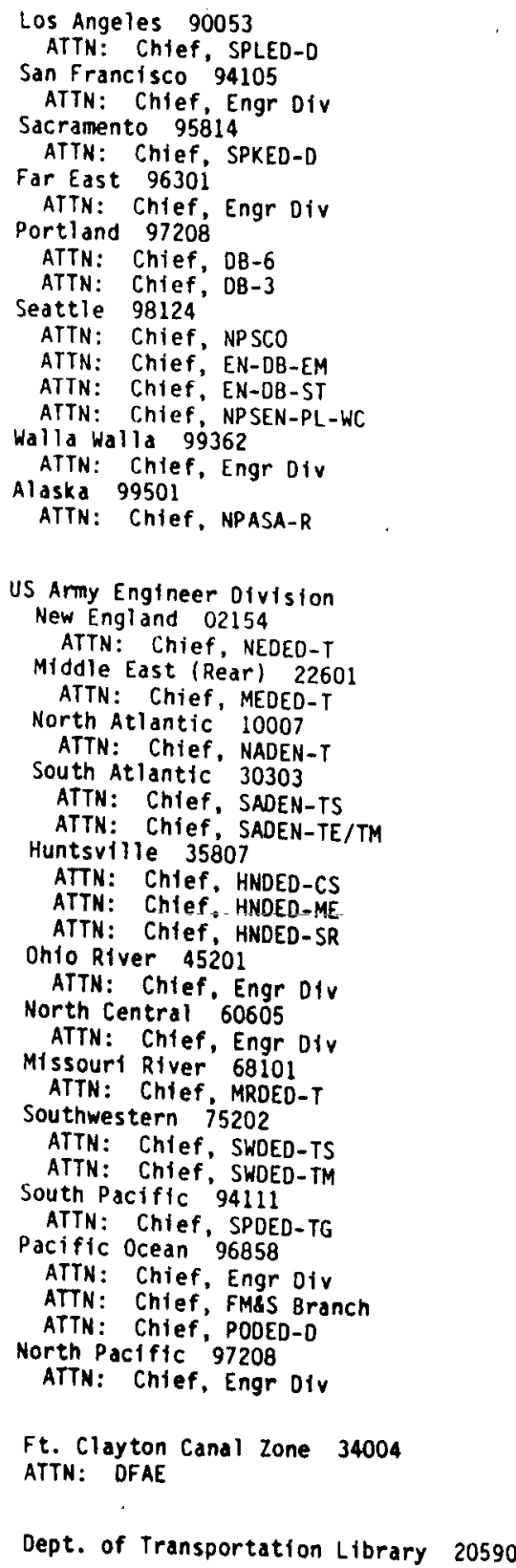

Transportation Research Board 20418 


\section{Cast1lia, Fernando}

Fixity of members embedded in concrete / by Fernando Castilla, Phillippe Martin, John Link. - Champaign, IL : Construction Engineering Research Laboratory ; available Erom NTIS, 1984.

61 p. (Technical report / Construction Engineering Research Laboratory ; M-339).

1. Concrete piling. 2. Piling (civil englneering) I, Martin, Phillippe.

II. Link, John. III. Title. IV. Series: Technical Report (Construction Englneering Research Laboratory); $M-339$. 